\title{
Hypothetical Syllogistic and Stoic Logic
}

Antbony Nicholas Speca

A thesis submitted in conformity with the requirements

for the degree of Doctor of Philosophy

Graduate Department of Philosophy

University of Toronto

(C) Copyright 1999, Anthony Nicholas Speca 
Acquisitions and Bibliographic Services

The author has granted a nonexclusive licence allowing the National Library of Canada to reproduce, loan, distribute or sell copies of this thesis in microform, paper or electronic formats.

The author retains ownership of the copyright in this thesis. Neither the thesis nor substantial extracts from it may be printed or otherwise reproduced without the author's permission.
L'auteur a accordé une licence non exclusive permettant à la Bibliothèque nationale du Canada de reproduire, prêter, distribuer ou vendre des copies de cette thèse sous la forme de microfiche/film, de reproduction sur papier ou sur format électronique.

L'auteur conserve la propriété du droit d'auteur qui protège cette thèse. $\mathrm{Ni}$ la thèse ni des extraits substantiels de celle-ci ne doivent être imprimés ou autrement reproduits sans son autorisation.

\section{Canadä}


SPECA, AVTHONI NICHOLAS, Hypothetical Syllogistic and Stoic Logic Ph.D. thesis, Deparment of Philosophy, University of Toronto, 1999.

Aristotle recorded his intention to discuss hypotherical syllogistic fully ( $A$ n. pr. 50a39), but no such treatment by him has been available since at least $200 \mathrm{AD}$, if ever it even existed. The contributions of his successor Theophrastus have also perished, as have those of Aristote's followers of the subsequent few centuries. Furthermore, almost all of the surviving sources, especially the Greek commentators and Boethius, did not report hypotherical syllogistic accurately. Rather, they conflated it with Stoic logic, which it resembles in some respects, but from which it is significantly different. Modern scholars, who have not appreciated the nature or extent of this conflation, have unintentionally perpetuated the problem. As a result, the original form of hypothetical syllogistic has been misunderstood, and part of the influence of Stoic logic in late antiquity has remained unclear.

This thesis is an account of the conflation of hypotherical syllogistic and Stoic logic. The first chapter is a study of Aristotle's remarks on hypothetical syllogistic, which suggest that it was not a sentential logic such as the Stoics would develop. The second chapter details the conflation as it appears in the Greek commentaries on Aristotle, which consists principally in confusing the original Peripatetic division of hypothetical statements and syllogisms, whose criteria are semantic, with the Stoic division of complex propositions and inference schemata, whose criteria are syntactic. The third and fourth chapters focus on Böethius's On bypothetical syllogismsand On Cicero's Topics, in which even further conflation demonstrates that hypotherical syllogistic and Stoic logic had completely ceased to retain their distinct natures by the end of antiquity. 


\section{Acknowledgments}

For their supervision and comments, I thank the members of my thesis committee: co-supervisors Brad Inwood and Calvin Normore, and advisor John Magee. The remaining errors are mine. I also thank Brad Inwood particularly for his patience and help in transforming my Greek into a useful research tool, and John Magee for agreeing to serve as my advisor despite not knowing me or my work previously. To Calvin Normore go my thanks for our professional camaraderie, which began even when I was merely a prospective graduate student.

I am also grateful to Alan Code, who has encouraged me in all my scholarly endeavors, and who undertook the external appraisal of this thesis. George Schumm helped me to enjoy logic despite my original intention never to pursue it beyond curricular requirements. Additionally, many of my fellow students have also enriched my graduate years with conversation, argument, and friendship; I especially want to note Joshua Mozersky and Mark Silcox.

While I was composing this thesis, I benefitted from holding a Connaught Scholarship from the University of Toronto and an Ambassadorial Scholarship from the Rotary Foundation. The latter scholarship enabled me to spend an academic year at the University of Auckland in New Zealand, whose Department of Philosophy received me with hospitality. I thank each of these institutions for their aid.

When I had finished my undergraduate thesis, I dedicated it to my parents for their unswerving support and love, and to Chrysippus of Soli for the idea that I had stolen from him. I dedicate this new thesis again to my parents, whose support and love continues unswervingly, and to Claudius Galen, upon whose discernment I have capitalized this time. 


\section{Contents}

Preface 1

1. The Aristotelian Background 4

2. The Greek Commentators on Aristote 33

3. Boethius: On bypotbetical syllogisms 60

4. Boethius: On Cicero's Topics 88

References $\quad 116$ 


\section{Preface}

This thesis is the history of a mistake. Largely because of it, aspects of Peripatetic and Stoic logic have been partially confused for at least eighteen hundred years. The first man identifiable as responsible for this mistake, at least in the sense of canonizing it, is Alexander of Aphrodisias. Alexander, who was the Empire's official Peripatetic philosopher around the turn of the third century $A D$, undertook to produce a series of commentaries on the work of Aristotle. One of these commentaries concerns the Prior Analytics, in which Aristotle had put aside, but apparently never retumed to, a full discussion of what he had called syllogisms from a hypothesis. Nevertheless, Alexander was at least partly familiar from other sources with what he himself called hypothetical syllogisms, and proceeded to explain what he thought Aristotle had had in mind.

Alexander's problem would be familiar to a modern historian of logic. He had read a few tantalizing comments about some subject in what had survived of Aristotle's work. He had good reason to believe that Aristotle had at least intended to discuss the subject in more detail, but did not have any account of it by Aristote himself. At the same time, he had accounts from other sources, possibly including even Aristotle's successor Theophrastus and close associate Eudemus, who had both developed the subject further. Alexander's problem, then, as a modem historian of logic would see it, was to plausibly reconstruct what Aristotle might have intended on the basis of judicious interpretation of Aristode's remaining comments and the related work of others.

Nevertheless, as he himself probably saw it, his problem was altogether different. Alexander was not a dispassionate historian who sought to recover past logical theory with accuracy, and to evaluate it without bias. Rather, he was firstly and consciously a Peripatetic - that is, a follower of Aristotle. Although his ancient master had invented formal logic, in the five centuries since Aristodle's death it had become, not a Peripateric domain, but a Stoic one. Moreover, Stoic logic differed from the Peripatetic in many fundamental respects, and so supplanted it as the Stoa grew at the expense of the Peripatos into the pre-eminent philosophical school of the period. Alexander's own problem in commenting upon the Prior Analytics, then, was less the problem of an exegete, and more that of a champion. 
This combination of limited source material and partisan scholarship led him to his mistake. Basic to Stoic logic were patterns of inference that closely resembled, but were yet significantly different from, certain sorts of hypotherical syllogism. Distant from the original Peripatos to which he belonged in spirit, but in an intellectual atmosphere in which the common logical wisdom was Stoic, Alexander failed to recognize crucial differences between hypothetical syllogistic and Stoic logic. The resuscitated version of hypothetical syllogistic that he presented in his commentary on the Prior Analytics, then, is not what Aristotle had in fact had in mind. It is rather a partial conflation of Peripatetic and Stoic logic.

Now, Alexander was most likely not uniquely responsible for this understandable mistake. The Aristotelian revival of which his work is part had first begun about two centuries before his time. His influential commentaries, however, are the pinnacle of this revival, and are for this reason among the very earliest such work to have survived to the present. Thus, he probably did more than any other to bring the contlation of hypothetical syllogistic and Stoic logic into the loyical canon. Indeed, by the end of antiquity, succeeding commentators on Aristotle seem not to have even been aware that there had ever been any difference between the two. This thesis, then, is the history of Alexander's ancient mistake.

It is also a history of much the same modern mistake. The first man identifiable as responsible for it at least in the sense of canonizing it, is Carl Prantl. In 1855, Prand published the first systematic treatment of ancient logic, in which one of his problems as a presumably dispassionate historian was to recover accurately what Aristotle, or at least the first Peripatetics, had had in mind with regard to hypothetical syllogistic. However, because all the logical work of Aristode's successors and associates had long since perished, Prantl tumed for guidance to Alexander's commentary, and to later commentaries in the same tradition. Although he found there a conflation of hypothetical syilogistic and Stoic logic, he did not realize it. For all the logical work of the Stoics had also long since perished, leaving him with the immense task of making sense of the scattered fragments and testimonia regarding Stoic logic that had survived - in many cases, as objects of criticism in the Peripatetic commentaries.

This limited source material led Prand to his mistake. Unable to see Stoic logic, or even early Peripatetic logic after Aristotle, except as refracted through the lenses of the commentators, he conceived a distaste for the way in which he thought the Stoics had made nonsense of Peripatetic logic. Trusting Alexander to have recorded a purely Peripatetic hypothetical syllogistic, he 
understandably became party to Alexander's conflation with Stoic logic. While most scholars have since disagreed with many of the conclusions he reached in his influential book, especially about the Stoics, they have yet argued according to his agenda, asking more whether the commentators had recorded either Peripatetic hypothetical syllogistic or Stoic logic, and less in what way they might have conflated them.

As a history of these two mistakes as such, however, this thesis is also a proposal for their correction. The man most responsible for providing the means for this correction, at least in the sense of having mostly avoided the mistake himself, is Claudius Galen. Galen, who wrote a short introduction to logic, was a more careful reporter than his contemporary Alexander. Although he was also not a historian of logic, he had no more interest in championing hypotherical syilogistic than he had in reconstructing it. Unimpressed by scholastic debates and partisanship, and by what he thought was useless Peripateric and - especially — Stoic terminological quibbling, he presented hypothetical syllogistic in a practical way that exposes a key difference between it and Stoic logic.

This difference led me to my thesis. In it, I have attempted to reconstruct the hypothetical syllogistic of the first Peripatetics free from conflation with Stoic logic, and in so doing to illustrate an aspect of the influence of Stoic logic during late antiquity and into the early Middle Ages. 


\section{The Aristotelian Background}

1. Sometime around $200 \mathrm{AD}$, over five centuries after Aristotle's death, the neo-Peripateric commentator Alexander of $A$ phrodisias observed of his ancient master that:

He says that many other syllogisms are also brought to a conclusion from a hypothesis, discussion of which he sets aside as if intending to speak about them more carefully. However, no book of his about them is in circulation. ${ }^{1}$

Alexander was referring to a passage in the Prior Analytics, in which Aristotle had briefly discussed

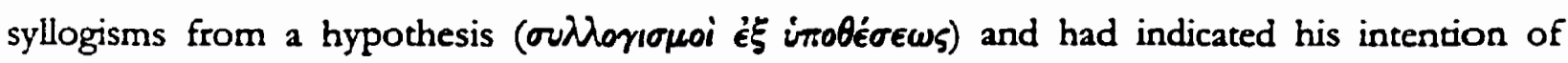
composing a separate and fuller account of them:

Now, many other syllogisms are also brought to a conclusion from a hypothesis, which need to be further examined and indicated clearly. I will discuss later, then, what their differences are and in how many ways the syllogism from a hypothesis is made. ${ }^{2}$

In fact, such a discussion would have completed Aristotle's account of the syllogism, since

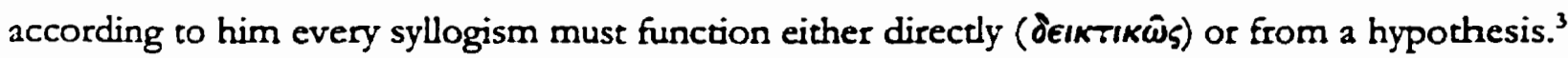
Aristotle had recognized clearly that his definition of the syllogism as a $\lambda \dot{o}$ certain things are proposed, something else follows of necessity from their being so, encompasses many more kinds of syllogisms than simply the fourteen moods of the three syllogistic figures that he had developed in the first chapters of his treatise. Having gone on to identify the direct syllogism with these three syllogistic figures, he had presumably meant to produce a complementary and similarly detailed system for syllogisms from a hypothesis. ${ }^{5}$ At any rate, this two-fold division of the syllogism, into what followers of Aristotle dubbed the categorical (karmyopıkos) and the hypothetical (imobetıkós), became canonical in later antiquity. Yet, while the Prior Analytics has remained the seminal source for the categorical syllogism to the present, no separate treatise by Aristote on the hypothetical syllogism appears to have existed since some point before the end of

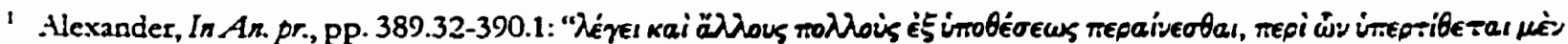

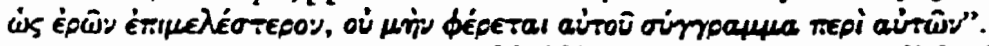

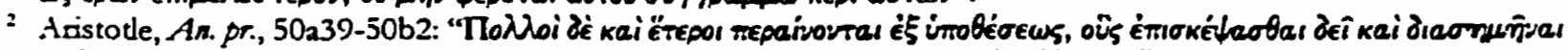

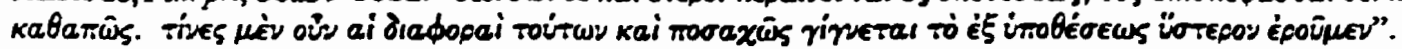

3 Ibid, 40b23-25.

- Ibid, 24b18-20.

5 Ibid, 41a13-20. 
the second century $A D$, if ever it did.

According to the traditional story of the fate of Aristotle's written work, Aristote left his books to his successor Theophrastus, who passed them on to their student Neleus of Scepsis upon his own death. Neleus, in turn, took them from Athens back to Scepsis and bequeathed them to his children, who allegedly took little interest in philosophy and left the books to molder. Nevertheless, when Neleus's descendants of the following century heard that their Attalid king, Eumenes II, intended to appropriate books from his subjects in order to establish a library in his capital Pergamum, they hid their cache in a sort of tunnel or cellar. There, many of the books succumbed completely to the damp and to worms. Perhaps, then, Aristotle's promised treatise on the hypothetical syllogism simply rotted away underground. However, even if the romantic story is mostly true, it seems implausible that Neleus had divested the Lyceum and all of Athens of every copy of every book by Aristotle - let alone what copies may have circulated in other locations and that his unphilosophical family single-handedly achieved the destruction of the greater part of the entire Aristotelian copus through neglect. ${ }^{6}$ All that is certain is that, for whatever reason, no treatise by Aristocle on the hypotherical syllogism was available by Alexander's time, if ever one had been - or at least that Alexander, who was the doyen of Peripateric studies in his day, could not find one after a presumably conscientious search. Indeed, no other contemporary or subsequent source reports the existence of such a treatise either. By the end of the second century $A D$, then, logicians who looked to the Peripatos could not consult their master's own words on the subject, besides what little he had written in the Organon.

The neo-Peripatetics thus turned perforce to other sources, for Aristotle had naturally communicated his ideas to his associates. Alexander, for instance, followed his statement that there was no available Aristotelian book on the hypothetical syllogism by pointing out that Theophrastus had himself mentioned them in his own Analytics, and that Aristotle's associate Eudemus had done

- For studies of this point, as well as of the consequently similarly implausible story that the Aristotelian corpus resurfaced more or less solely through the editorial efforts of Andronicus of Rhodes (who acquired the books in Rome from the amateur Peripatedic Tyrannio, who had been able to see them in the library of the Roman general Sulla, who had taken them as spoils of war from Athens, where they had formerly come into the possession of the bibliophile. Apellicon of Teos, who had rescued them from decrepitude by purchasing them from Neleus's family), see Moraux, Der Aristotelesmus bei den Griechen, vol. 1, pp. 3-94; Tarán, "P. M Ioraux, Der Aristotelismus bei den Griechen"; Barnes, "Roman Aristode". In addition to Athens, for example, Aristodle's works possibly also circulated in Alexandria, to which Theophrastus's successor Strato had connections, and Rhodes, the native island of Eudemus, to which he returned before Theophrastus's death. 
so as well.' Later, the doxographer Diogenes Laërtius recorded a list of books by Theophrastus that confirms the existence of this Anabtics, as well as of at least fourteen other works on logical subjects. ${ }^{8}$ Alexander and his colleagues may have had access to some of these works, and used them to determine what Aristotle had had in mind for his intended exposition of the hypothetical syllogism. There is thus some reason to think that the accounts that have survived from the neoPeripatetic commentators represent a significant part of early Peripatetic - and possibly even Aristotelian - teaching on the subject. Taken together with the relevant passages from Aristodle's own surviving work, they provide important evidence for reconstructing the character and development of hypothetical syllogistic in the early Peripatos."

However, since the latter part of the nineteenth century, when historians of logic began to take the first small steps towards such a reconstruction, certain crucial doubts about this evidence have not received due consideration. For, unhappily for present scholarship, none of Theophrastus's logical writings survived the end of antiquity at all, even if they survived much beyond his death and were thus available centuries later to Alexander and other later logicians. (The same Neleus and family supposedly inherited Theophrastus's books as well.) Eudemus's own written work, whose titles Diogenes did not record, is now also completely lost, as is that of the other associates and followers of Aristotle. Only Aristotie's Organon itself remains. The entire post-Aristotelian development of hypothetical syllogistic, then, is unattested in its onginal form. Yet, without the original work, a key source for verifying that Alexander and other commentators faithfully reported early Peripatetic hypotherical syllogistic is lost. At least some small doubt must therefore linger over any purported reconstruction on the basis of the commentaries of the neo-Peripaterics, who were removed in time from the original Peripatetics by half a millennium or more.

Now, this doubt is by itself relatively minor. Other considerations, however, serve to heighten it. One principal reason why the vast majority of Aristotelian and early Peripatetic work perished within the first few centuries after Aristotle's death is that newer philosophical schools - most notably the Stoa, the skeptical Academy, and the school of Epicurus - eclipsed the Peripatos during this period. While these ascendant schools competed for dominance in philosophy, Aristotle's and Theophrastus's immediate successors seem to have devoted most of their efforts to

: Alexander, In An. pr., p. 390.2-3.

8 Diogenes, 5.42-50.

' By 'early Peripatos' and 'early Peripatetics', I mean no doctrinal division of the school, but merely the immediate circle of Aristotle - especially Aristotle himself, his successor Theophrastus, and his associate Eudemus. 
what would now be considered scientific and not strictly philosophical pursuits, and later even ceased to produce much in writing. The Peripatos faded; while there were Peripatetics after Aristotle and Theophrastus, they appear to have been relatively unimportant even in their own time. ${ }^{\text {to }}$ Pre-eminence in the field of logic in particular passed to the most successful and popular of the newer schools, the Stoa. The Stoics, however, developed their own, distinct formal logic, inspiration for which came not so much from the Athenian Peripatos as from a minor Socratic school at Megara, whose renowned logician Diodorus Cronus was a teacher of Zeno, the school's founder. Canonical Stoic logic owes its essential shape to Chrysippus, the third scholarch of the Stoa and, alongside Aristotle, probably the most gifted logician of antiquity. Titles of his logical treatises, as Diogenes recorded them, number over one hundred, and range extensively over the field." Contemporary enthusiasts given to hyperbole proclaimed that the gods themselves have Chrysippus's logic if they have logic at all. 12 Aristotle's work, by contrast, became obscure.

Alexander and other early neo-Pcripatetic commentators thus began to revive Peripatetic logic in an intellectual environment in which 'logic' generally meant Stoic logic. This environment demanded that they explicate Peripateric logic in relation to, or even in opposition to, Stoic logic, and frequent discussion and criticism of Stoic logic show that the commentators recognized and responded to such demands. Indeed, their revival of Peripatetic logic in this environment touched off a contemporary debate about the relative merits of the two rival systems, the nature of whose precise points of contention has itself recently become a subject for debate. ${ }^{13}$ Because the commentators were such strong champions of Peripatetic logic, then, it is a surprising and difficult source of doube that, beginning at least with Alexander, they also drew on Stoic logic as a source for their presumably Peripateric hypothetical syllogistic. For the very circumstances that demanded that the neo-Peripatetics take Stoic logic into account made it easy for them to take Stoic logic on board as weil - either through ignorance, mistake, or willful appropriation - and thus to conflate two distinct logical traditions.

This conflation is what scholars have thus far not duly considered, so that some have even unwittingly followed in it. I contend, in fact, that it influenced the reports of the neo-Peripaterics

${ }^{10}$ For an extended discussion of the decline of the Peripatos, see Lynch, Aristotk's Scbool, pp. 135-62.

"Diogenes, 7.189-198.

12 Ibid, 7.180. Diogenes actually wrote that the gods would bave Chrysippus's 'òariektık'', which includes as an element logic in the modern sense.

13 Mueller, "Stoic and Peripatetic Logic"; Frede, "Stoic vs. Aristotelian Syllogistic". 
to such an extent that they eventually failed to recognize that Peripatetic hypothetical syllogistic and Stoic logic had been importantly different. Part of my purpose in this thesis is to establish this contention, and thus to establish more accurate limits on the extent to which the neo-Peripatetic commentaries support a reconstruction of early Peripateric hypothetical syllogistic. Further, in order to characterize the precise nature of the conflation of Peripatetic and Stoic logic that I contend occurred, I shall also necessarily go some way towards characterizing the original early Peripatetic hypotherical syllogistic in itself. Finally, in illustrating this conflation as it appears in the work of the commentators from Alexander to Boethius, I shall illustrate an aspect of the legacy of Stoic logic through to at least the end of antiquity, if not into the Middle Ages.

2. In order to be able to recognize the hypothetical syllogistic of the commentators as a conflation of Peripatetic and Stoic logic, it is necessary to recognize its Peripatetic origins as distinct from its Stoic origins - and especially the former, inasmuch as the commentators are a chief source for reconstructing early Peripatetic hypothetical syllogistic, despite the mixed character of their accounts. But, in order to be able to recognize the Peripatetic origins of the hypothetical syllogistic of the commentators, it is necessary to consider the remnants of what Aristotle wrote on the subject.

Since every syllogism is, according to Aristote, either direct or from a hypothesis, and since the direct syllogisms are the syllogisms of the three figures that he codified, a syllogism from a hypothesis is simply any pattern of inference that qualifies as a syllogism but is not in some mood of the three figures. The principal problem in understanding Aristotle's hypothetical syllogistic, then, is in understanding what unifies this diverse collection of syllogisms. Ostensibly, a syllogism is from a hypothesis because some hypothesis functions in it; thus, the problem is in understanding what a hypothesis is in the context of a syllogism. Now, Aristotle did not directly address this issue in what survives of his work; he did, however, name and discuss a few of these sorts of syllogism, and in some cases indicated what part of them is the hypothesis. The sort that received the most attention from him, and for which he gave a detailed account, he called the syllogism through, or

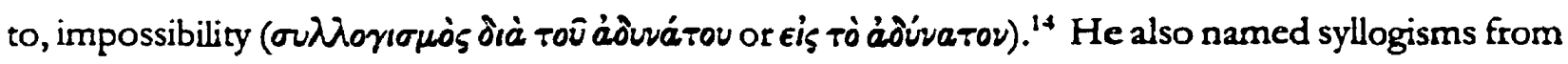

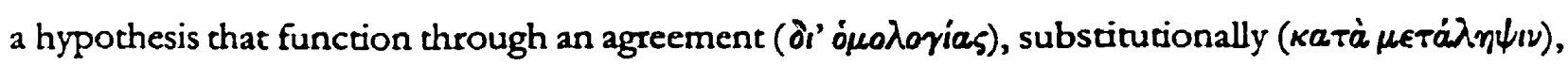

it Aristode, An pr., 41a23-30. 


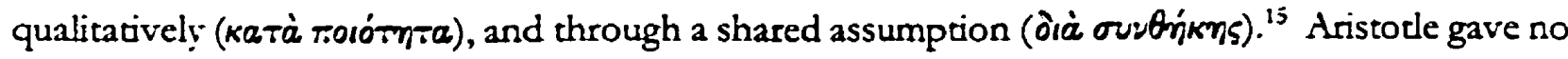
explicit indication that he thought of this list as exhaustive, however, nor any proof that there is no other type of syllogism besides the direct and those from a hypothesis.

Aristotle explained the syllogism through or to impossibility as follows:

For everyone who produces a syllogism through impossibility concludes a falsehood and shows the initial point by hypothesis, when something impossible follows from the proposed contradictory. For example, that the diagonal [of a square] is incommensurable [with the side] follows from the fact that, given that it is proposed to be commensurable, odd numbers will be equal to even ones. On the one hand, then, one deduces syllogistically that odd numbers will be equal to even ones, and shows, by hypothesis, that the diagonal is incommensurable, since a falsehood results from the contradictory. ${ }^{16}$

This sort of syllogism, then, proceeds from the supposition of the contradictory of the intended conclusion, together with a syllogistic derivation of something impossible from it. Given that the contradictory leads to something impossible, which must always be false, it follows that the contradictory is itself false, and therefore that the intended conclusion is true. Later, in comparing it with the direct syllogism, Aristotle wrote:

The proof to impossibility differs from the direct in that it poses that which, by means of reducing it to an admitted falsehood, it wants to refute. The direct proof, on the other hand, begins from admitted positions. They both assume two admitted premisses, then, but while the one assumes those from which the syllogism proceeds, the other assumes one of these premisses and one as the contradictory of the conclusion. ${ }^{17}$

Thus, the general form of the syllogism through impossibility is evidently 'Suppose that p; but, q; therefore, $r$ (which is impossible); therefore, not-p'. The hypothesis in the syllogism, as Aristotle's descriptions imply and as he explicitly designated it elsewhere, is ' $P$ ', the contradictory of the intended conclusion. ${ }^{18}$

Regarding the other sorts of syllogism from a hypothesis, however, Aristotle wrote very little.

His only other example is of the syllogism through a shared assumption:

For instance, if you were to hypothesize that, if there is not some one potentiality for contraries, there is also not one science of them, and you were then to argue that there is

${ }^{15}$ Ibid. 41 a 39-40, 45b16-18, and 50a18.

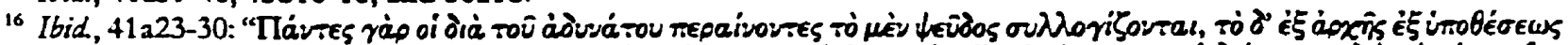

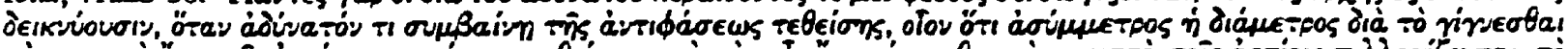

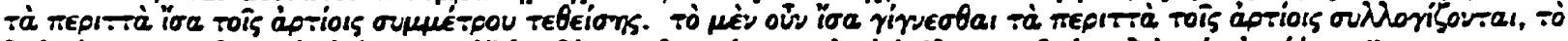

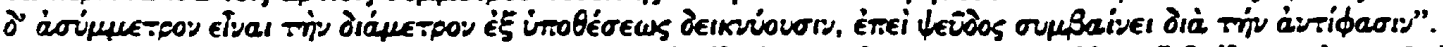

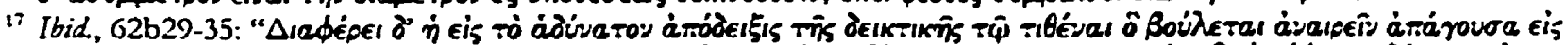

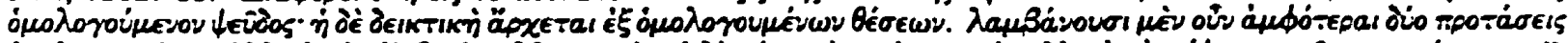

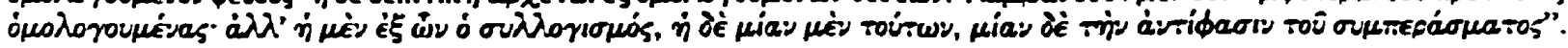

18 Ibid., 50,25-32. 
not any potentiality for contraries (as if for the healthy and the sick, for the same thing will be simultaneously healthy and sick), then it has been shown that there is not one potentiality for all contraries, but it has not been shown that there is not [one] science of them. It has to be agreed [that there is not one science of them], however - but not in virne of a syllogism, rather in virtue of a hypothesis. ${ }^{19}$

The form of this syllogism is, roughly, 'Suppose that, if $\mathrm{p}$, then q; but, $\mathrm{p}$ (since something impossible follows from not-p); therefore, $q$ '. It thus has, as a part, a syllogism through impossibility. Nevertheless, it is but an example; presumably it may even have a direct syllogism as a part instead. Similarly, the hypothesis in this syllogism is the supposition that, if $\mathrm{p}$, then $\mathrm{q}$; however, Aristotle did not state that the hypothesis must have the form of a conditional sentence. He in fact later

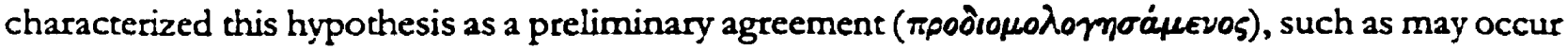
between participants in a logical debate. ${ }^{20}$ Conceivably, then, such an agreement may take one of many forms, so long as it indicates a logically useful relationship of some sort. These considerations suggest that the general form of the syllogism through a shared assumption is 'Suppose preliminarily that $p$ and $q$ are so related that $q$ follows from $p$; but, (given some derivation), $p$; therefore, $q$ ', and its hypothesis is the premiss expressing the agreed logical relationship between 'p' and ' $q$ ', whatever it may be.

Now, since the hypothesis in a syllogism through a shared assumption is a preliminary agreement, this sort of syllogism and the syllogism through an agreement appear to be the same. Indeed, Aristotle wrote that all syllogisms from a hypothesis that are not through impossibility are

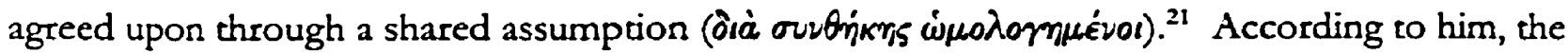
syllogism through impossibility does not require any preliminary agreement, because the falsity of the impossible result obviates the need for one." That is to say, in a syllogism of the form 'Suppose that $p$; but, $q$; therefore, $r$ (which is impossible); therefore, not-q', the necessary falsity of ' $r$ ' compels interlocutors to reject the supposition ' $\mathrm{P}$ ' irrespective of their prior attitudes towards it. Thus, syllogisms from a hypothesis divide into two types: syllogisms through impossibility, which require no preliminary agreement, and syllogisms through a shared assumption or an agreement, which turn directly on one. It follows, then, that substitutional and qualitative syllogisms - the remaining two

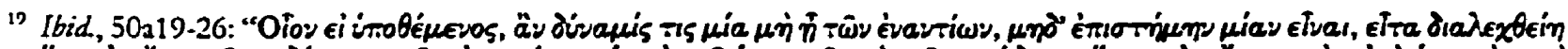

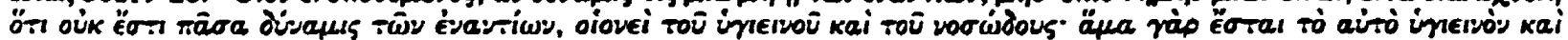

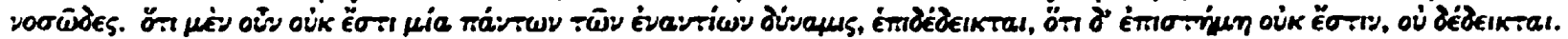

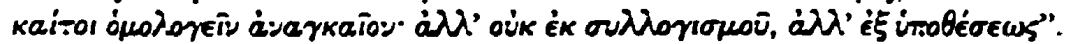

20 Ibid, $50_{2} 32$ and 36.

21 Ibid, 50a18-19.

$=$ Ibid, $50235-38$. 
sorts of syllogisms from a hypothesis that Aristotle named - belong to one of these two types.

Aristotle, however, gave no examples or descriptions of the substitutional or qualitative syllogism that he designated as such. Nevertheless, he did write that every syllogism from a hypothesis that is not through impossibility contains a part that proceeds in respect of what is

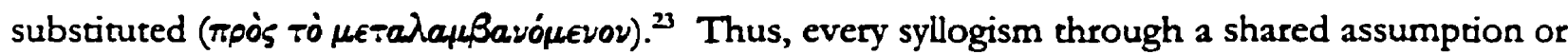
an agreement is apparently also a substitutional syllogism. Indeed, it is clear that the syllogism through a shared assumption or an agreement proceeds to its conclusion through a surrogate syllogism, whose own conclusion has a logical relationship to the intended conclusion of the original syllogism in virtue of some preliminary agreement, and which serves, in a sense, as a substitute for a more immediate deduction of the intended conclusion. For instance, in the case of Aristotle's example of the syllogism through a shared assumption, a syllogism to 'There is not one potentiality for contraries' substitutes for a syllogism to 'There is not one science of contraries', in virtue of a preliminary agreement that makes the latter logically consequent upon the former. Moreover, Aristotle wrote that the qualitative syllogism also proceeds in relation to what is substituted (ív roîs

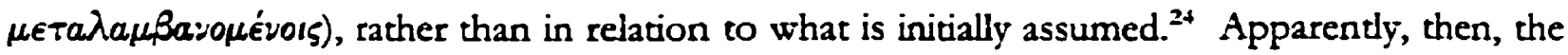
qualitative syllogism is a special sort of substitutional syllogism. The syllogism through impossibility, by contrast, proceeds to an impossibility from what is initially assumed, and is therefore not substitutional.

Aristode's two types of syllogism from a hypothesis thus divide in respect of two criteria: the syllogism through impossibility does not require a preliminary agreement and proceeds directly from its premisses, and the substitutional syllogism requires a preliminary agreement and proceeds indirectly through further, substitute premisses. Since the qualitative syllogism belongs to the substitutional type, it ostensibly functions from a preliminary agreement expressing a qualitative relationship, such as between the higher and lower, or the more and less beautiful. For any further information about it, however, as well as about Aristote's other syllogisms from a hypothesis, it is necessary to turn to the commentators. As I have already raised doubts about the possible Stoic origins of their hypothetical syllogistic, I shall leave aside their reports for now. Later in this chapter and throughout the next chapter, in the course of more thoroughly separating the Peripatetic and Stoic origins of their hypothetical syllogistic, I shall return to the evidence in their texts.

\footnotetext{
3 Ibid, 41 238-39.
}

24 Ibid, 45b1 ?-19. 
3. Now, as I have noted, the main problem in understanding what unifies the various syllogisms from a hypothesis is understanding what a hypothesis is. Since Aristotle designated the hypothesis of the syllogism through impossibility as the contradictory of the intended conclusion, which is a simple or categorical statement, but the hypothesis of the substitutional syllogism as a preliminary agreement regarding some sort of logical relationship, which is a complex statement combining two simple statements, it follows that the feature that unifies these syllogisms is not the formal structure of the hypothesis. In fact, the only limit on the form of the hypothesis in the substitutional syllogism is that it signifies a logically useful relationship of some sort; it may do so in one of many forms, however, even regarding the same things. Nevertheless, scholars long thought that Aristotle must have had a formal similarity between the various syllogisms from a hypothesis in mind; it was not until 1980 that Jonathan Lear recognized that this interpretation was incorrect. As he noted, it had led his predecessors to view syllogisms from a hypothesis as Aristotle's attempt to analyze inferences from a conditional sentence within the syllogistic, which is by itself incapable of providing a formal model of them. ${ }^{25}$ However, this view focuses so much on the conditional form of the hypothesis in Aristotle's single example of the substitutional syllogism that scholars supposed that the syllogism through impossibility also conceals an implicit conditional sentence or even, according to William and Martha Kneale, that Aristotle would have done better to have formalized such syllogisms as arguments in modus tollens. ${ }^{26}$ In other words, this view ignores the fact that Aristotle's single example of the substitutional syllogism is not necessarily completely general. It also ignores Aristotle's own claim that the hypothesis of the syllogism through impossibility is the explicit simple statement that is the contradictory of the intended conclusion, and not some implicit

25 Lear, Aristotle and Logical Theory, p. 35.

${ }^{36}$ Kneale and Kneale, The Development of Logic, pp. 98-99. For a different but no less unsuccessful 2pproach, see Striker, "Aristoteles über Syllogismen "Aufgrund einer Hypotheser", especially pp. 43-47. She suggested that syllogisms through impossibility and substitutional syllogisms are formally similar because they both tum on some inference rule that is neither a formal syllogistic mood nor a conversion rule, nor depends on them, and which can be either logically valid (for syllogisms through impossibility) or agreed to more or less ad boc (for substitutional syllogisms). According to her, this rule is the hypothesis in each syllogism. The problems with Striker's interpretation are threefold. Firstly, Striker made no attempt to explain why Aristotle had explicitly designated both the proposed contradictory as the hypothesis of a syllogism through impossibility and the conditional sentence as the hypothesis of the substiutional syllogism. There seems to be no way to reconcile Aristote's claims with her own. Secondly, Striker's hypotheses are not at all a part of the syllogisms to which they belong, as Aristotle's account requires. Thirdly, as I mentioned above, Aristotle thought of substitutional syllogisms, but not syllogisms through impossibility, as depending on an agreement. Striker tried to capture this distinction by noting that, while the inference rule operating in the syllogism through impossibility is logically valid, the rule operating in the substitutional syllogism is ad hoc and not necessarily logically valid. However, Aristotle thought that the syllogism through impossibility requires no agreement because the falsity of the impossible result is obvious, not because the validity of some reductio-rule is obvious. 
complex statement.

Lear thus abandoned the idea that there is any formal similarity between Aristode's syllogisms from a hypothesis. He wrote:

This picture does not go to the heart of the matter. It cannot provide a unified account of hypotherical syllogisms, because it does not acknowledge that the underlying problem is not with the formalization of certain statements or inferences, but with the role certain statements play within an argument. ${ }^{2 i}$

According to him, then, the similarity between syllogisms from a hypothesis is instead the argumentarive role belonging to certain premisses. Not a formal or syntactic feature, but rather a pragmatic feature, unifies them. In the context of a deduction, it is important whether certain premisses are assertions or merely suppositions; only if it is possible to indicate this difference of role (as with a natural deduction system that allows introduction and discharge of premisses), is it possible to know whether a deduction is an unconditional proof of its conclusion or simply an inference to a conclusion on the basis of certain suppositions. Aristotle's direct syllogistic, however, is incapable of capturing the notion of argumentative role, and thus incapable of indicating whether any given premiss is an assertion or a supposition. On Lear's interpretation, then, Aristotle was aware of this inadequacy in his syllogistic, and developed his theory of syllogisms from a hypothesis in order to account for $\mathrm{it}^{28}$ The hypothesis, then, as the literal meaning of the word implies, is simply a premiss that has a suppositional argumentative role. It need not take any particular form. Moreover, both the syllogism through impossibility and the substitutional syllogism have such premisses. In the former type of syllogism, it is necessary that one premiss - the contradictory of the intended conclusion - is merely a supposition for the sake of argument that a derivation of an impossibility will prove false. No complete analysis of the syllogism can fail to recognize the role of the contradictory. In the latter type of syllogism, the agreement between interlocutors that justifies the final move to the conclusion is also a supposition for the sake of argument, for it is a preliminary agreement between interlocutors. Again, no complete analysis can fail to recognize its role.

Now, I have no objection to Lear's interpretation in itself, but I think that it is lacking in an important respect. According to Lear, the syllogism from a hypothesis differs from the direct syllogism insofar as it is irrelevant to the latter but not to the former whether certain premisses are

7 Lear, Aristotk and Logical Theory, pp. 35-36. Emphasis in original

29 Ibid, p. 39. 
assertions or suppositions. For instance, no-one who wants to prove that $p$ asserts that not-p, but someone who wants to prove that $\mathrm{p}$ may indeed temporarily suppose that not-p for the sake of argument, in order to derive an impossibility from it. Nonetheless, in a substitutional syllogism of the form 'If $\mathrm{p}$, then $\mathrm{q}$; but (given some derivation), $\mathrm{p}$; therefore, $\mathrm{q}$ ', it indeed appears to be irrelevant whether or not the premiss 'If $p$, then $q^{\prime}$ - that is, the hypothesis - is an assertion or a supposition. Someone who wants to prove that $q$ may well assert that, if $p$, then $q$, and then undertake a derivation that $p$. Hence, Lear's interpretation calls for further explanation of Aristotle's apparent failure to consider statements such as 'If $p$, then $q$ ' except as suppositions in the context of an agreement between interlocuiors.

Examination of how Aristotle sought to account for the validity of syllogisms from a hypothesis makes this point more plain. For Aristotle, any purported syllogism gains a guarantee of its validity through reduction to the syllogisms of the first figure - that is, through the deduction of the same conclusion from the same premisses using only first figure syllogisms and certain obviousiy valid rules. The first figure syllogisms are themselves basic because they are obviously valid as well -

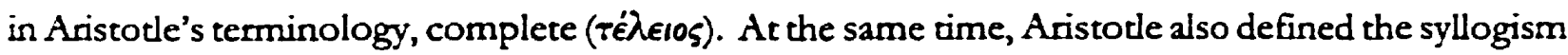
as a $\lambda o ́$ 'o their being so, and divided the syllogism in this broad sense into those that are direct and those that are from a hypothesis. Thus, it was crucial to Aristodle's logical program that he demonstrate that every pattem of inference that qualifies as a syllogism in this broad sense, whether direct or from a hypothesis, is also reducible to the syllogisms of the first figure. Such a demonstration would show, in effect, that the categorical syllogistic is sufficient to capture any logically necessary inference. $^{29}$ He accomplished this demonstration in the case of the direct syllogism by going through reductions of all the moods of the second and third figures seriatim, and then proving that it is not possible to construct a direct syllogism except either in one of these moods or in a mood of the obviously valid first figure. ${ }^{30}$ The direct syllogism therefore carries a guarantee of validity. Syllogisms from a hypothesis, on the other hand, lack such a guarantee, since they are not in fact reducible to the syllogisms of the first figure.

Aristotle, however, tried to circumvent this difficulty by claiming that every syllogism from a hypothesis includes a direct syllogism as a part, and so is at least partially reducible to the syllogisms

20 In this way, it is analogous to a modern completeness proof. See ibid, pp. 1-33, especially p. 16.

so Aristotle, An. pr., 40b30-41220. 
of the first figure. For instance, as I have cited above, he explained that the syllogism through impossibility functions in part through a syllogistic derivation of an impossibility from the contradictory of the intended conclusion; later, he explicitly designated this derivation as a direct syllogism. ${ }^{3 i}$ Since the syllogism through impossibility has the form 'Suppose that p; but, q; therefore, $\mathrm{I}$ (which is impossible); therefore, not-p', the derivation ' $\mathrm{p}$; but, $\mathrm{q}$; therefore, $\mathrm{r}$ ' is thus a direct syllogism. Similarly, in the case of the substiturional syllogism, Aristotie explicitly designated the substitute syllogism as direct. Thus, in the substitutional syllogism 'Suppose that $\mathrm{p}$ and $\mathrm{q}$ are so related that $q$ follows from $p$; but, (given some derivation), $p$; therefore, $q$, the unspecified derivarion that $p$ is a direct syllogism..$^{32}$ Hence, at least some part of any syllogism from a hypothesis carries a guarantee of validity. Moreover, Aristotle was able to effect a kind of reduction for the syllogism through impossibility, recognizing that, for any syllogism 'Suppose that p; but, q; therefore r (which is impossible); therefore not-p' a direct syllogism 'q; but, not-r; therefore, not-p' is constructible. ${ }^{33}$ This constructibility is not the same as reducibility; however, it does show that the syllogism through impossibility is in some sense redundant.

Nonetheless, in the case of the substitutional syllogism at least, the inferential move via the hypothesis carries no guarantee of validity even if there is a guarantee of validity for the substitute syllogism, because this move is simply not reducible to the syllogisms of the first figure. At the same time, as Aristotle himself claimed and as I cited above, their conclusions are necessary given their premisses, since it is clear that anyone who agrees that $q$ follows from $p$ must concede that $q$ upon a derivation that $\mathrm{p}$. Thus, they are syllogisms by definition. The case of the substitutional syllogism, then, illustrates how Aristotle's logical program falters, for it presents a counter-example to his claim that the direct syllogisms of the first figure can express anything that qualifies as a syllogism by definition. It illustrates, in other words, the gap between Aristotle's definition of the syllogism and the model of his syllogistic, and between the notions of logical necessity and syllogistic

II Ibid, 50230-31.

32 Ibid, 50226-28. It is worth noting, however, that Aristotle's actual example of a substitutional syllogism invokes 2 syllogism through impossibility rather than 2 direct syllogism as the substitute: there is not one potentiality for contranies because, if there were one, the same thing would be both healthy and sick. Aristotle wrote that this

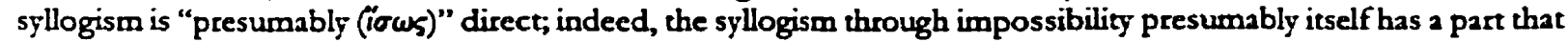
is a direct syllogism, as I have just explained. However, since syllogisms from a hypothesis are thus iterable, Aristolle's claim that every syllogism from a hypothesis has a part that is a direct syllogism requires a proof that such iteration is always finite, and ends in a direct syllogism. He did not provide this proof in his surviving work.

33 Ibid., 45a36-b11 and 62b38-63b21. 
validity. ${ }^{3+}$

It also illustrates an important difference between Aristotle's hypothetical syllogistic and modern logic that makes the demands of Lear's interpretation of the hypothesis more plain. In modern logic, logical necessity and validity are the same notion under different aspects; thus, a modern logician considers the inference 'If $p$, then $q$; bus, $p$; therefore, $q$ ' perfectly valid, since it meets the sole criterion that its conclusion is lugically necessary given its premisses. That is to say, in the terms of Lear's interpretation of the nature of the hypothesis, it is irrelevant to the modern logician whether the conditional sentence 'If $\mathrm{p}$, then $\mathrm{q}$ ' is an assertion or a supposition. The inference from both a conditional sentence and its antecedent to its consequent is simply valid, the argumentative context notwithstanding. Lear's interpretation demands, then, a further explanation for why Aristotle did not consider the hypotheses in substitutional syllogisms except as suppositions. In other words, Lear's interpretation demands an explanation for why Aristotle did not treat the substitutional syllogism and its hypothesis in accordance with modern sentential logic and a modern notion of validity.

It is easy to suppose, in fact, that the substitutional syllogism represents a tentative step towards a sentential logic in the modern sense, for Aristotle's hypothetical syllogistic lacked for its full development an account of the hypothesis or hypothetical statement. His direct syllogistic, for example, depends fundamentally on an account of the categorical statement, as Aristotle determined the structure and order of the figures and moods of the direct syllogism by examining every combination of the four types of categorical statement in a pair of premisses and eliminating those from which no conclusion follows of necessity. Aristotle's stated intention to return to a discussion of how many ways in which a syllogism proceeds from a hypothesis, then, was an intention to provide this missing account of the sorts of hypothetical statement. In this way, the various syllogisms from a hypothesis would have received an order as well. But, since every syllogism from a hypothesis is either through impossibility or substitutional, and since Aristote had already explained the syllogism through impossibility in detail, his intention was mostly to divide the

${ }^{3}$ Lear wrote that the substiturional syllogism does not threaten Aristodle's chaim that the direct syllogistic is adequate for the expression of all syllogisms because it is not a syllogism at all, for the reasons I have just outlined. The part that is a syllogism, moreover, is reducible. Yet, Aristotle's definition of the syllogism is broad enough to capture the substiturional syllogism in its entirety: it is indeed a $\lambda$ oros in which, given that some things are posited, something else follow's from them of necessity. It is thus not a syllogism only in the narrow sense that it is not reducible to the syllogisms of the first figure. So, if it fails to qualify as a counter-example to Aristotle's claim for this zeason, then the phrase 'of necessity' in Aristotle's definition means syllogistic necessity, and his claim is of much less metalogical interest. See Lear, Aristotk and Logical Theop, p. 53. 
substitutional syllogism into its various kinds in virtue of the various kinds of hypothetical statement. Moreover, since the hypothesis in the substitutional syllogism is a complex statement that seems to express some logical relationship between simple statements, Aristotle's intention was to classify complex statements in virtue of the various kinds of sentential relationship.

In modern logic, the canonical form of such classification is the classification of the sentential operators that bind atomic sentences together into molecular ones, such as 'if and 'or'. A modern logician thus divides molecular sentences in respect of such operators, differentiating between conditionals, disjunctions, conjunctions, and so on. It is easy to suppose, then, that Aristode's substitutional syllogism lacked for its full development a theory of the sentential operator and the molecular sentence, and that his intended treatise on the syllogism from a hypothesis would have been a treatise in sentential logic. However, not only is this supposition incorrect if Lear's interpretation is correct, it is also probably anachronistic in any case. No technical terms for different types of molecular sentence, such as 'conditional' and 'disjunction', appear in Aristotle's surviving work, and he did not refer to any class of sentence as molecular - or even, for that matter, as hypothetical (inobetikós) rather than categorical. Indeed, as I have pointed out above, the hypothesis in a syllogism through impossibility is a simple, categorical statement and not a complex one. Additionally, independent evidence from the Prior Analytics explains why the hypothesis in a substitutional syllogism must indeed be a supposition and not an assertion as Lear argued, and thus why Aristotle would not have developed his hypothetical syllogistic along the lines of a sentential logic.

4. In 1951, Jan Eukasiewicz drew attention to the following passage from the Prior Analytics, in which he thought Aristode "intuitively used the laws of propositional logic": ${ }^{35}$

Now, given that the same thing is and is not the case, it is impossible that the same thing is the case of necessity. I mean, for example, that $B$ is large of necessity given that $A$ is white and $B$ is large of necessity given that $A$ is not white. For, when this particular thing - the $\mathrm{B}$ - is large of necessity given that that particular thing - the $\mathrm{A}$ - is white, but $\mathrm{C}$ is not white given that $B$ is large, then it is necessary that, if $A$ is white, $C$ is not white. And, when it is necessary that the latter of two things is the case given that the former is the case, then it is necessary that the former is not the case given that the latter is not the case. So, given that $B$ is not large, A cannot be white. But, if it is necessary that $B$ is large given that $A$ is not white, then it follows of necessity that, given that $B$ is not large, the same $B$ is large.

${ }^{35}$ Eukasiewicz, Aristotk's Syllogistic, pp. 49-51. 
But, this is impossible. ${ }^{36}$

At first glance, Aristotle seems to have been arguing as follows:
(1) Given that $p, q$
(assumption)
(2) Given that not-p, q
(assumption)
(3) Given that not-q, not-p
(1, contraposition)
(4) Given that not-q, q
(2,3, transitivity).

The argument is valid, but Eukasiewicz claimed that Aristotle was wrong to have thought (4) impossible, since it is logically equivalent to ' $q$ '. This reading of (4), however, depends on interpreting at least one use of the particle 'if in the passage (at 'if $A$ is white, $C$ is not white'), as well as all uses of the genitive absolute construction (which I have translated using the word 'given'), as uses of a sentential operator. On this reading, (4) is true if and only if ' $q$ ' is true. Now, this interpretation is natural enough, especially in the context of a sentential logic. However, an alternative interpretation, according to which the particle if and the genitive absolute construction consistently signify the inferential relation of syllogistic consequence, eliminates the problem, for there is simply no possible syllogistically valid inference from the premiss ' $B$ is not large' to the conclusion $\mathrm{B}$ is large'. ${ }^{37}$ As Aristotle himself wrote immediately after his argument:

Thus, if B will be large given that the former [sc. the A] is not white, then it follows that, if

$B$ is not large, it is large, just as through [a syllogism of] three terms. ${ }^{38}$

Aristotle was demonstrating, then, not a logical principle for conditional sentences, but what a modern logican would call a metalogical principle for syllogistic inference. Despite appearances, he was using both the particle 'if and the genitive absolute construction, not as sentence-forming operators on sentences, but as signs of the syllogistic consequence proper to an inference.

A second passage from the Prior Analytics further illustrates his inferential use of the particle 'if and of the genitive absolute construction. Aristotle wrote:

Firstly, then, it is clear from what follows that it is not possible to deduce a false statement from true statements. For, if, given that $A$ it is necessary that $B$, then given that not $B$ it is

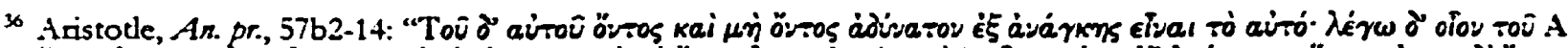

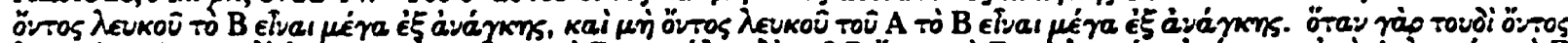

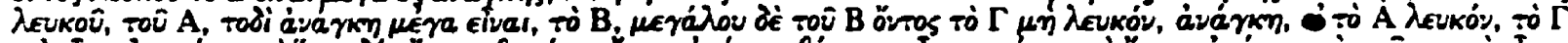

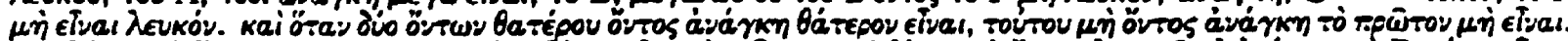

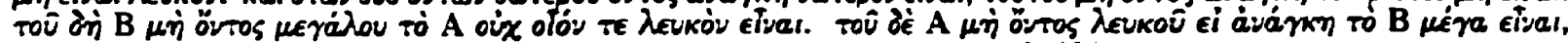

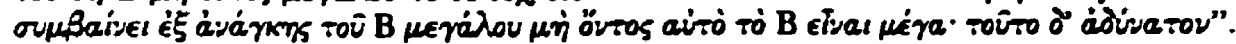

37 The Kneales noted that the better interpretation of this passage is that it concerns inferential entailment, but they then proceeded to interpret it as Eukasiewicz did. They seem to have failed to recognize that, for Aristotle, inferential entailment is a syllogistic nocion. See their The Development of Logic, p. 96-97.

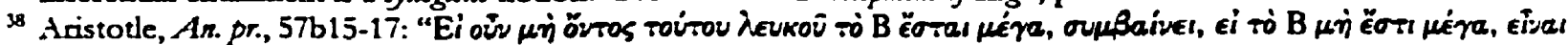

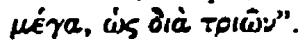


necessary that not $A$. Therefore, if it is true that $A$, it is necessary that it is true that $B{ }^{39}$

Following Eukasiewicz's line, the Kneales claimed that Aristotle was here discussing a principle of sentential logic - namely, the principle of contraposition: if q given that $p$, then not-p given that not-q. ${ }^{*}$ As before, however, this reading depends on interpreting at least one use of the particle 'if (at 'if it is true that $A$, it is necessary that it is true that $B$ '), as well as all uses of the genitive absolute construction, as uses of a sentential operator. It also depends on reading the variables ' $A$ ' and ' $B$ ' as sentential variables. However, the context of the passage makes clear that Aristotle had neither sentential logic nor sentential variables in mind:

But, let it not be supposed that $A$ is set down as one term and that something is shown to follow of necessity given that some one thing is the case, for it cannot be. For the conclusion is the necessary result, and three terms and two premisses are the fewest through which this comes to be.

... Although $A$ is set down as one thing, then, it comprises two premisses."

The principle that Aristotle stated, then, describes a property of the relation between premisses and conclusion in an inference; as he himself wrote, his argument shows that it is not possible to deduce

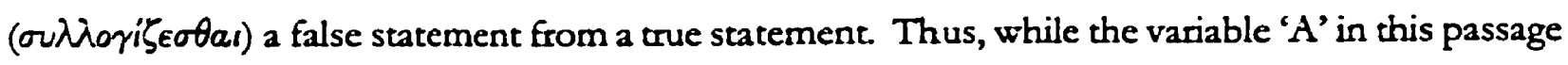
does not stand for a term, it also does not stand for a sentence. Rather, it stands for a set of sentences that are the two premisses of a syllogism. The variable 'B' need not stand for a sentence either, except accidentally insofar as the conclusion of a syllogism is a single sentence. Thus, Aristotle again used the particle if and the genitive absolute construction to signify syllogistic consequence, despite appearances. Indeed, he commonly used the particle if in this sense even when formulating his direct syllogisms - for example, writing If every A is B and every B is C, then every $A$ is $C^{\prime} .42$

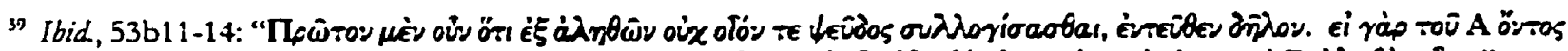

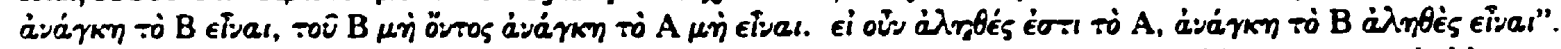

to Kneale and Kneale, The Development of Logic, p. 96. Once again, the Kneales noted that this passage probably concerns inferential entailment, but then proceeded to interpret it as I describe.

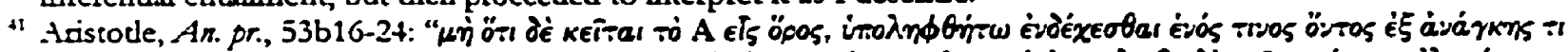

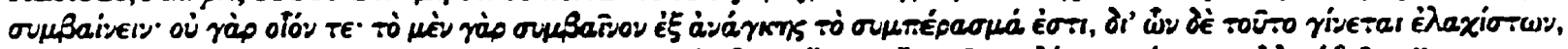

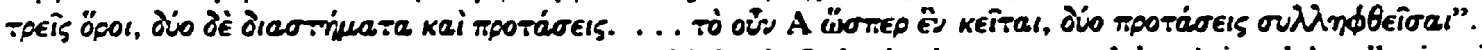

\$2 See, for example, ibid, 25b26-29a19 passim. On this basis, Eukasievicz suggested that Aristotle's syllogism is actually a conditional sentence with a conjunctive antecedent, rather than an inference from premisses to conclusion - see his Aristote's Syllogistic, pp. 1-3. If so, my interpretations of the above two passages would be misguided. Nevertheless, I shall not take up this point, because Timothy Smiley and John Corcoma have already overturned it conclusively - Smiley noting in particular (p. 139) that, even in English, only the context determines whether the particle 'if indicates a conditional or a deduction. See Smiley, "What is a syllogism?"; Corcoran, "Aristotle's natural deduction system". See also Lear, Aristotk and Logical Theory, pp. 8-9, for a summarization of the arguments against Eukasiewicz's view. 
Now, in modern sentential logic, it is a theorem that an inference is valid if and only if the conditional sentence, whose antecedent is the conjunction of the inference's premisses and whose consequent is the inference's conclusion, is crue, and that an inference is invalid if and only if such a condirional sentence is false. However, this theorem holds because, in modern logic, an inference is valid if and only if its conclusion is tue if its premisses are true. No valid inference proceeds to a false conclusion from true premisses, and thus no conditional sentence corresponding to a valid inference has a true antecedent and false consequent. In Aristotle's logic, by contrast, in which there is a gap between logical necessity and syllogistic validity such as I pointed out above, this theorem is not provable. Some true conditional sentences correspond to inferences that are only logically necessary, insofar as the inferences are not reducible to the syllogisms of the first figure. Thus, while all syllogistically valid inferences correspond to true conditionals, some true conditionals such as 'If both $\mathrm{p}$ and if $\mathrm{p}$, then $\mathrm{q}$, then $\mathrm{q}$ ' - correspond to syllogistically invalid inferences. At the same time, however, Aristotle committed himself to the theoretical equivalence of logical necessity and syllogistic validity, since according to him the categorical syllogistic is sufficient to capture any logically necessary inference. It is unimportant here that this alleged equivalence actually fails; rather, it is important that, if these notions were equivalent as Aristodle claimed, then every true conditional sentence would indeed correspond to a syllogistically valid inference, and the theorem would therefore be provable.

What is more, since Aristotle regularly used both the particle 'if' and the genitive absolute construction to signify syllogistic consequence, he seems to have simply accepted this theorem implicitly. I do not mean that Aristotle could have formulated the theorem as such; he did not even have a term for the conditional sentence, as I have said. Rather, he seems to have simply taken for granted a strong correspondence between conditional sentences and syllogisms - in other words, to have been at least partially unaware of the fact that conditional sentences are not syllogisms. As I cited just above, however, syllogisms have a certain structure for Aristotle: they must proceed from two premisses and three terms. Thus, certain apparently true conditional sentences, such as 'If every human is mortal, then Socrates is mortal' or 'Given that every human is mortal, Socrates is mortal', do not represent complete syllogisms because their antecedents are not complex enough in form. Instead, they represent only partial syllogisms - for instance, of the form 'Every human is mortal; but, ... ; therefore, Socrates is mortal', in which the ellipsis indicates a potential premiss, such as 'Socrates is a human', that the antecedent of the conditional sentence lacks. Now, this partial 
syllogism is neither syllogistically valid nor invalid, for only complete syllogisms are syllogistically valid or invalid. ${ }^{43}$ For Aristotle, then, who did not differentiate sharply between conditional sentences and syllogisms, the apparently true conditional sentences 'If every human is mortal, then Socrates is mortal' and 'Given that every human is mortal, Socrates is mortal' are actually neither true nor false, for in a distinct sense they are not complete.

In Aristotle's logic, then, it is impossible to assert the "partial" conditional sentence 'If every human is mortal, then Socrates is mortal' or 'Given that every human is mortal, Socrates is mortal', for every assertion must naturally be true or false. It is possible, however, to suppose it, for to suppose it is essentially to suppose it to be true, and to suppose it to be true is essentially to suppose that there is a true additional sentence, such as 'Socrates is a human', that completes it. More generally, then, it is impossible to assert, but possible to suppose, any conditional sentence of the form 'If $p$, then $q$ ' or 'Given that $p, q$ ' that does not represent a complete syllogism. At least some substitutional syllogisms, however, have hypotheses of the form 'If $p$, then $q$ ' or 'Given that $p, q$ ' that do not represent complete syllogisms; for instance, the hypothesis in Aristotle's own example of the substitutional syllogism is If there is not one potentiality for contraries, then there is not one science of contraries'. Thus, in at luast some substitutional syllogisms, the hypothesis must be a supposition. Moreover, the general form of the hypothesis in a substitutional syllogism is 'Suppose that $p$ and $q$ are so related that $q$ follows from $p$ ', as I discussed above. Because the inferential relation that the word 'follows' signifies is always expressible as a conditional sentence with the particle 'if or with a genitive absolute construction, the hypothesis in a substitutional syllogism may always have the form 'If $p$, then $q$ ' or 'Given that $p, q$ '. Finally, a hypothesis of this form may never represent a complete syllogism, for then the substitutional syllogism would merely be a chain of two direct syllogisms in which the conclusion of one is a premiss of the other, and not an independent type of syllogism. Therefore, the hypothesis in a substitutional syllogism must always be a supposition. Lear's interpretation of the hypothesis is correct, and the explanation that this interpretation demands is now clear: Aristotle did not conceive of the hypothesis in the substitutional syllogism except as a supposition in the context of an agreement between interlocutors precisely because he conceived of it as representing a partial syllogism that interlocutors suppose valid in full.

43 Even a partial syllogism of the form 'p; but . . .; therefore, not-p' is not syllogistically invalid, despite the fact that it is not possible to complete it in such $a$ way that it yields $a$ valid syllogism. 
Moreover, since the hypothesis in the substitutional syllogism must be a supposition, the substitutional syllogism cannot be part of a sentential logic. I have already pointed out above that, in a substitutional syllogism of the form 'Suppose that $p$ and $q$ are so related that $q$ follows from $p$; but (given some derivation), $\mathrm{p}$; therefore, $\mathrm{q}^{\prime}$, the unspecified derivation is a direct syllogism according to Aristotle. Thus, at least this portion of the syllogism is part of a logic for terms. However, since the hypothetical portion also represents a partial direct syllogism that interlocutors suppose to be complete, the entire substitutional syllogism is part of a logic for terms. My convenient use of sentential variables to formulate the substitutional syllogism is therefore an improper disguise, because it implies that the hypothesis expresses the relationship berween the unanalyzed sentences ' $p$ ' and ' $q$ ' rather than relationship between certain terms in ' $p$ ' and ' $q$ '. Depending on the particular categorical statements in question, a better formula for a substitutional syllogism might be 'Suppose that, if every $A$ is $B$, then every $C$ is $D$; but, (given some direct syllogism), every $A$ is $B$; therefore, every $C$ is $D$ '.

Without the disguise of sentential variables, it becomes plain how the hypothesis represents a partial syllogistically valid inference, and thus how the entire substiturional syllogism is part of a logic for terms. If the two simple statements that compose the hypothesis share a common term for instance, in ' Given that every $A$ is $B$, every $A$ is $C$ ' - the hypothesis is essentially a supposition that there is a syllogism such as 'Every $A$ is $B$; but, every $B$ is $C$; therefore, every $A$ is $C$ '. The hypothetical part of the substitutional syllogism thus turns on the logical relationships between the terms ' $A$ ', 'B', and ' $C$ ', and not between the unanalyzed sentences 'Every $A$ is $B$ ' and 'Every $A$ is $C$ '. Moreover, even if the two simple statements that compose the hypothesis share no common terms from which to construct a single direct syllogism, the hypothesis is nevertheless a supposition that the move from antecedent to consequent is syllogistically valid, and not a mere assertion. That is to say, interlocutors who agree that, if every $A$ is $B$, then every $C$ is $D$, are essentially supposing that there is a chain of direct syllogisms that begins from 'Every $A$ is $B$ ' and ends in 'Every $C$ is $D$ ' - for instance, such as 'Every $A$ is $B$; but, every $B$ is $D$; therefore, every $A$ is $D$; but, every $C$ is $A$; therefore, every $C$ is $D^{\prime}$. Chains of direct syllogisms such as this one, however, are as much a part of a logic for terms as the single direct syllogism.

In fact, the only sort of hypothesis that cannot represent any syllogistically valid inference or chain of inferences has the form 'If $A$ is $B$, then $C$ is $D$ ', in which the component parts of the hypothesis are both singular and have differing subject terms. This sort of hypothesis represents 
a syllogism from two singular statements, which Aristotle's model of the categorical syllogistic disallows. An example is 'If pleasure is the end, then virtue is not chosen for its own sake', or the major premiss in Aristotle's own example of the substitutional syllogism, which is essentially 'If the potentiality for contraries is not one, then the science of contraries is not one'. Nevertheless, in the context of Aristotle's logic generally, some such inferences are yet theoretically possible, for they may be logically necessary, and logical necessity and syllogistic validity are theoretically identical. Now, this inconsistency is to be expected given the actual gap between logical necessity and syllogistic validity that I pointed out above; it would rather be surprising if the mere four syllogisms of the first categorical figure were in fact sufficient to capture anything that qualifies as a syllogism by definition. It is thus no objection to my interpretation of Aristotle's hypotherical syllogistic that he himself had adopted a inherendy problematic account of logical necessity. In any case, the hypothesis in the substitutional syllogism is a preliminary agreement between interlocutors, and there is no reason to suppose that interlocutors will always correctly agree that some syllogistically valid inference or chain of inference exists.

Thus, because Aristotle explicitly tied his notion of validity to the notion of syllogistic consequence, he was unable to consider the hypothesis in a substitutional syllogism except as a supposition that a syllogistically valid inference exists. Consequently, as I claimed above, the treatise that Aristotle intended to compose about the many ways in which a syllogism can be from a hypothesis could not have amounted to anything like a modern account of the molecular sentence, or of the sentential operators that bind atomic sentences into molecular ones, such as 'if and 'or'. That is to say, his intended account of the syllogism from a hypothesis could not have been, even in part, a sentential logic. The fact that the Stoics, in contrast to Aristotle, did have an account of the relacionships between unanalyzed molecular sentences, and of the sentential operators that express these relationships, makes this point significant to understanding the separate Peripatetic and Stoic influences on the hypothetical syllogistic of the commentators, as I shall explain in the next chapter.

5. It is difficult to determine from the sparse evidence of the Prior Analytics the exact form that Aristotle's fully developed account of the substitutional syllogism would have taken, if it would not have been a logic for sentences. Nonetheless, the way in which Aristotle thought of the hypothesis in a substitutional syllogism as a supposition that a syllogistically valid inference exists between two 
simple statements suggests how he might have divided this type of syllogism more finely. By definition, every simple statement affirms or denies that something belongs to something else. " Thus, the hypothesis in a substitutional syllogism is the supposition that something belongs or does not belong to something else, given that some other thing belongs or does not belong to something else. There are, then, four possible types of hypothesis:

(1) That $A$ belongs to $B$ given that $C$ belongs to $D$,

(2) That $A$ belongs to $B$ given that $C$ does not belong to $D$,

(3) That $A$ does not belong to $B$ given that $C$ belongs to $D$,

(4) That $A$ does not belong to $B$ given that $C$ does not belong to $D$.

Furthermore, as Aristode recognized, not-p follows from not-q if and only if $q$ follows from $p$; thus, types (1) and (4) and types (2) and (3) do not essentially differ. Thus, Aristotle may well have intended to divide the hypothesis in a substitutional syllogism into two main types: (i) the supposition that something belongs to something else given that some other thing belongs to something else, and (ii) the supposition that something does not belong to something else given that some other thing belongs to something else (or vice versa). More simply, he may have intended to divide it into (i) the supposition that something is given that something else is, and (ii) the supposition that something is not given that something else is (or vice versa). As I shall show in the next chapter, early Peripatetic hypothetical syllogistic incorporated this division even if Aristotle had not formulated it as such.

Some evidence that Aristotle himself may have intended this division is available from his Topics. In this work, he suggested the following way in which an interlocutor might reason in the context of a logical debate:

Now, in regards to what is proposed, you should examine what, given that it is, what is proposed is, or what is of necessity if what is proposed is. If you want to establish [what is proposed, you should examine] what, given that it is, what is proposed will be, for what is proposed will have been shown if the former has been shown to be. If you want to refute [what is proposed, you should examine] what is if what is proposed is, for we will have refuted what is proposed if we show that what follows from what is proposed is not. ${ }^{45}$

The dialectical strategy that he described in this passage resembles the first and fourth types of hypothesis that I suggested above. He also described another dialectical strategy that resembles the

4 Aristode, De int, 17a23-24.

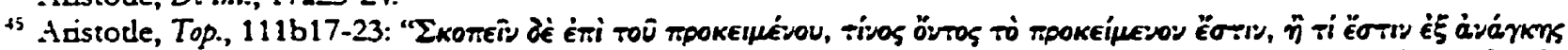

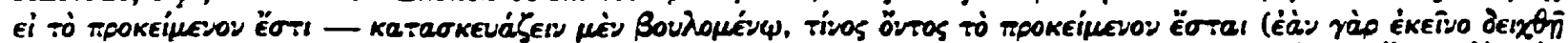

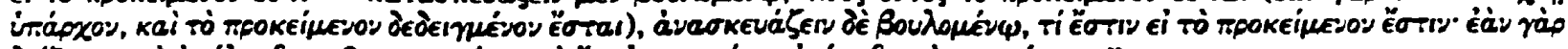

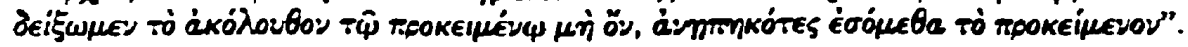


second and third types of hypothesis:

In cases in which, of necessity, only one of two things is - for instance, sickness or health for a person - if we are able to argue, in regards to the one, that it is or is not, then we will also be able [to argue], in regards to the other, [that it is or is not]. This topic is converrible for both purposes, for we will have shown that the other is not in showing that the one is, and we will have shown that the other is if we have shown that the one is not. ${ }^{\text {t6 }}$

With certain topics, then, Aristotle may have lain the groundwork for the two-fold division of the substitutional syllogism that I have outlined. Because the hypothesis in a substitutional syllogism must be a supposition that a syllogistically valid inference exists, it is even somewhat similar to a premiss in the sorts of dialectical reasoning that Aristotle discussed in the Topics, which must be plausible. Interlocutors will naturally be more likely to suppose that a syllogistically valid inference exists if the hypothesis that represents it is plausible.

All the same, even if certain topics suggest the basis for a division of the substitutional syllogism, topical arguments are not substitutional syllogisms. To accept some premiss in a dialectical exchange as plausible is simply not the same as to suppose that a syllogistically valid inference exists; thus, a dialectical premiss is not a hypothesis. For instance, an interlocutor may well accept as inductively plausible that, if some souls are immortal, then all souls are immortal, but cannot reasonably suppose that there is a syllogistically valid inference from the former to the latter. ${ }^{47}$ Indeed, even if a direct proof that some souls are immortal is available, the conclusion that all souls are therefore immortal does not yet follow of necessity. That is to say, then, that the inference is merely a topical argument and not a substitutional syllogism. ${ }^{\text {s }}$ Nevertheless, an interlocutor certainly could suppose that there exists a syllogistically valid inference where in fact there does not, especially since logical necessity and syllogistic validity are theoretically equivalent in Aristotle's logic. There are thus similarities between topical arguments and substitutional syllogisms that Aristodle himself may have recognized, and that may have informed the development of the theory

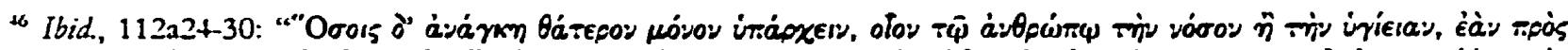

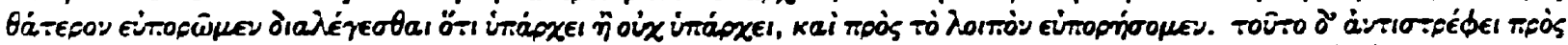

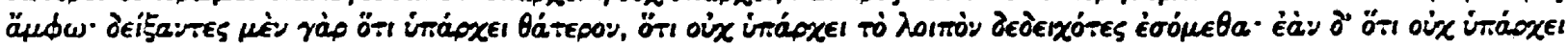
ذеi

"77 Ibid., 110237-b4.

t8 Paul Slomkowski does not seem to bave recognized this crucial point in his monograph on Aristote's Topics, in which be sought to show that the vast majority of topical arguments work as syllogisms from 2 hypothesis. His argument depends, in fact, on incorrectly interpreting Aristote's substitutional syllogism as a part of a sentential logic. The chief argument Slomkowski adduces for this interpretation is that some topical arguments function according to the principles of sentential logic. However, even if so (such as in Tf some souls are immortal, then all souls are immortal; but, etc:), it does not follow that syllogisms from a hypothesis do so 25 well, for they are not the same. See his Aristotk's Topics, pp. 95-132, especially Pp. 102-03. 
of syllogisms from a hypothesis in the early Peripatos along the lines I have sketched.

6. In the absence of any further surviving work on hypothetical syllogistic by Aristotle himself, however, it is necessary to tum to the work of his followers and associates to discover exactly how this development proceeded - and especially to the work of his immediate successor Theophrastus, whose name the later, neo-Peripatetic commentators often associated with the subject. But, as I mentioned in the introduction to this chapter, this work is lost in its original form. In order to chart the development of hypothetical syllogistic in the early Peripatos beyond Aristode, then, it is necessary to turn instead to the reports of the commentators themselves. Although $I$ have already raised doubt about the origins of these reports, the commentator Alexander named and discussed three sorts of hypotherical syllogism that, upon examination, are clearly Peripateric and not Stoic: the qualitative syllogism that Aristotle had mentioned, the proof through an analogy (òtiłıs ò'

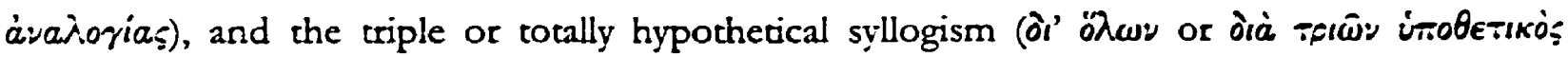
$\sigma u \lambda \lambda$ 구 $\left.\sigma \mu \delta_{5}\right)$. He also explicitly connected Theophrastus to the last of these sorts of syllogism. The manner in which the first two sorts of syllogism function provides clear further evidence that early Peripatetic hypothetical syllogistic was not a logic for sentences; the totally hypothetical syllogism, however, is a less clear case.

Alexander often referred to the qualitative syllogism as the syllogism from the more, the less,

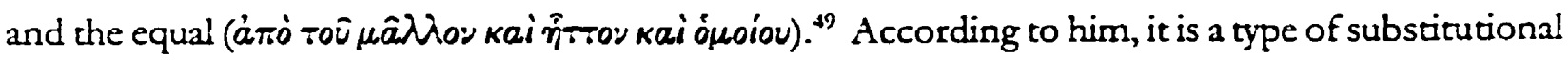
syllogism that functions according to some qualitative relationship:

There is a substitution in these syllogisms also - for instance, in If the better is something that is not productive of happiness, then the less good is not as well; but, health is better than wealth and is not productive of happiness; [etc.]'. For the latter premiss is both substituted and in need of categorical demonstration. Similarly, too, regarding the syllogism 'If the less good is choiceworthy in itself, the better is as well; but, wealth is less good than health and is choiceworthy in itself; [esc.]', for, again, the latter premiss is substituted and in need of categorical demonstration. The syllogism from the equal is also of this sort ${ }^{50}$

The qualitative syllogism thus has a threefold form, as Alexander's name for it suggests. One form is from the more, and is roughly: If the more $A$ is not $B$, the less $A$ is not $B$; but (given some direct

19. Alexander, In An. pr., p. 266.3-4.

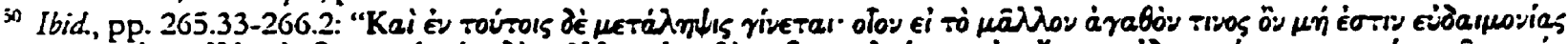

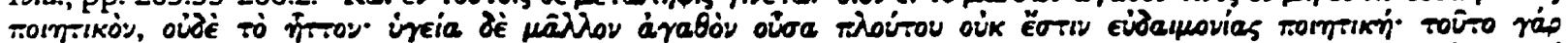

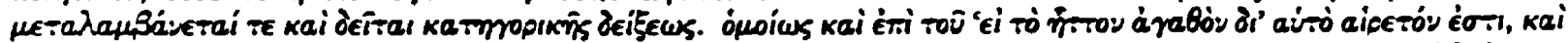

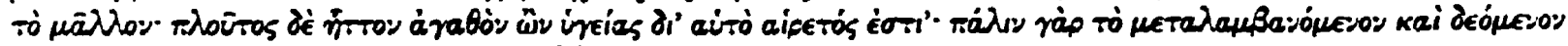

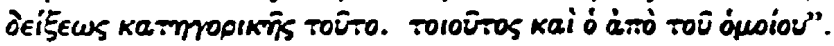


syllogism), something more $A$ is not $B$; therefore, something less $A$ is not $B$ '. Another is from the less: 'If the less $A$ is $B$, the more $A$ is $B$; but (given some direct syllogism), something less $A$ is $B$; therefore, something more $A$ is B'. Another example later in Alexander's commentary illustrates the form from the equal: 'If something equally $A$ is/is not $B$, then some other thing equally $A$ is/is not $B$; but, something equally $A$ is/is not $B$; therefore, some other thing equally $A$ is/is not $B{ }^{31} A$ s Aristotle had already implied, then, the qualitative syllogism fits the pattern of the substitutional syllogism, in which the intended conclusion follows from a substitute conclusion in virtue of a hypothesis that relates them, and whose antecedent element itself follows from a substitute direct syllogism.

This sort of syllogism is completely Peripatetic in origin. Aristotle had already named it in his Prior Analytics, and no similar syllogism survives from Stoic logic. Indced, in its various forms, the qualitative syllogism closely resembles certain dialectical strategies from the more, the less, and the equal that .tristotle had detailed in his Topics. ${ }^{52}$ The development of the substitutional syllogism in the early Peripatos, then, consisted in part in systematizing the logical relationships that involve comparative adjectives. Because there are certain logically necessary inferences that depend on these relacionships - for example, since it follows that, if both the more $A$ is more $B$ and the more $A$ is not in fact $B$, it also follows that the less $A$ is also not $B$ - the hypothesis in a qualitative syllogism can theoretically correspond to a partial syllogistically valid inference in Aristotle's logic. The example of the qualitative syllogism thus provides further evidence that the substitutional syllogism is not a part of a sentential logic, for sentential logic is simply inadequate to capture the comparative relationships upon which the qualitative syllogism turns.

The proof through an analogy also provides the same evidence. According to Alexander, this hypotherical proof is the same proof that Aristotle had employed in the Prior Analytics to show that the expressions 'is not $A$ ' and 'is not- $A$ ' are not equivalent in meaning: 'The expression "cannot walk" is to the expression "can not-walk" as the expression "is not white" is to the expression "is not-white"; but, "cannot walk" is not equivalent in meaning to "can not-walk"; therefore, "is not white" is not equivalent in meaning to "is not-white". 53 Apparently, the proof has the general form ' $A$ s $A$ is to $B$, so $C$ is to $D$; but, $A$ is/is not $E$ to $B$; therefore, $C$ is/is not $E$ to $D$ '. This kind of

\footnotetext{
51 Ibid, p. 325.16-18.

52 Aristotle, Top., $114637-115224$.

53 Aristotle, $A n$. pr., 51b10ff.; Alexander, In $A n$. pr., $397.25 \mathrm{ff}$.
} 
hypothetical proof is completely Peripateric in origin; like the qualitative syllogism, it resembles a dialecrical strategy that Aristode discussed in his Topics, and, once again, no similar Stoic syllogism exists. ${ }^{54}$ It is also a sort of substiturional syllogism, for its intended conclusion follows in virtue of a hypothesis that specifies a relationship between the intended conclusion and some substitute conclusion on which a logically necessary inference may turn. Thus, like the qualitarive syllogism, it shows that the development of the substitutional syllogism was not the development of a logic for sentences, since its hypothesis turns on an analogical relationship that a sentential logic simply cannot capture.

The triple or totally hypothetical syllogism, by contrast, seems at first glance to be a logic for sentences. This sort of syllogism appears nowhere in Aristotle's extant writings, but Alexander reported that Theophrastus had discussed it in his own Prior Analytics. ${ }^{55}$ Alexander also reported that Theophrastus arranged the totally hypotherical syllogism in three figures, and constructed the following schemata as moods belonging to the figures:

(1.1) If $A$, then $B$; but, if $B$, then $C$; therefore, if $A$, then $C$

(1.2) If $A$, then $B$; but, if $B$, then $C$; therefore, if not $C$, then not $A$

(2.1) If $A$, then $C$; but, if $B$, then not $C$; therefore, if $A$, then not $B$

(3.1) If $A$, then $B$; but, if not $A$, then $C$; therefore, if not $B$, then $C$

(3.2) If $A$, then $B$; but, if not $A$, then $C$; therefore, if not $C$, then $B$.

This arrangement of the totally hypothetical syllogism echoes Aristotle's arrangement of the direct syllogism - for example, (1.1) resembles a categorical syllogism in the first mood of the first figure, and (2.1) a categorical syllogism in the first mood of the second figure. ${ }^{56}$ This resemblance, as well as the direct attribution to Theophrastus, show that this type of syllogism is wholly Peripateric in character, and not Stoic. Neither Alexander nor any other commentator, however, recorded why Theophrastus had developed this new type of syllogism.

Indeed, it is unclear in what sense the totally hypothetical syllogism is a hypothetical syllogism at all. According to Aristotle, the syllogism from a hypothesis is either through impossibility or substitutional; the totally hypothetical syllogism is neither of these sorts. Yet, according to Aristotle, every syllogism is either direct or from a hypothesis; thus, the totally hypothetical syllogism must be from a hypothesis, because it is clearly not direct. For his part, Alexander suggested that the

it Aristodle, Top., 136b33-13737.

55 For what follows, see tlexander, In $A n$. pr., pp. 326.8-328.7.

so Alexander noted that Theophrastus himself had called schemata 3.1 and 3.2 moods of the second figure rather than the third, and schema 2.1 a mood of the third figure rather than the second; in any case, the resemblance to the categorical syllogisms is clear. 
totally hypothetical syllogism may not be a syllogism in the proper sense, for Aristotle had required every syllogism to show that something does or does not belong to something else. The totally hypothetical syllogism, however, only shows what is or is not if something else is or is not; it does not, as Alexander wrote, prove anything categorically. Thus, the problem of its classification does not arise. However, Alexander also wrote that Theophrastus had shown how the totally hypothetical syllogisms reduce - in some way that Alexander did not specify - to the direct syllogisms of the first figure. If so, then Theophrastus seems to have developed a new kind of hypothetical syllogism that is neither through impossibility nor substitutional. One possibility, then, is that Theophrastus had begun to consider the properties of the sentential operator if and to formulate inferences from conditional sentences in the modern sense. That is to say, Theophrastus had perhaps taken an important step towards developing a sentential logic.

In 1983, Jonathan Barnes argued for this possibility. ${ }^{57}$ He claimed that the neo-Peripatetic commentators had not restricted the combinations of subject terms that can appear in hypothetical syllogisms, so that the most general form of the major premiss in a substitutional syllogism might be 'If $A$ is $B$, then $C$ is $D$ ', in which the subject terms are different singulars. Furthermore, he noted that, in scholia to Ammonius's commentary on the Prior Analytics, there is an example of a totally hypothetical syllogism with differing singular subject terms: 'If the sun is over the earth, it is day; if it is day, it is light; therefore, if the sun is over the earth, it is light'. ${ }^{58}$ On the basis of these two considerations, Barnes assumed - "not without hesitation" - that Theophrastus had constructed a sentential logic with his totally hypothetical syllogisms. ${ }^{59}$ He seems to have reasoned that, because a logic for terms is insufficient to accommodate the inference to which the Ammonian example corresponds, it follows that Theophrastus's totally hypothetical syllogism must be a part of a logic for sentences.

Barnes, however, was right to hesitate. As I have argued, so long as logical necessity and syllogistic validity are theoretically identical, there theoretically exists a syllogistically valid inference or chain of inferences corresponding to even the Ammonian example - even if there actually does not. Now, it is perhaps possible that this inconsistency might have come to Theophrastus's attention and impelled him towards developing a sentential logic, but there is no independent

57 Barnes, "Terms and Sentences", especially pp. 290-95.

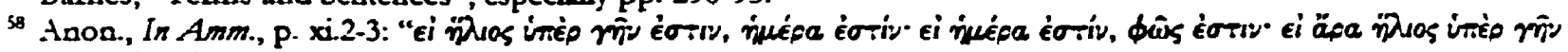

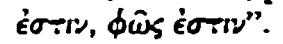

50 Barnes, "Terms and Sentences", p. 294. 
evidence to suggest that he thought his master wrong on this point. Indeed, the fact that Theophrastus reduced his totally hypotherical syllogisms to the first figure categorical syllogisms strongly suggests otherwise. Consistent with his interpretation of the totally hypotherical syllogism as a logic for sentences, however, Bames suggested that Theophrastus's reduction scheme was an attempt to translate a logic for sentences into a logic for terms. As Alexander reported, Theophras-

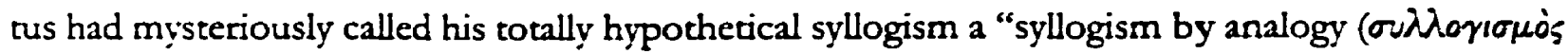
karà àaioyiay)". This name suggested to Barnes that Theophrastus had thought that a hypothetical statement such as 'If the sun is over the earth, it is day' is in some sense reformulable as the categorical statement 'Everything such that the sun is over the earth is such that it is day', so that all the totally hypothetical syllogisms have categorical analogues. ${ }^{60}$ Barnes, however, was unable to produce any textual evidence for this kind of reduction scheme, precisely because there is none. As he himself noted, existing evidence rather suggests that some early Peripatetics might have thought that a hypothetical statement such as 'If it is human, it is an animal' is in some sense reformulable as the categorical statement 'Every human is an animal'. ${ }^{61}$ A reduction scheme based on this sort of reformulation, however, suffices only for totally hypothetical syllogisms whose categorical elements have the same impersonal subject term — such as Alexander's own examples, for instance.

At any rate, my analysis of Aristotelian hypothetical syllogistic suggests that Theophrastus probably did not have sentential logic in mind when he developed the totally hypotherical syllogism. For Aristode, a sentence of the form 'If $p$, then $q$ ' represents a partial syllogism and is not a conditional sentence in the modern sense; it relates terms and not unanalyzed sentences. Thus, even if Theophrastus took an interest in the transitivity of the particle if, he probably understood it as a property of syllogistic entailment and not of sentential implication. Moreover, Alexander's report does not rule out that Theophrastus had sometimes formulated his totally hypothetical syllogisms without the particle 'if - for irstance, using the genitive absolute construction that Aristotle had regularly used in such contexts. On this reading, the totally hypothetical syllogism is part of a logic for terms. For instance, the first-figure totally hypothetical syllogism 'If it is a human, it is an animal; but, if it is an animal, it is a substance; therefore, if it is a human, it is a substance' demonstrates the syllogistic relationships between the three terms 'human', 'animal', and 'substance', and not the

60 Ibid, pp. 313-16.
61 Ibid, pp. 312-13. 
unanalyzed categorical statements in which these terms feature. In this way, it is "analogous" to a categorical syllogism in Barbara. The totally hypothetical syllogisms of the other figures demonstrate the same result for other possible combinations of affirmative and negative categorical statements, and some reduction scheme to the direct syllogisms of the first figure ensures their syllogistic validity. Like his master before him, then, Theophrastus was interested in metalogical investigation into the properties of syllogistic entailment - such as its transitivity - but not in sentential logic.

Indeed, it is noteworthy that Barnes's argument that Theophrastus's totally hypothetical syllogism is a part of sentential logic depends in part on the trustworthiness of the reports of the neo-Peripatetic commentators in the circle of Ammonius. As I have suggested already, and as I shall show in the next chapter, their trustworthiness is doubtful. What is more, Bames presented no textual evidence to support his claim that these commentators had generally treated hypothetical syllogistic as a logic for sentences by consistenty allowing for dissimilar singular subject terms in the same hypothetical statement, and I can find no reason to agree with him. Even if they had, Barnes might well yet require a separate and further argument to prove that this pracrice suggests that the early Peripatetics had done so as well, and that it was not also the result of the commentators' own conflation of early Peripatetic and Stoic logic to which I have alluded. The existence of one single example of a totally hypothetical syllogism in which the subject terms of the component categorical statements differ is thus not strong evidence. Indeed, one author who belonged to the circle from which Barnes obtained his key example seems rather to have misconstrued the Stoic indemonstrables, which are for sentences, as instead for terms - for instance, as in 'If a human, then also alive; but, not alive; also not a human'. ${ }^{62}$

7. Theophrastus's contributions to hypothetical syllogistic were not limited to the invention of the totally hypothetical syllogism, however. As I mentioned in the introduction, Alexander reported that Theophrastus had mentioned hypothetical syllogisms generally in his Analytics. In fact, Alexander's report prefaces a list of the types of hypothetical syllogism that he took Aristote as having intended to discuss, had Aristotle fulfilled the promise in his own Analytics to examine and indicate clearly the many ways in which syllogisms are from a hypothesis. Alexander's presumably Theophrastean list, however, includes types of hypothetical syllogism that have clear Stoic analogues, and for which Alexander even reported Stoic names. Thus, the question of the extent

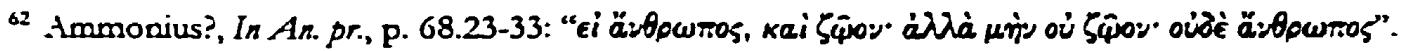


to which, and the direction in which, Theophrastus and the other early Peripaterics developed hypothetical syllogistic is bound very closely to my own contention that the neo-Peripatetics conflated Peripatetic and Stoic logic. I shall turn to them both in the next chapter. 


\section{The Greek Commentators on Aristotle}

1. Roughly eight centuries after the death of Theophrastus in the early third century BC, the extent to which he and other associates of Aristotle had developed the hypothetical syllogistic left inchoate by their master seems to have become obscure. Early in the sixth century $A D$, in a dedication to his monograph on the subject, Boethius wrote:

Because you had entirely acquired knowledge of categorical syllogisms, you often sought knowledge of hypothetical syllogisms, concerning which nothing is written by Aristode. Theophrastus, a man full of all learning, only goes through the elements of these things; Eudemus advances further along the way to instruction, but in such a way as if he seems to have sown some seeds and yet not produced a harvest. ${ }^{1}$

However, his contemporary John Philoponus wrote:

Since Aristotle ... taught us nothing about them [sc. hypothetical syllogisms], but rather devoted all his attention to the categorical syllogism... let us say a little bit about them. For it should be known that both those who learned from Aristode - Theophrastus, Eudemus, and the others - wrote lengthy treatises about them, and the Stoics did as well. ${ }^{2}$

Unfortunately, whatever writings Theophrastus and Eudemus devoted to hypothetical syllogistic - lengthy or otherwise - perished quite long ago. As regards "the others" to whom Philoponus referred, not even their identities are recoverable beyond doubt: only to Heraclides of Pontus, Phanias of Eresus, and Strato of Lampsacus are any treatises on logic even attributed - and none that are certain to have dealt with hypothetical syllogistic. ${ }^{3}$ Among later Peripatetics, only Boethus of Sidon has any sure connection with the subject; reportedly, he examined the relationship between hypotherical and categorical syllogistic, which suggests that hypothetical syllogistic was already fairly

1 Boethius, De byp. 5.h, 1.1.3: "Nam cum categoriconum syllogismorum plenissime notitiam percepisses, de bypotheticis syllogismis saepe quaerebas, in quibus nihil est ab Aristotele conscriprum. Theophrastus vero, vir omnis doctrinae capax, rerum tantum summas exsequitur; Eudemus latiorem docendi gradius viam, sed ita ut veluti quaedam seminaria sparisse, nullum tamen frugis videanur extulisse proventum".

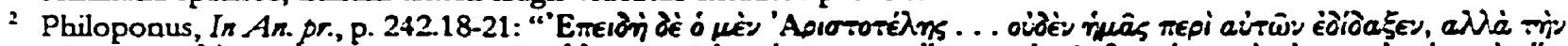

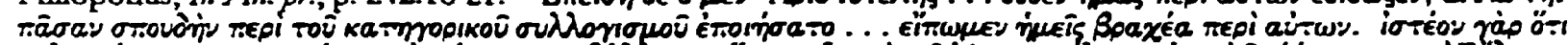

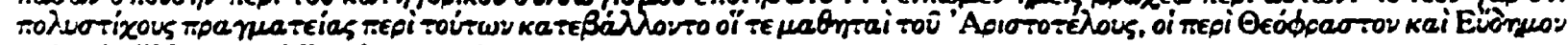

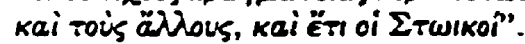

3 For Heraclides, see Diogenes, 5.88; none of the titles of his few logical writings suggest that they dealt with hypothetical syllogistic. For Phanias, see Philoponus, In Cat., p. 7.20, who claimed that he had written an Anabytics.

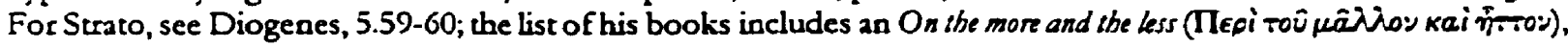
which may have dealt with the qualitative syllogism. 
sophisticated by the first century BC, when he lived.

Evidence for the development of hypothetical syllogistic in the Peripatos after Aristotle, then, is fragmentary, second-hand, and scarce. Further complicating the issue is the fact that the sources for this evidence all post-date the development of Stoic logic, whose indemonstrable argument schemata are similar enough to hypothetical syllogisms for Philoponus to have thought that the Stoics had concerned themselves as extensively with the subject as Theophrastus and Eudemus. But, if the Stoic "hypotherical syllogisms" were in fact importantly different from the Peripatetic in ways that Philoponus did not fully understand, then he and other later commentators may have conflated two distinct logical theories, at least in part. The same concern may even apply to whatever contributions later Peripatetics such as Boethus may have made. At the same time, determining the original character of early Peripatetic hypothetical syllogistic is a necessary condition for determining precisely how distinct the Stoic indemonstrables are from it, and thus for determining the extent to which Peripatetic and Stoic logic became conflated during late antiquity and into the early Middle Ages. My purpose in this chapter is to make this determination.

2. In 1855, Carl Prand drew attention to a pivotal passage from Alexander's commentary on the first book of Aristotle's Prior Analytics, in which Alexander provided a detailed list of the types of hypothetical syllogism and seems to have suggested a Peripateric origin for them. Alexander wrote:

Having spoken about syllogisms from an agreement and those that are through an inference to impossibility, he [sc. Aristotle] says that many other syllogisms are also brought to a conclusion from a hypothesis, discussion of which he sets aside as if intending to speak about them more carefully. However, no book of his about them is in circulation. Theophrastus mentions them in his own Analytics, and Eudemus and some others of his followers do as well.

Now, he presumably means hypothetical syllogisms through a continuous statement (which is also called a connected proposition) and an additional assumption, those through a separative statement (or disjoined proposition), and also those through a negated conjunction - if they are indeed different from the ones already stated.

Besides the ones stated, there are presumably also those from an analogy, those that they call qualitative (which are from the more or the less or the equal), and whatever other varievies of syllogisms from a hypothesis there are, which have been discussed elsewhere. ${ }^{5}$

- Galen, Inst. log., 7.2. For direct citations of this work, I have used the excerpts in Hülser, Die Fragmente zur Dialeksik der Sioiker (FDS).

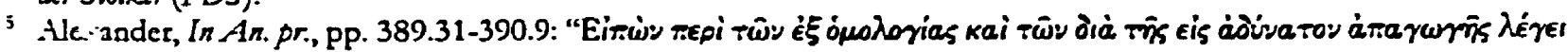


This list is the earliest of its kind to have survived; it is thus one of the most significant sources for early Peripatetic hypothetical syllogistic. At the same time, however, Alexander's altemative terms 'connected' and 'disjoined', as well as the terms 'additional assumption' and 'negated conjunction',

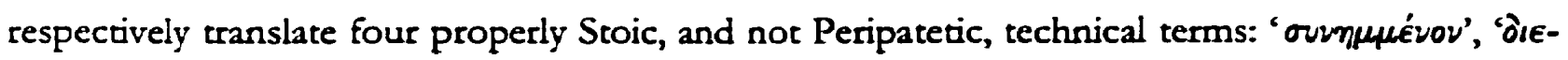

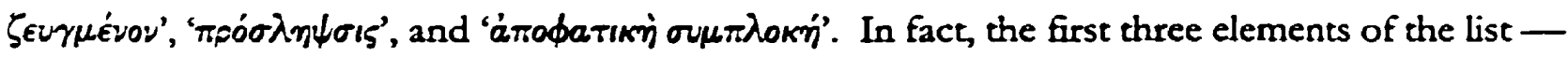
syllogisms from a continuous statement or connected proposition, from a separative statement or disjoined proposition, and from a negated conjunction - seem to correspond directly to the five Stoic indemonstrables, which divide into three types: two from the connected proposition, one from the negated conjunction, and two from the disjoined proposition. Thus, Alexander's list may also be significant for determining the relative independence of a primary bit of Stoic logic.

However, it is not clear whether the source or sources upon which Alexander relied were Peripatetic, Stoic, or some other. He did not specify them, and despite his implication that the list is Theophrastean, even the tone of his language seems at first glance to indicate that he himself was

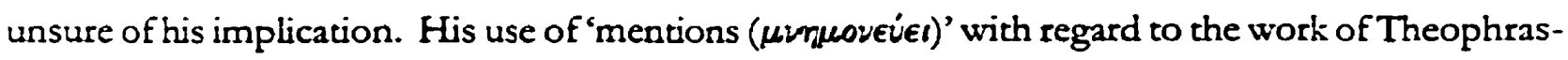
tus and Eudemus is curiously casual, and the potential optatives in the two key phrases Now, he

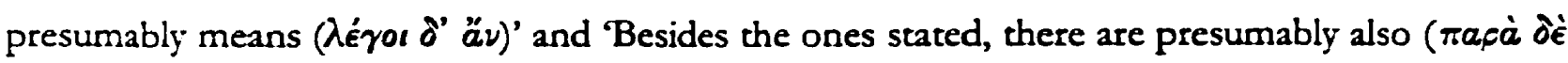

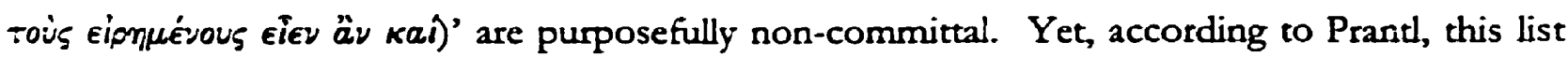
derives directly from the lost work of Theophrastus and Eudemus. In his estimation, Alexander's mention of these two Peripatetics, taken together with Philoponus's report and the fact that Theophrastus's name often appears elsewhere in connection with hypothetical syllogistic, was enough to seal the case. ${ }^{6}$ Alexander's alternative Stoic terminology did not suggest to Prantl any possibility of independent Stoic influence; on the contrary, he dismissed the notion that Alexander either ignorantly or disingenuously included Stoic material in a list of apparently Peripatetic types of hypothetical syllogism as "stiff-necked". ${ }^{7}$

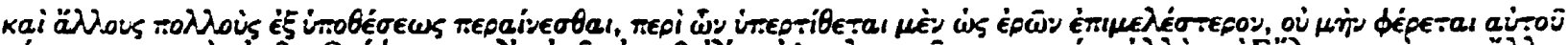

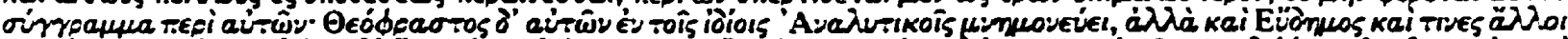

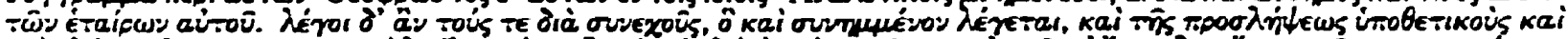

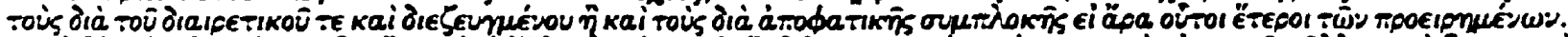

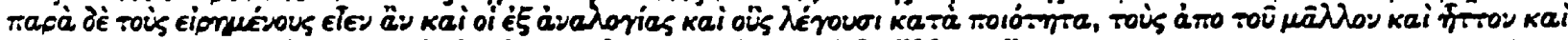

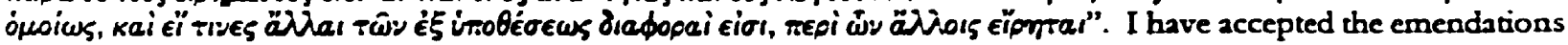
that Barnes has proposed - see his "Theophastus and Hypothetical Syllogistic", p. 139, nn. 2 and 3.

- Prantl, Geschichte der Logik im Abenlande, vol. 1, p. 379.

- Ibid, pp. 379-80: "Wer jedoch hartnäckig es nicht glauben wollte, dass diese Voraussetzungsschlüsse wirklich den älteren Peripatetikern angehören, könnte sich hievon [si] wohl aus der lïppischen Weise überzeugen, in welcher diese Syllogismen von den Stoikern in die sogennanten àvaróbeı auf einem verstandlosen Ausschreiben einer älteren Doctrin beruhen muss, diese aber keine andere als eben die 
Some scholars after Prant, however, were in fact stiff-necked in precisely this way. In 1947, Ivan Bochenski took issue with Prantl's attribution; he noted that Alexander had written merely that Theophrastus and Eudemus "mentioned" hypothetical inferences and nothing more, and suggested that, given Boethius's corroborating report in addition, Philoponus's own contrary report was apparently an exaggeration. ${ }^{8} \mathrm{He}$ also claimed that no work on hypothetical syllogistic appears in the list of books that Diogenes had recorded as the work of Theophrastus. Hence, since there is no doubt that the Stoics concerned themselves with some of the types of syllogism that appear on Alexander's list, Bocheński concluded that, although Theophrastus and Eudemus "could well have tossed out some ideas" on hypothetical syllogistic, Prand's implication that they had invented the Stoic indemonstrables was "pure fantasy".9 Alexander's list, then, was to Bocheriski's mind of little consequence as a source for the hypotherical syllogistic of the early Peripatos.

Scholarly opinion has until recently accorded with these conclusions. ${ }^{10}$ However, in 1985, Jonathan Barnes wrote that he had come to "... share the view of Carl Prantl that in our passage from Alexander's commentary we possess an account of the content of Theophrastus's work on hypothetical syllogistic"." Bames came to this conclusion on the basis of two considerations: (1) that Philoponus's report deserves more weight as evidence for early Peripatetic hypothetical syllogistic than scholars (presumably following Bocheniski) have in fact allowed it, and (ii) that, while Alexander did not unequivocally affirm that Theophrastus dealt with the types of hypothetical syllogisms that he listed, he nevertheless unequivocally implied it. ${ }^{12}$

With regard to (1), Barnes marshaled the following three arguments:

(1) The fact that there is no evidence whatsoever, in Diogenes's list of books or elsewhere, that Theophrastus wrote a book entitied something like On bypothetical syllogisms does not indicate that he did not deal with the subject. Philoponus's "lengthy treatises" may refer to works lost even in name,

peripaterische sein kann".

"Bocheriski, La Logique de Theophraste, pp. 109-11.

- Ibid. p. 111: "Théophraste et Eudème ont bien pu jeter quelques idées-mais vouloir leur attribuer toute la liste d'.tlexandre, avec les 5 àvañóôtikta, est une pure fantasie".

${ }^{10}$ See, for example, Pohlenz, Die Stoa, vol 2, pp. 29-30; Kneale and Kneale, The Dexelopment of Logic, p. 105; Obertello, A.M. Severino Boegio: De hypotheticis syllogismis, p. 20; Graeser, Die Logischen Fragmente des Theophrast, pp. 92-93; Repici, La logica di Teofrasto, pp. 143; Maróth, "Die Hypothetischen Syllogismen", pp. 411-12.

"Barnes, "Theophrastus and Hypotherical Syllogistic", p. 130. Although Barnes agreed with Prantl that tlexander reported Theophrastus's work, be did not agree with him that the Stoics had merely copied Theophrastus's logic see ibid, pp. 138-39 and his "Aristotle and Stoic Logic", pp. 45-49.

12 Barnes, "Theophrastus and Hypothetical Syllogistic", pp. 127-30. 
or to works whose titles do not immediately suggest that hypothetical syllogistic features among the contents. Furthermore, according to Alexander, Theophrastus brought up hypothetical syllogisms in his Analytics, which does appear in Diogenes's list of books; this report is formally consistent with Philoponus's.

(2) Boethius's contrary report is itself suspect. Just before mentioning Theophrastus and Eudemus, he claimed that hypothetical syllogistic appears only cursorily and confusedly in very few Greek works, and in no Latin works whatsoever. But he was mistaken; there did indeed exist Latin discussions of hypotherical syllogistic in his time, and there were Greek discussions of which he was ignorant. Furthermore, analysis of his text has suggested to some scholars that it closely follows a Greek source or sources at least in part; this consideration opens up the possibility that he was even disingenuous in his claims about other existing discussions.

(3) Boethius and Philoponus do not formally contradict each other. Theophrastus and Eudemus may only have "gone through the elements" of hypotherical syllogistic, or only "sowed some seeds", even though their treatises were "lengthy". Lengthy treatises may well be elementary - or even be thought to be so. What is more, Boethius may have merely judged - or affected to judge - that Theophrastus's and Eudemus's work was elementary. Even if Philoponus was in error about the length of these treatises, length is no good guide to sophistication, especially in the case of formal logic.

With regard to (ii) on the other hand, Barnes wrote:

Alexander supposes that in $A \operatorname{Pr} 1.44$ Aristotle "has in mind" an exposition of hypothetical syllogistic, and he proceeds to catalog the arguments which Aristotle would have discussed had he kept his promise. Alexander was not in telepathic communication with Aristotle's ghost: how, then, did he know what Aristotle had in mind? Plainly, he inferred Aristotle's intentions from the performance of Aristotle's associates. Observing what arguments Theophrastus had discussed, he reasonably deduced that those were the arguments which Aristotle had intended to discuss. Alexander's catalog of hypothetical syllogisms is thus a list of the contents of Theophrastus' work on hypothetical syllogistic.

... although Alexander does not state that his arguments were discussed by Theophrastus, he unequivocally implies that they were. The gist of the passage from Alexander is this: "Aristotle does not discuss the 'many other' hypothetical syllogisms. Theophrastus does. They are the following ..." The train of thought is a crass non sequitur except on the assumption that the arguments listed by Alexander are the arguments Alexander takes Theophrastus to have discussed. We can affirm with complete confidence that Alexander believed Theophrastus to have discussed the arguments which he catalogs. I see no reason 
to question his belief.'13

In what follows, however, I shall indeed question both Alexander's belief and Barnes's crust in it.

3. Now, my criticism of Bames will not focus on the arguments that he provided for (1); to my mind, he was correct to argue against Bocheński on behalf of Philoponus. Indeed, Bochenski had been too quick in his assessment that Philoponus exaggerated; the list of Theophrastus's books that Diogenes recorded is certainly not telling evidence, especially under a misguided expectation that works dealing with hypotherical syllogistic always bear a title that makes it obvious that they do. ${ }^{\text {it }}$ For instance, not only did Alexander report that Theophrastus brought up the subject in his own Analytics, which appears on the list, Diogenes also recorded a book by Theophrastus entited $O n$ the

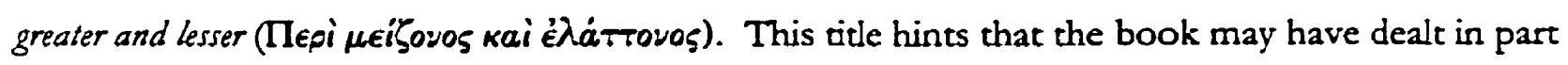
with qualitative syllogisms, which, as Alexander wrote, are from the more or the less or the equal

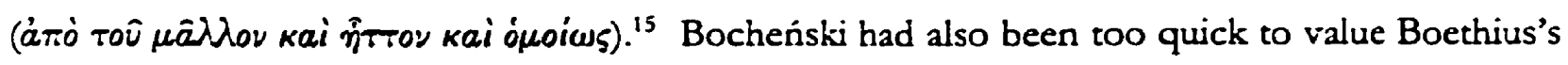
report over Philoponus's. Boethius's suspicious comment regarding Latin and Greek works on hypothetical syllogistic in general casts doubt on his claim about Theophrastus and Eudemus in particular, that his own treatise on the subject possibly follows Greek sources closely heightens that doubt. ${ }^{16}$ All the same, I think that Barnes himself was, in his turn, too quick in his argument for (ii): Alexander's words need not imply that Theophrastus dealt with the full list of the types of hypotherical syllogism - and even if Alexander believed that Theophrastus had, there is reason to question his belief. Perhaps, then, as Barnes suggested, Philoponus's claim that Theophrastus and Eudemus wrote lengthy treatises on hypothetical syllogistic is more trustworthy than scholars have allowed; on the character and content of these treatises, however, I part company with Barnes.

Barnes's argument that Alexander's list is a trustworthy guide to Theophrastus's work has two

13 Ibid, pp. 129-30.

it Diogenes, 5.42ff.

is Ibid, 5.49. Barnes speculated that Theophrastus's 'A: no supporting explanation for why be thought so. 'Aváreiy' is a technical term in Peripatetic logic that means 'to reduce' - e.g., a syllogism from the second or third figure to one of the first figure, or an argument to syllogistic form. This reading renders the title as 'Of reduced topics'; perhaps, then, Barnes thought that the book concerned the reduction to syllogistic form of those topical arguments that turn on qualitative relations (see Aristote, Top., 114b37-115a2t). In any case, I think that On the greater and lesser is at least as probable a candidate. See Barnes, "Theophrastus and Hypothetical Syllogistic", pp. 134-35.

${ }^{16}$ Boethius, De byp. syl, 1.1.3. It is not as sure as Barnes implied, however, that there were other Latin works on bypotbetical syllogistic - see my discussion in the next chapter. 
parts. Firstly, he argued that, since Nlexander claimed that Aristotle "presumably has in mind ( $\lambda \dot{\text { rou }}$ '̆ ä:)" the syllogisms on the list, it is plain that Alexander inferred this claim from Theophrastus's own writings on the subject. Even supposing Barnes is correct in this regard - for it is natural to read Alexander as suggesting that Theophrastus discussed these "many other" syllogisms - it does not yet follow that Alexander's list enumerates only Theophrastus's work on the subject. Possible ways in which other, non-Theophrastean material found its way onto the list are (i) that Alexander collected his list from a variety of sources, some or most of which may have been later than Theophrastus (and may even have been Stoic in origin or influence), (ii) that Alexander himself or one of his non-Theophrastean sources was not particularly sensitive to the differing Peripatetic and Stoic origins or characters of various argument schemata, and thus conflated distinct theories, or (iii) that loyalty to the Peripatos led Alexander or one of his sources to attempt to subsume Stoic logic to the Peripatetic, along the lines of Prant's idea that the former could only be a restatement of the latter. Now, I am only speculating about something like that for which I shall in fact shortly argue; nonetheless, because some or all of these speculative possibilities remain open until a satisfactory account of early Peripatetic hypothetical syllogistic becomes available, taking Alexander's list as such an account without further investigation poses a serious risk of circularity.

In the second part of his argument, Barnes claimed that Alexander had unequivocally implied that he was enumerating Theophrastus's hypothetical syllogisms because the sense of Alexander's passage would otherwise require a "crass non sequitur". Now, I agree that, as a species of the general principle of charity, it is proper to avoid interpretations that require a non sequitur, however, if one or more of my speculations above is in fact correct, it would explain both the potential optative in the phrase ' $\lambda \dot{\varepsilon}$ ' a break in continuity. Thus, since the possibility of non-Theophrastean sources for the list may help explain or eliminate the non sequitur, the second part of Barnes's argument has little force without resolution of the questions surrounding the first part. Moreover, it seems to me a better strategy to decide, if possible, whether or not Alexander committed a non sequitur on the basis of independent investigation into his sources, rather than to decide whether or not his sources were fully Peripatetic on the basis of a perceived non sequitur. The principle of charity in interpretation is a good one generally, but avoiding the ascription of a non sequitur to Alexander is itself to be avoided if independent investigation supports it. Hence, I conclude that Barnes was too quick in his interpretation of Alexander's list. 
It remains to be seen, however, whether or not there is enough independent evidence to conduct such an investigation successfully, so that the types of hypothetical syllogism on Alexander's list find their proper origins as Peripatetic, Stoic, both, or some other. I think that there is, and in the remainder of the chapter I shall provide it, concluding that early Peripatetic hypotherical syllogistic had indeed taken on a Stoic cast by the time Alexander composed his list. In particular, I shall contend that, although the types of hypothetical syllogism on Alexander's list almost all have Peripatetic origins, the theory behind them had evolved away from its original Peripatetic roots by the time he wrote, under the influence of Stoic logic.

4. Hypothetical syllogistic begins with hypothetical statements; thus, understanding the early Peripatetic account of hypothetical syllogistic begins with understanding their account of hypotherical statements. In this regard, Alexander's list is once again important. For two of the types of syllogism on his list, he recorded two sets of terms each: there are inferences on the basis

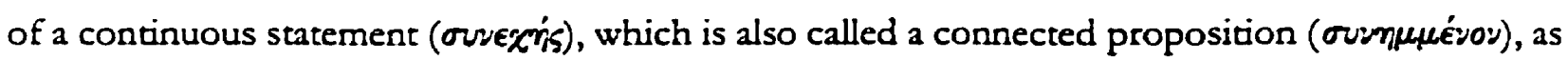
well as on the basis of a separative statement (òraıfetı́óy), which is also called a disjoined

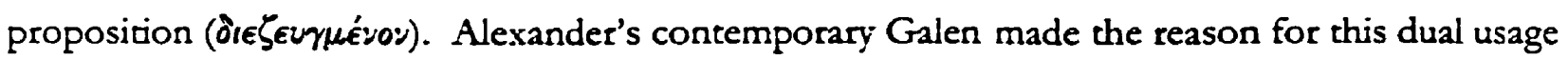
clear in his short introduction to logic, as well as the reason why I have rendered some terms with 'statement' and others with 'proposicion':

So such a sentence, 'If it is day, the sun is over the earth', is called a connected proposition (áfiw $\mu a)$ according to the newer philosophers, but a continuous hypothetical statement

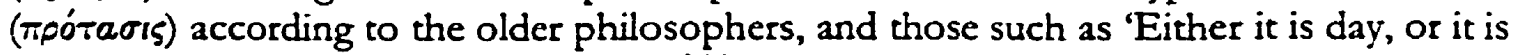
night' are called disjoined propositions ( $a^{\prime} \xi^{\prime}(\omega \mu a)$ by the newer philosophers, but separative

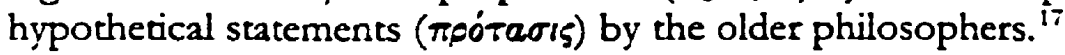

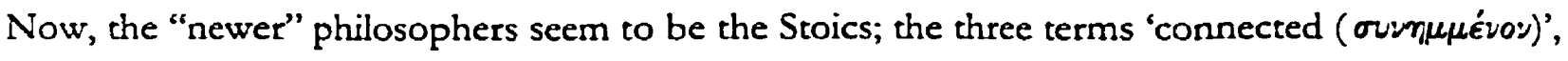

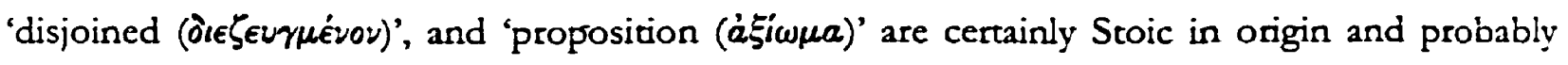
received their technical senses from Chrysippus. The "older" philosophers presumably do not include Aristotle; nowhere in his surviving works appear the terms 'hypothetical (iтobe-ikós)',

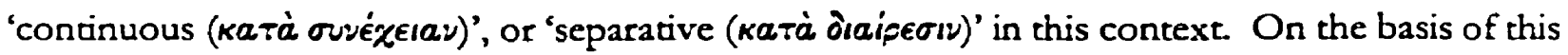
evidence, Bochenski concluded that the older philosophers who set this terminology, and whom

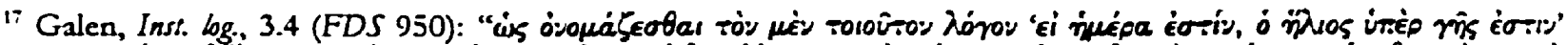

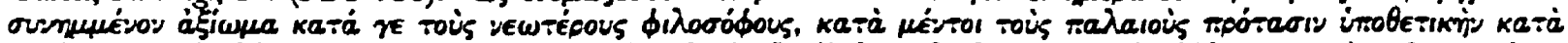

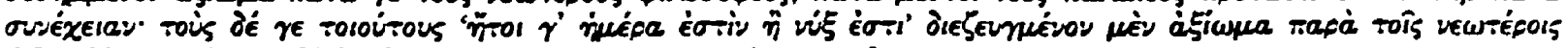

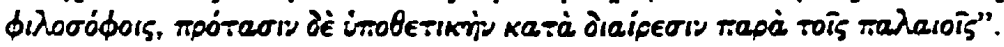


he reckoned must have come between Aristode and Chrysippus, were the early Peripaterics - and specifically. Theophrastus and Eudemus because of their stature. ${ }^{18}$ Indeed, Galen's other uses of the designation 'older philosophers' in the same work seem clearly to point to the Peripatetics, and in later repetitions of the synonymous terms in question, he explicitly attributed the terms of the newer philosophers to Chrysippus and the Stoics. ${ }^{19}$

Ultimately, however, the existence of a set of technical terms can only suggest, but not confirm, the existence of a theory. As I noted above, Boche niski himself thought that Theophrastus and Eudemus probably had done no more than contribute some ideas towards the theory of hypothetical syllogistic that the later, neo-Peripatetic commentators reported, despite his conclusion that they had set the terminology that these commentators used. Barnes, on the other hand, concluded that Theophrastus and Eudemus had indeed formulated the theory for which they had set this terminology, and that the commentators had later reported it. As I also noted above, here Barnes has the persuasive case - but only that Theophrastus and Eudemus formulated some theory for which they used these terms, and not necessarily the very one that appears in the later commentaries. Granted, then, that these terms are most probably Peripatetic in origin - and probably also Theophrastean or Eudemean, as Alexander suggested by his list; more important is the nature of the theory that demanded their invention. Not only does the existence of a set of technical terms fail on its own to confirm the existence of a theory, it also does not on its own confirm the nature of the theory. Now, if Theophrastus or Eudemus invented these terms, then the theory was surely fully Peripatetic in nature at first - but it did not necessarily remain so. Theories change, as do the significations of the terms to which they give rise. In fact, a closer look at Galen's and Alexander's work provides evidence not only of the original early Peripatetic theory, but also of its subsequent change.

5. Using Theophrastus's and Eudemus's terminology for the hypothetical statement, Galen wrote:

Another kind of statement is those [sid] in which we make an assertion, not about the existence of things, but rather to the effect that one thing is, given that another thing is, and that one thing is, given that another thing is not. Let such statements be called hypothetical.

18 Bocheński, La Logique de Theophraste, p. 108.

"See Galen, Inst. log., 1.5, 2.2, and 7.7 for such occurrences of 'older philosophers' or 'the old usage' (which scem to refer to Aristotle as well), and see 5.5 and 14.2 for attributions to Chrysippus and the Stoics. 
Some are continuous, when they say that a certain thing is of necessity, given that something else is; some are separative, when they say either that something is, given that something else is not, or that something is not, given that something else is. ${ }^{20}$

It is striking that Galen both defined the hypothetical statement, and distinguished between its continuous and separative kinds, without reference to any special logical operator, such as 'if or 'or'. ('Given' helps translate a genitive absolute construction; as I showed in the last chapter, Aristode himself often used it in a similar context.) He went on to give the reason:

Now, the separative statement is equivalent in meaning to such a sentence: 'If it is not day, it is night', which is expressed in the form of a connected proposition. All those who attend only to the spoken form call it a connected proposition, but all those who attend to the nature of things call it a disjoined proposition. Likewise, such a form of speech as well: 'If it is not night, it is day', is a disjoined proposition by the very nature of things, but has its expression in the form of a connected proposition. ${ }^{2 t}$

According to Galen, then, a hypothetical statement is not continuous just because of its spoken form - that is, because it has 'if as its main operator. A separative statement may just as well have

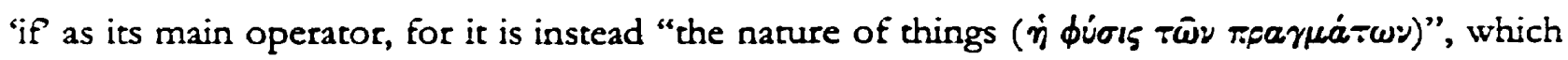
Galen specified in detail in the previous passage, that determines whether a statement is continuous or separative. 'If it is not day, it is night' is a statement that expresses that something is, given that something else is not, and is therefore separative rather than continuous, despite its main operator. Presumably; a statement such as 'The triangle is equilateral, or it is not equiangular' is continuous and not separanive, again despite its main operator.

Alexander, too, seems to have held that a separative statement might take if as its main operator, though the evidence for his view is not so straightforward. Unlike Galen, Nlexander nowhere specifically defined the hypothetical statement or its two kinds; however, as he wrote in his commentary on Aristode's Topics.

An entailment is what necessarily is through the fact that something else is, and an incompatible is what necessarily is not through the fact that something else is. "2

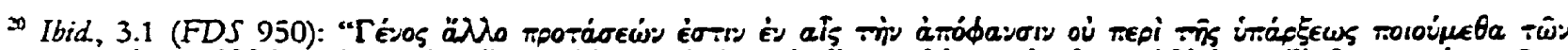

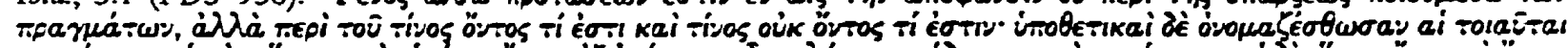

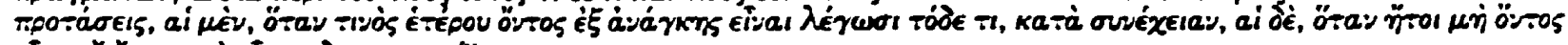

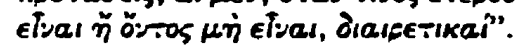

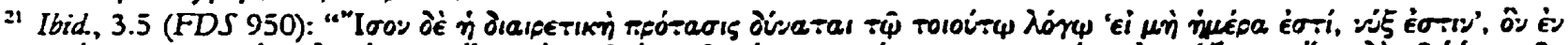

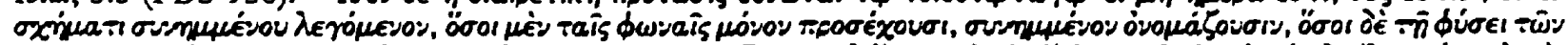

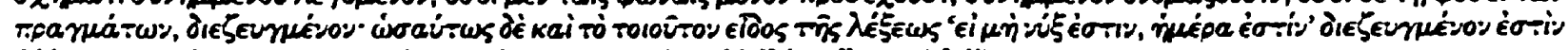

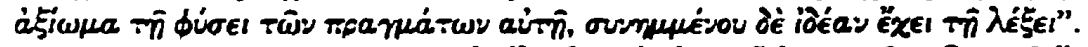

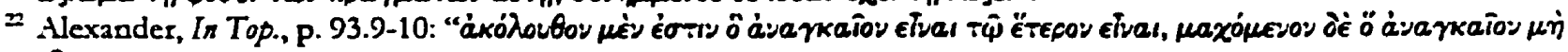
etrai". 
According to Alexander's definitions, then, what Galen called a continuous hypothetical statement

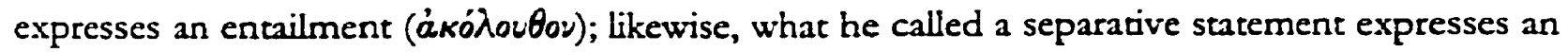
incomparible (цаxónevo:). Indeed, Galen himself made the same claim using similar terms,

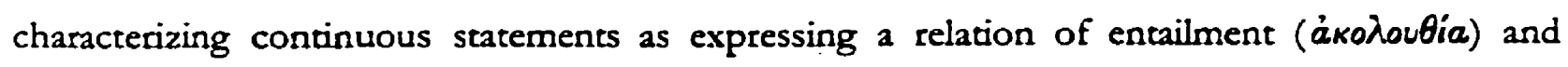
separative statements as expressing an incompatibility $(\mu \dot{a}) \boldsymbol{l}){ }^{23}$ Moreover, Alexander sometimes referred to the very continuous and separative statements themselves as 'relations of entailmen' and 'incomparibilities' respectively, which rules out the possibility that, on his view, actually continuous statements can express an incompatbility, and actually separative statements a relation of entailment. ${ }^{2 t}$ A statement such as 'If it is night, it is not day', then, either is or expresses an incompatibility according to Alexander's definitions, for it expresses that something is not given that something is. It is thus separative rather than continuous on his account, despite its main operator. Similarly, 'The triangle is equilateral, or it is not equiangular' is continuous and not separative for the same reasons.

Regarding sentences that have the form of a negated conjunction, by contrast, Alexander was much more distinct. As I have cired, he suggested in his list that syllogisms from a negated conjunction might not be different from those from either a continuous or a separative hypothetical statement. A second passage from his commentary provides the explanation for this suggestion. In the course of arguing, like Aristotle before him, that hypotherical syllogisms are in some sense reducible to categorical syllogisms, he wrote:

And the same thing also applies to the mode from a negated conjunction, if it is indeed even different from the modes already discussed [sc. those from a continuous and from a separative statement] and not the same as the one from a connected proposition that begins from an affirmation and ends in a negation - that is, If $A$, then not $B^{\prime}{ }^{25}$

Alexander was suggesting, in effect, that the syllogism from a negated conjunction is redundant, since the hypothetical syllogism from a connected proposition - or, rather, a separative statement - of the form 'If $A$, then not $B$ ' has the same force. If so, it follows that all negated conjunctions, ostensibly of the form Not both $A$ and $B$ ', are reformulable without loss of meaning as 'If $A$, then not B'. They may thus all take 'if as their main operators, according to Alexander, even though they

3 Galen, Inst. log., 4.4, 14.7.

it See, for example, tlexander, In $A$ n. pr., pp. 178.13, 178.22, 264.28, 264.33, and 330.30 .

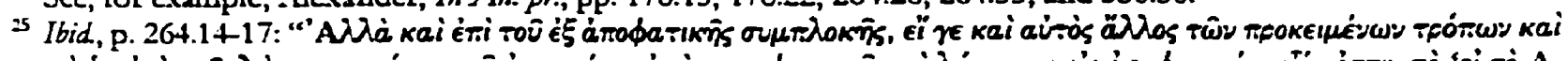

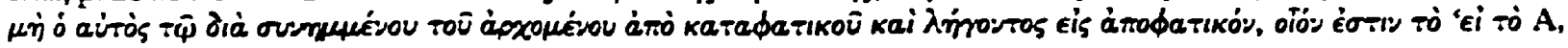
où т̇ं B"'. 
are separative statements, since they are, or express, an incompatibility.

Galen was in accord with Alexander on this point. Some separative statements, he noted,

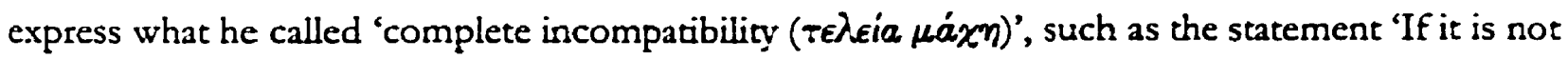
night, it is day'. The incompatibility that this statement expresses is complete because it can neither simultaneously be both night and day, nor simultaneously fail to be both night and day. Others, by

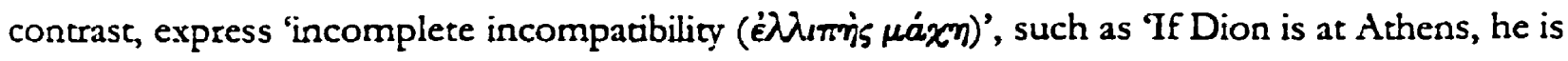
not on the Isthmus'. For, although Dion cannot be both at Athens and on the Isthmus simultaneously, so that there is an incompatibility, he can certainly be neither at Athens nor on the Isthmus, so that the incompatibility is, in a sense, incomplete. As Galen wrote:

The nature of things in this case, then, [sc. If it is not day, it is night] shows complete incomparibility, but the other shows incomplete incompatibility, according to which we say something like 'If Dion is at Athens, Dion is not on the Isthmus'.

... With regard to incomplete incompatibility, then, it is customary for the Greeks to speak in this way: 'Dion is not both in Athens and on the Isthmus', and all statements that share in incomplete incompatibility will have such a spoken form indicating it. ${ }^{26}$

Separative statements expressing incomplete incompatibility, then, customarily have the form of a negated conjunction, though they may just as well take if as their main operators, as the first part of the citation shows.

Moreover, according to Galen, the negated conjunction is not even the proper form for expressing incomplete incompatibility. He continued:

But, if an utterance is made concerning different things that have neither a relation of entailment nor an incompatibility with one another, we will call such a proposition conjoined - as, for instance, regarding the proposition 'Dion walks and Theon talks'. For these things here, having neither incompatibility nor a relation of entailment, are interpreted as being in conjunction. ${ }^{27}$

By definition, then, true conjunctions are not hypothetical, since hypothetical statements express either a relation of entailment or an incompatibility. True negated conjunctions are also not hypothetical for the same reason, as Galen then clarified. Rather, they are merely denied conjunctions - that is, denials of two assertions that are neither incompatible nor share any relation

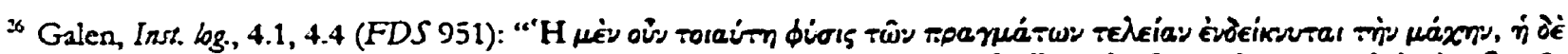

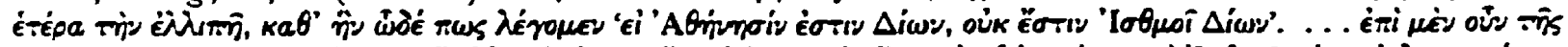

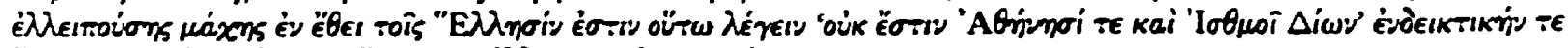

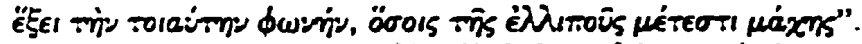

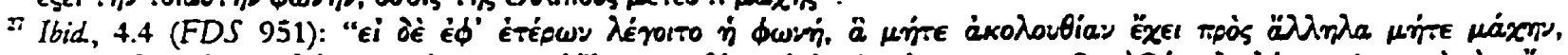

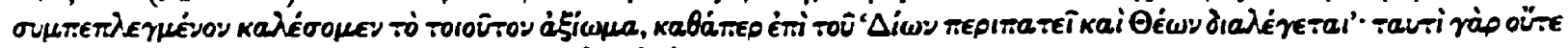

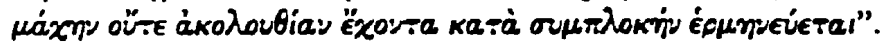


of entailment, but which coincidentally are not simultaneously true, such as 'It is not the case that both Dion walks and Theon talks'. ${ }^{28}$ Consequenty, nor only may a so-called negated conjuncrion expressing incomplete incompatibility take 'if as its main operator, the negated conjunction is a form that is more appropriate to a statement that is not even hypothetical. Thus, as Alexander suggested, there is no hypothetical syllogism from the negated conjunction, for a syllogism such as 'Dion is not both at Athens and on Isthmus; but, Dion is at Athens; therefore, he is not on the Isthmus' actually takes its force from the incomplete incompatibility that its major premiss expresses, and not from its major premiss's form. For this reason, it is actually a syllogism from a separative statement, though the ever-pragmatic Galen was willing to countenance it as from a negated conjunction, so long as there was no confusion about the real source of the argumentative force. ${ }^{29}$

In general, then, according to both Galen and Alexander, the spoken form of a hypothetical statement does not determine whether the statement is continuous or separative. Instead, a statement is continuous or separative according to whether it expresses a relation of entailment or an incompatibility, regardless of spoken form. Yet, as Galen observed in one of the passages I cited above, some philosophers did not appreciate this distinction, calling a statement such as If it is not night, it is day' connected because of its spoken form, even though it expresses an incompatibility. Now, he was almost certainly directing this objection against the Stoics, who did indeed distinguish propositions strictly by their main operators. ${ }^{30}$ The use of the Stoic terms 'connected' and 'disjoined' in the passage in question bears out this reading, as does Alexander's use of the term 'connected proposition' in his own passage regarding negated conjunctions. Indeed, Galen was well aware of Stoic usage; as he pointed out, it is more proper to call a sentence whose main operator is 'or' a disjoined proposition, and a sentence whose main operator is 'if a connected proposicion. ${ }^{31}$ Moreover, in a repetition of his objection, in this case with respect to the conjunction, Galen explicitly named Chrysippus and the Stoics as his targets:

But here as well Chrysippus and his circle attend more to the spoken form than to the facts, and call everything constructed with the so-called conjunctive connectives - even if they are constructed from incompatible things or things in a relation of entailment - conjoined

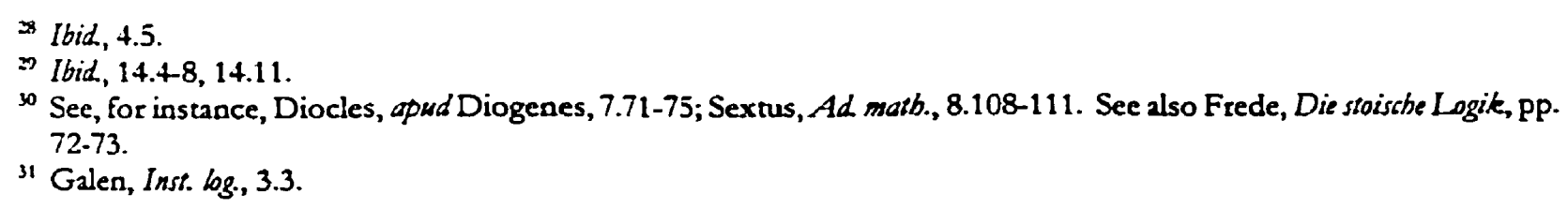


propositions. They use terms carelessly in cases in which a certain precision of instruction is at issue, and claim for themselves alone private meanings in cases in which the words do not signify anything different. They would not use terms in this way if they wanted to speak good Greek and be clear to their listeners. ${ }^{32}$

Even two centuries later than Galen, Dexippus observed in his commentary on the Categories that, while Aristotle called the assemblage of many parts of speech a conjunction, those who insist that a conjunction is only what is formulated with a conjunctive connective follow the Stoics closely. ${ }^{33}$

To Galen's mind, then, the Stoics were guilty of attending too much to logical syntax, and of ignoring the semantic definitions for continuous and separative statements that he and Alexander had reported. Galen recognized, in other words, that the connected and disjoined propositions of Stoic logic do not correspond to the continuous and separative statements of Peripateric hypotherical syllogistic. The Stoics would have treated some separative statements as disjoined propositions, but some as connected and some as negated conjunctions; likewise, they would have treated some continuous statements as connected propositions, but some as disjoined. Thus, when Galen recounted that the Peripatetics had called the statement 'If it is day, the sun is over the earth' continuous, while the Stoics had called it connected, and that the Peripatetics had called the statement 'Either it is day or it is night' separative, while the Stoics had called it disjoined, he was presumably conscious of the way in which he formulated his examples.

The early Peripatetic hypothetical syllogistic that emerges from Galen's and Alexander's accounts, then, emphasizes semantics over logical syntax. On this theory, a statement such as 'If it is day, it is light' is continuous because it expresses a relation of entailment, while a statement such as 'If it is day, it is not night' is separative because it expresses an incompatibility. It is irrelevant that the two statements are equivalent in form. Likewise, the syllogism from the former statement, 'If it is day, it is light; but, it is day; therefore, it is light' is continuous because it begins from a continuous statement, while the syllogism from the latter statement, 'If it is day, it not night; but, it is day; therefore, it is not night' is separative because it begins from a separative statement. It is irrelevant that the two syllogisms are equivalent in form. A complete Peripateric hypothetical syllogistic would thus have had no formal criteria for distinguishing between continuous statements

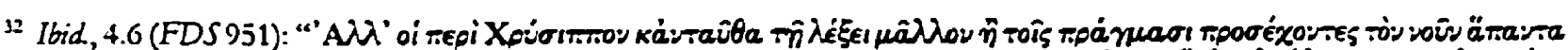

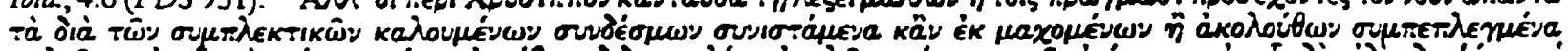

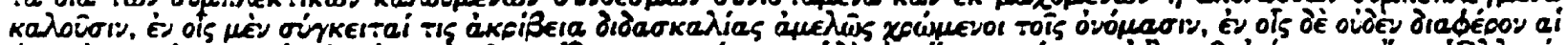

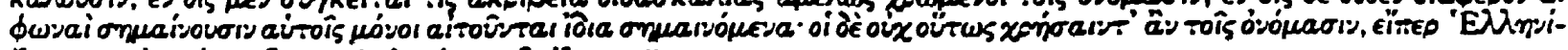

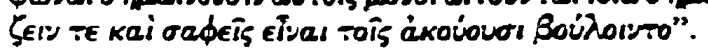

33 Dexippus, In Cat., p. 22.17-21. 
and their syllogisms on the one hand, and separative statements and their syllogisms on the other. ${ }^{3+}$ As Galen realized, earlỵ Peripatetic hypothetical syllogistic was at variance with Stoic logic, in which complex propositions and the indemonstrable arguments divided strictly according to logical syntax.

6. Some were not as careful as Galen was in distinguishing Peripatetic and Stoic logic, however. As Galen himself wrote:

When something is believed to be through the fact that something else is, then, it is mostly called the continuous hypothetical statement by the older philosophers, but also even when we think that the one thing is if the other thing is not - for instance, that it is day if it is not night. Mostly, then, they call such a statement separative. Nevertheless, it is also called a disjoined proposition by some of the newer philosophers, just as the other form of the hypothetical statement, which we have said is continuous, is also called a connected proposicion. ${ }^{35}$

According to Galen, then, the "older philosophers" had sometimes called a statement such as "If it is not night, it is day' continuous, even though it expresses an incompatibility and not a relation of entailment, while some "newer philosophers" had called it disjoined, even though its main operator is 'if and not 'or'. Now, the early Peripatetics surely did not formulate their semantic division of hypothetical statements simply to fail to apply it consistently, nor the Stoics their syntactic division of complex propositions. Rather, Galen was reporting a subsequent dilution of terminolog:. At some point, then, the Peripatetics (perhaps later representatives such as Boethus), as well as some heterodox Stoics, began to use their terms interchangeably.

Alexander, too, seems to have thought that the Peripatetic and Stoic terms are respectively synonymous. As I have cited, he coordinated them in his list enumerating the types of hypothetical syllogism; he also changed freely between them in other discussions. ${ }^{36}$ Moreover, unlike Galen, he never pointed out that a statement whose main operator is 'if, such as 'If it is not night, it is day', can be separative and not continuous. Alexander thus seems to have confused Peripatetic

"In one sense, however, the statements 'If it is day, it is light' and 'If it is day, it is not night' do differ formally: the latter includes a negative particle that the former does not. In Peripateric logic, however, aegations and affirmations are two different types of statement; the negative particle is simply not an operztor like 'if or 'or' (see Aristotle, $D e$ int., 17a25ff.). Moreover, even if it were, a strict formal distinction between these two statements would not get be necessary. In modern logic, for instance, in which the negative particle is indeed a sentence-forming operator on sentences, these two statements are both formally conditionals.

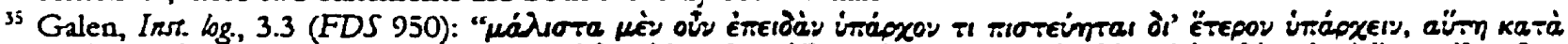

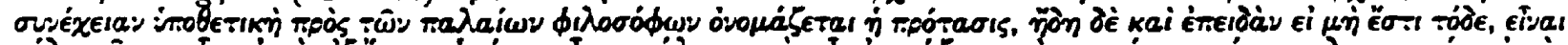

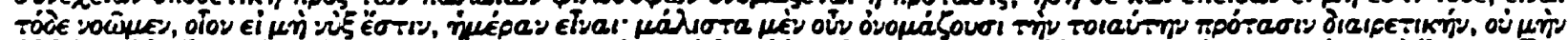

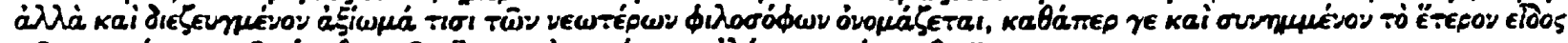

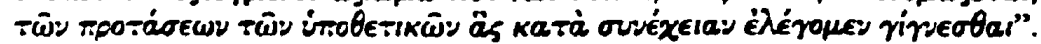

${ }^{36}$ See, for example, Alexander, In $A n$. pr., pp. 19.20-21 and 262-63, passim. 
hypothetical statements with Stoic complex propositions, and Peripatetic hypothetical syllogisms with the Stoic indemonstrables. I contend, in fact, that his confusion is merely the earliest surviving example of a confusion between Peripatetic hypothetical syllogistic and Stoic logic that became common in late antiquity. In particular, I contend that Peripatetic hypothetical syllogistic, which originally lacked any stricty formal distinction between hypothetical statements and syllogisms, assimilated one as a result of later conflation with Stoic logic. Indeed, the objections that Galen made to the Stoic emphasis on logical syntax, which are in sum that the Stoics ignored the Peripateric semantic criteria for dividing hypothetical statements, show that this emphasis was both external to the original theory and was peculiarly Stoic.

My contention gains much of its plausibility from the ease with which a neo-Peripatetic commentator might conceivably have made the mistake that $I$ have just attributed to Alexander. As Galen recorded, some of the Peripateric and Stoic authorities that these commentators may have consulted had already begun the process of conflation. Alexander, who lived nearly five centuries after the early Peripaterics but thought of himself as a member of their school, thus understandably misconstrued Stoic logic as Peripateric hypothetical syllogistic in different language. Peripatetic continuous statements were to him more or less the same as Stoic connected propositions, separative statements the same as disjoined propositions, and hypothetical syllogisms the same as the five indemonstrables. The errant Stoic third indemonstrable, to which there seems to have been no early Peripateric analogue, was in its tum eliminable as an independent schema by application of the very Peripatetic criteria for differentiating between hypothetical statements that itself had differentiated the Peripateric division from the Stoic, and which remained a part of the theory in any case. Even so, Alexander hedged on including it in his list of hypothetical syllogisms. He seems, then, not to have fully understood the argument that he adduced against it, which probably reflects an early Peripatetic attempt against the Stoic syntactic division of the five indemonstrables. As a result of such misunderstanding, however, Peripatetic hypothetical syllogistic took on a Stoic cast, incorporating a set of syntactic criteria for distinguishing between hypotherical syllogisms and hypothetical statements in place of its original semantic criteria.

For instance, in his commentary on the Topics, Alexander went so far as to explicate several of Aristotle's topics as "in accordance with" or "fitting" various Stoic indemonstrables. ${ }^{37}$ Alexander seems to have thought that Aristotle had in fact had the indemonstrables in mind. For instance, he 37 Alexander, In Top., pp. 165.6-166.13, 174.5-175.26, and 336.13-20. 
wrote that the topic for cases in which only one of two predicates can be true of something at one time - in a sense, the topic from incompatibility - fits the Stoic fourth and fifth indemonstrables, both as if Aristotle had restricted this dialectical strategy to disjunctions, and as if the Stoics had merely restated it. He made similar claims with regard to the first and second indemonstrables as well. Yes, Aristotle had put no such syntactic restrictions on the formulation of topical arguments; likewise, the Stoic indemonstrables do not merely restate the topics. An argument such as If it is day, then it is not night; but, it is day; therefore, it is not night' is, according to the Stoics, in the form of a Eirst indemonstrable; however, on Aristotle's theory, it belongs to the topic for cases in which only one of two predicates can be true of something at one time. That is to say, it belongs to the topic that Alexander claimed fit the fourth indemonstrable, and not the first. The Stoic indemonstrables do not match Aristotle's topics as Alexander supposed, and precisely for the reason that logical syntax is not fundamental to the topics in the way that it is to the indemonstrables.

Alexander also wrote that the hypothetical syllogism from a separative statement, as well as the "so-called indemonstrables", are types of substitutional syllogism. ${ }^{38}$ Thus, all the hypothetical syllogisms that Alexander enumerated in the middle part of his list - namely, those from a continuous statement or connected proposition, from a separative statement or disjoined proposition, and from a negated conjunction - are substitutional. Alexander's testimony suggests, then, that much of early Peripatetic hypothetical syllogistic was a development of Aristode's account of the substitutional syllogism. Now, as I discussed in the previous chapter, Aristotle had considered the substitutional syllogism to proceed from a hypothesis or hypothetical statement that represents some preliminary agreement on the part of interlocutors in a dialectical exchange. An interlocutor, however, can conceivably make one and the same agreement by means of several formally different hypotheses. For instance, an interlocutor can agree that Dion is not on the Isthmus, given that he is at Athens, by agreeing either that, if Dion is at Athens, he is not on the Isthmus, or that Dion is not both at Athens and on the Isthmus. Similarly, he can agree that it is night, given that it is not day, by agreeing either that, if it is not day, it is night, or that it is either day or night. In all of these cases, the subsequent argument would proceed to its intended conclusion through the derivation of a substitute conclusion that, in conjunction with the agreement, permits the derivation of the intended conclusion. The hypothetical syllogisms in the middle part of Alexander's list are in this sense substituticnal.

30. Alexander, In An. pr., pp. 325.37-326.1 and 326.4-5. 
Nevertheless, it is clear that in the context of Aristode's account of the substitutional syllogism, there is no reason to draw any sharp formal distinction between the various ways in which an interlocutor can make one and the same agreement. That is to say, there would have been no reason for an early Peripatetic preoccupied with hypotherical syllogistic to think that the most appropriate way to further develop Aristote's account of the substitutional syllogism would be to distinguish, according to logical syncax, between conditionals, negated conjunctions, disjunctions, and their respective syllogisms. Aristotle's substitutional syllogism is not a logic for sentences, in which logical operators such as 'if and 'or' are the focus. Like his categorical syllogistic, it is a logic for terms, in which predication is the focus. The hypothesis in a substitutional syllogism is thus not a molecular sentence, but rather a supposition that, given that something is or is not predicated of something else, it follows syllogistically that something is or is not predicated of something else. Galen's definition of the hypothetical statement and its types, in which logical syntax is not criterial, is essentially an account of the hypothesis in this sense, as are his and Aiexander's definitions of the relations of entailment and incompatibility. As I pointed out above, Aristote had already examined dialectical interchanges involving these two relations in his Topics in an informal way, without any particular stress on the form of the argument.

For early Peripaterics developing the substitutional syllogism, then, the important distincrion to make is between a separative type of syllogism that begins from an incompatibility and a continuous type of syllogism that begins from a relation of entailment, irrespective of the logical syntax of their major premisses. The distinction important to the Stoic indemonstrables, by contrast, is indeed in respect of the logical syntax of their major premisses, because the indemonstrables are a sentential logic whose focus is on logical operators such as 'if and 'or'. The first and second indemonstrables, which begin from a connected proposition, are for this reason different from the third indemonstrable, which begins from a negated conjunction, and again from the fourth and fifth indemonstrables, which begin from a disjoined proposition. Thus, while the indemonstrables are substitutional syllogisms in some sense, it is not the sense that Alexander intended, for the three types of indemonstrable do not correspond to the two types of substitutional syllogism. Alexander, then, erroneously thought that the Peripateric continuous and separative syllogisms divided, like the indemonstrables, according to the logical syntax of their major premisses.

Now, it is important to note that I do not claim that the early Peripatetics did not even consider a particular hypothetical syllogistic schema, such as the one from a conditional or the one from a 
disjunction. They may well have considered them all; the reasoning that these schemata capture is natural enough. However, I do claim that the merely formal differences between the schemata did not form the basis for their theoretical distinction between the separative and the continuous hypothetical syllogisms, even if they had envisioned syllogisms whose major premisses were formally conditionals or disjunctions, as they most probably did.

Indeed, there is even some evidence that Theophrastus himself might have been interested to at least some extent in the logical syntax of hypothetical statements. Simplicius reported:

In hypothetical statements in which the antecedent is not only true but also manifest and undisputed, they use 'since' instead of the connective 'if - that is, the paraconnective instead of the connective. On this account, the newer philosophers call such a proposition paraconnective. Theophrastus also clarified the reason for such usage in the first book of his Prior Analytics. 39

Supposing, then, that the reason that Theophrastus had clarified was the one that Simplicius arriculated, it appears that Theophrastus concerned himself with logical syntax in at least one case, explaining that the operator 'since' indicates that the antecedent part of a hypothetical statement is not only true but also manifestly true. Yet, this passage does not in fact demonstrate that Theophrastus, like a Stoic, attended to logical syntax as a theorecical tool for making distinctions between hypothetical statements and their corresponding syllogisms. For, firstly, it is not clear what a hypothetical syllogism from this paraconnective proposition would be, or in what way it would even differ from one from a connective or connected proposition. ${ }^{*}$ Secondly, and more importantly, the manner of Simplicius's report seems to suggest that the distinction between the paraconnective proposition and the connective proposition is semantic and not syntactic: a paraconnective proposition is semantically the same as a connective proposition except that its antecedent is manifestly true. The operator 'since' is merely an unnecessary syntactic mark of this semantic difference."

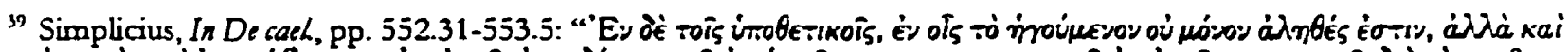

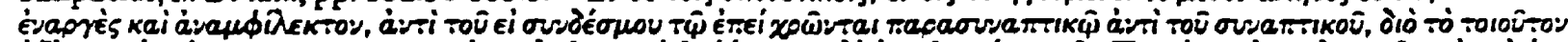

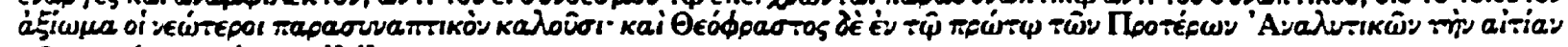

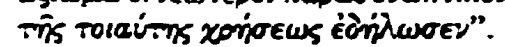

to The examples of syllogisms from paraconnectives in the scholia to Ammonius's commentary on the Prior Anabytics are not even formulated with 'since' (although their disjunctive antecedents are all of the form 'A or not A' and are therefore tautologically true), and their schema is, strictly-speaking, no different from the one from a connective proposition. See Anon., In Amm., p. xi.13-26.

"Simplicius was wrong to have claimed that the newer philosophers call the proposition paraconnecrive for the reasons he gave, if by 'newer philosophers' he meant, as is likely, the Stoics. For the Stoics distinguished between propositions first and foremost syntacrically; thus, according to them, a proposition is paraconnective precisely because its main operator is 'since', and is therefore true or false precisely on the basis of whether or not it meets 
Thus, if Theophrastus had also concerned himself with the logical syntax of continuous and separative statements, he would have done so in similar fashion. That is to say, he would firstly have distinguished between separative and continuous statements on semantic grounds, as he in fact did, and then he would perhaps have pointed out a syntactic feature that marks this distinction. The operator 'or', for example, is the natural mark of a separative statement. However, because the operator 'if can also indicate an incompatibility as Theophrastus defined it, a statement whose main operator is 'or' is separative insofar as it expresses an incompatibility, and not simply insofar as its main operator is 'or'. Theophrastus's interest in logical syntax, then, would have been limited and secondary. Only later, under the influence of Stoic logic, did his inheritors begin to attend primarily to it.

7. On this account of the conflation between hypothetical syllogiscic and Stoic logic, it is clear that Alexander's list of hypothetical syilogisms is of mixed Peripatetic and Stoic origin. Alexander wrote:

Having spoken about syllogisms from an agreement and those that are through an inference to an impossibility, he [sc. Aristode] says that many other syllogisms are also brought to a conclusion from a hypothesis, discussion of which he sets aside as if intending to speak about them more carefully. However, no book of his about them is in circulation. Theophrastus mentions them in his own Analytics, and Eudemus and some others of his followers do as well.

As I pointed out in the previous chapter, the hypothetical syllogism from an agreement ( $\sigma \lambda \lambda \lambda_{0} / \sigma$ -

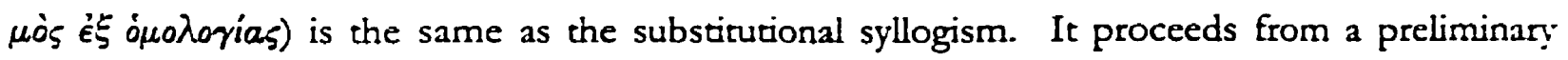
agreement or hypothesis that logically binds the intended conclusion with a substitute conclusion that, when demonstrated categorically, permits the derivation of the intended conclusion. By

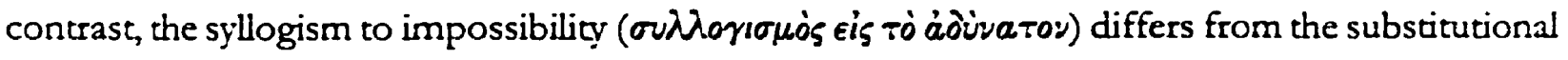
syllogism because, as Aristotle wrote and as I also discussed in the previous chapter, while substitutional syllogisms require a preliminary agreement, syllogisms to impossibility do not; the derivation of the impossibility shows the hypothesis to be false and its contradictory to be true, both as a matter of fact. As Alexander claimed, then, these types of hypotherical syllogism originated with Aristotle and are wholly Peripateric in character.

whatever criteria of truth there are for the paraconnective proposition (sce, for instance, Diocles, apud Diogenes, 7.71-72). In this case, then, Simplicius was thus confusing Peripatetic and Stoic logic like Alexander, but in reverse. 
Alexander continued:

Now, he likely means hypothetical syllogisms through a continuous statement (which is also called a connected proposition) and an additional assumption, those through a separative statement (or disjoined proposition), and also those through a negated conjunction (if these are different from the ones already stated).

This middle part of the list has been my principal focus in this chapter, for Aristotle did not discuss these hypothetical syllogisms in any work available either to Alexander or to present scholars. By including them, Alexander implied that Theophrastus and Eudemus had developed them. However, as I have demonstrated, although the first two types of syllogism were indeed Peripatetic in origin, later Peripatetics or neo-Peripateric commentators conflated them with the Stoic indemonstrables. As a result of this conflation, the Stoic syntactic criteria for dividing the indemonstrables began to supplant the original, early Peripatetic semantic criteria for dividing hypothetical syllogisms. Alexander's list thus conceals an important difference between how early Peripatetics such as Theophrastus and Eudemus had characterized continuous and separative hypothetical syllogisms and how a neo-Peripatetic commentator such as Alexander himself characterized them. The syllogism from the negated conjunction, by contrast, has no independent Peripatetic analogue, as Alexander's lack of specifically Peripatetic terminology for it suggests. The negated conjunction is simply a separative statement on the original Peripatetic theory; its syllogisms are therefore simply separative syllogisms.

The middle part of Alexander's list, then, is not purely Peripatetic, in contrast to the first part, for it reflects a treatment of hypothetical sylogisms that is unsuited to the early Peripatetic theory. The third and final part of Alexander's list, however, is again wholly Peripateric in origin. Alexander continued:

Besides the ones stated, there are likely also those from an analogy, those that they call qualitarive (which are from the more or the less or the equal), and whatever other varieties of syllogisms from a hypothesis there are, which have been discussed elsewhere.

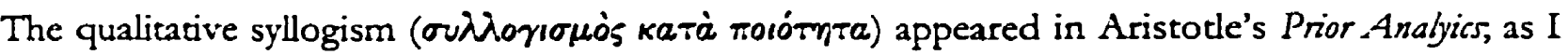
discussed in the previous chapter, it is a kind of substitutional syllogism. What the syllogism from

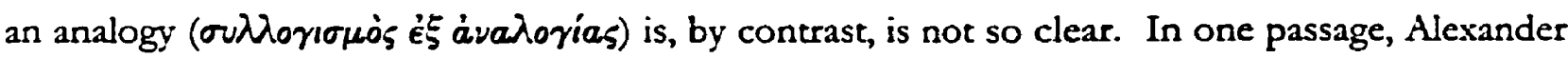
reported that Theophrastus had called his totally hypothetical syllogism by analogy (katà

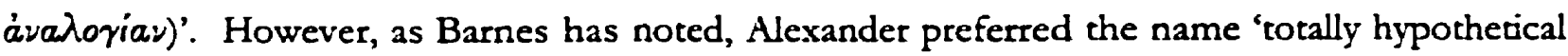
syllogism' and used the name 'through an analogy (ò' àvahoyias)' elsewhere to refer to a different 
sort of argument that he called a 'hypothetical demonstration' or 'hypothetical proof (òeists iтrobe-ıкท')', which I also discussed in the previous chapter. ${ }^{\text {t2 }}$ In any case, both the totally hypothetical syllogism and the proof through an analogy are wholly Peripateric in origin; the former originates with Theophrastus and the latter with Aristotle. The other varieties of hypothetical syllogism that Alexander mentioned elsewhere would presumably include the totally hypotherical syllogism, or perhaps the proof through an analogy, depending on what the syllogism from an analogy is.

I conclude, then, that some of the types of syllogism on Alexander's list - namely, those from a continuous statement or connected proposition and those from a separative statement or disjoined proposition - are not purely Peripatetic, although they have Peripatetic forebears. Thus, Alexander's list is not a list of Theophrastean or early Peripatetic hypothetical syllogisms as such, but rather of early Peripateric hypotherical syllogisms that had come, by his time, to blend somewhat with the Stoic indemonstrables. Indeed, the fact that the syllogism from a negated conjunction, which is not Peripateric even in inspiration, occurs in the list of types of syllogism that he thought Aristotle had likely had in mind - especially with the hedged waming that Aristotle might not have had it in mind if it is not in fact equivalent to ones that he more likely did - shows clearly that Alexander did not fully appreciate the difference between certain early Peripateric hypothetical syllogisms and the Stoic indemonstrables.

8. By the early third century $A D$, when Alexander was the pre-eminent neo-Peripatetic philosopher, Peripatetic hypothetical syllogistic was already blending with Stoic theory and losing its specifically Peripatetic character in the process. By the early sixth century $A D$, when Boethius and Philoponus issued their seemingly disparate reports of the extent to which Theophrastus and Eudemus had developed hypothetical syllogistic, this syncretism was even further advanced, with syntactic criteria for dividing hypothetical statements fully supplanting the original Peripateric semantic criteria. Evidence from the sixth-century Alexandrian school of Ammonius illustrates that, if Alexander may have seen at least some of the difference between certain Peripatetic hypothetical syllogisms and the Stoic indemonstrables, Ammonius and his students apparently saw very little or none.

The second part of the commentary on the Prior Analytics attributed to Ammonius consists of ${ }^{42}$ Barnes, "Theophrastus and Hypothetical Syllogistic", pp. 133-34. 
anonymous scholia that apparently derive from his work. These scholia contain a passage that carries the label "On hypothetical syllogisms, from the monograph of Ammonius". ${ }^{+3}$ The passage begins with an observation that Aristotle had not gone through any extensive account of hypothetical syllogistic but that the Stoics had done so quite exactly, and proceeds without any mention of Theophrastus and Eudemus to a list of the types of hypothetical syllogism, as follows:

How many forms of hypothetical syllogism are there? Now, the schemata are these: the first is the one that, from a relation of entailment and the positing of its antecedent, posits its consequent: 'If a human, then alive; but, the first; the second also'. The second is the one that, from a relation of entailment and the denial of its consequent, denies its antecedent: 'If a human, then also alive; but, not alive; also not a human', 'If not alive, then not a human; but, a human; therefore, alive'.

... The third is the one that denies, from the positing of an altemative and a negated conjunction: The same thing is not both a human and a horse; but, a human; therefore, not a horse'. The fourth is the one that denies, from the positing of an alternative: 'Either it is day or night; but it is day; therefore, not night'. The fifth is the one that posits, from the denial of an alternative: 'Either it is day or it is night; but, it is not day; therefore, it is night'. Now, there are only five. ${ }^{+}$

These "hypothetical syllogisms" are undisguisedly the five Stoic indemonstrables. Someone, perhaps Ammonius, carefully formulated each one with the proper logical operator and, in the first case, with Stoic numerical variables rather than the Peripateric alphabetical ones. Moreover, in a diagram summarizing the division of the schemata, the author labeled the first two schemata by the Stoic term 'connected' and the last three by the Stoic term 'disjoined'. Even though this diagram shows the schema from a negated conjunction as falling together with the fourth and fifth schemata under the class of syllogisms from a disjoined proposition, there is no hint of any rejection of the independence of the schema from a negated conjunction either in the list or elsewhere in the passage. Indeed, the author decreed, in canonically Stoic fashion, that there are these five and only these five schemata. As for the other types of syllogism that had appeared on Alexander's list, none finds mention - not even the Aristotelian syllogism to impossibility, which this author construed

\$3 Ammonius?, In Ar pr., pp. 67.32-69.28.

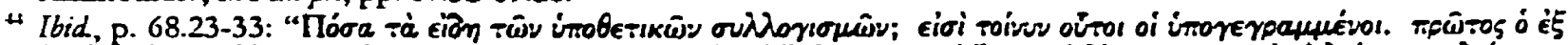

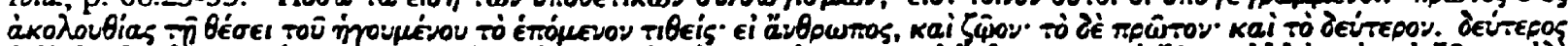

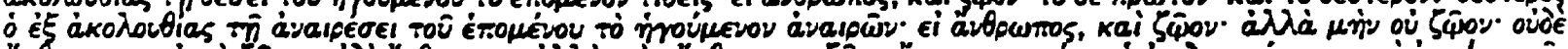

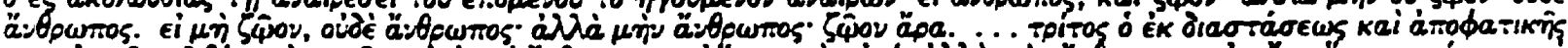

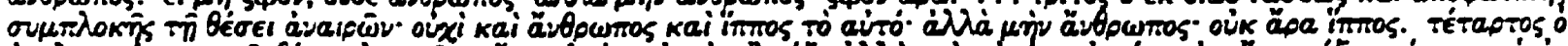

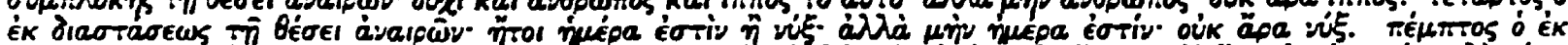

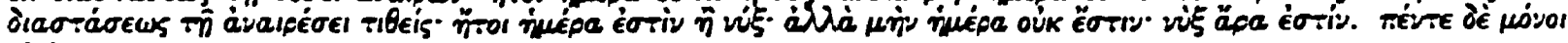
eiriv". 
as a series of hypothetical and categorical syllogisms rather than an independent type. ${ }^{45}$

Clearly, Ammonius or his sources had completely identified the Stoic five indemonstrables, and their syntactic criteria of division, with the Peripatetic hypothetical syllogisms. Nevertheless, the original Peripateric semantic criteria yet survived to some degree: not only did the author of this list classify the negated conjunction with the disjoined proposition as a Peripatetic would have, for they in some sense all express an incompatibility, he also used the terms 'continuous' and 'alternative

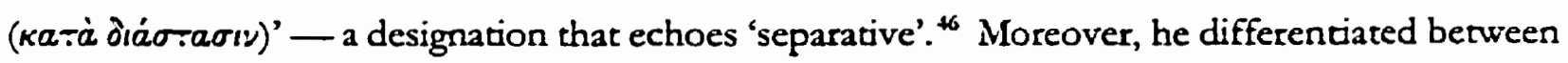
the syllogism from the negated conjunction and those from disjunction in a manner similar to that of Galen:

On the one hand, two cases make one syllogism, for if the statements either are not contradictory or are mediately contradictory, there is the third syllogism. On the other hand, one case - the case of immediate contradictories - makes two syllogisms, the fourth and the fifth. ${ }^{7}$

This distinction between two sorts of contradictory statements, to which the author refers by the

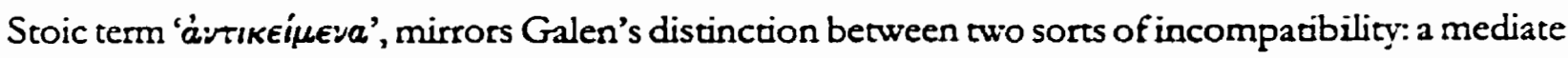

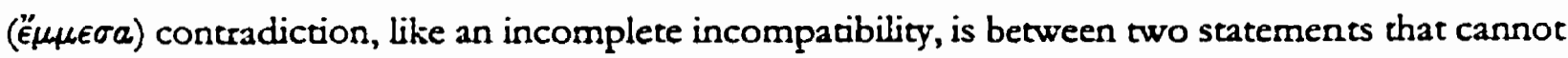
both be simultaneously true but may both be simultaneously false, such as 'It is a human' and 't is a horse', and takes the form of a negated conjunction. An immediate (ä $\mu \epsilon \sigma a$ ) contradiction, like a complete incompatibility, is between two statements that can simultaneously neither both be true nor both be false, such as 'It is day' and 'It is night', and takes the form of a disjunction. Additionally, the claim that a negated conjunction also concems statements that do not contradict at all echoes Galen's definition of the conjunction as proper only to those things that are neither incompatible nor in a relation of entailment.

However, as is plain from the character of this list, the fearures of the Peripatetic scheme of division that had survived had nevertheless lost their proper character as semantic by complete subordination to a Stoic syntactic scheme of division. Other scholia from Ammonius's school also associated with his commentary on the Prior Analytics include a second list of types of hypothetical syllogism that, although a superset of the one above, provides further evidence for the integration

${ }^{45}$ Ibid, p. 69.11-28.

to Ibid, p. 69.2 .

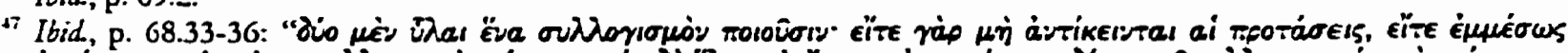

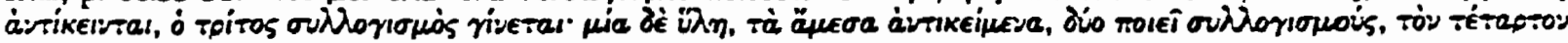
каi то̀ те́цтто". 
of a Stoic syntactic division with the original Peripatetic semantic division. ${ }^{\text {t8 }}$ The author of this second list formulated each type of syllogism that corresponds to an indemonstrable with the appropriate logical operator, and called them by the appropriate Stoic terms; he also included the syllogism from a negated conjunction as an independent type. Moreover, he too construed the syllogism to impossibility as a series of hypothetical and categorical syllogisms, and thus omitted it. At the same time, however, he reserved the disjunctive syllogisms for immediate contraries (ä $\mu \epsilon \sigma a$ éva:tia), in an echo of the Peripatetic semantic scheme, and called the syllogism from a negated

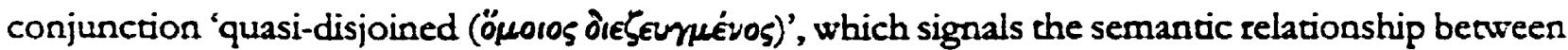
negated conjunctions and disjunctions. His list also includes a special type of syllogism reserved for

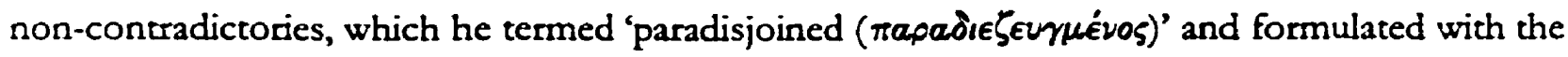
operator 'or'. ${ }^{\prime \prime}$ Thus, just as with the list above, certain aspects of the Peripatetic semantic scheme of division remained, but as secondary to a Stoic syntactic scheme.

Philoponus, a student of Ammonius's, also composed a list of types of hypotherical syllogism that again illustrates how later commentators extensively assimilated the Stoic indemonstrables to Peripateric hypothetical syllogistic. ${ }^{50}$ His list, from his own commentary on the Prior Analytics, exhibits all of the Stoic syntactic features of the first one that I discussed: the division of hypothetical syllogisms into schemata corresponding directly to the five Stoic indemonstrables in the proper order, the formulation of each major premiss with the appropriate logical operator (even to the point of specifying that a sentence is a disjunction in virtue of the logical operator 'or'), and the independence of the syllogism from the negated conjunction. Philoponus also rejected the independence of the syllogism to impossibility as well, on the same grounds that it is a series of hypothetical and categorical syllogisms. ${ }^{\text {st }}$ At the same time, his list also exhibits all of the same semantic, Peripatetic-like features of the first one that I discussed: the classification of the syllogism

t8 tnon., In Amm., vi. l-xii.16.

4) These last two terms, despite their Stoic appenrances, are not in the list of propositions in Diocles, apud Diogenes,

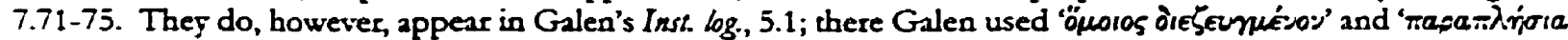

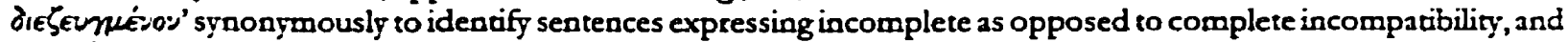
'rapabie Sennévov' to identify sentences expressing no incompatibility but of which at least one part must be true. Galen is the earliest source for the former term; the latter term, however, goes back to the first century AD. (See Frede, Die stoische Logik, pp. 98-100.) Because both of these terms (i) derive from the Stoic term 'òteకcunpévo:', (ii) do not go back to the early Stoa but only to the first two centuries $A D$, (iii) transgress against the Stoic division of complex propositions by main operator (both taking 'or' like the disjunction), and (iv) are instead distinguished on a more semantic basis, their introduction may well have resulted from the syncretism of Peripateric and Stoic logic that I bave argued began to occur just before or around this time.

so Pbiloponus, In An. pr., pp. 244.1-246.14.

5i Ibid, 246.15ff. 


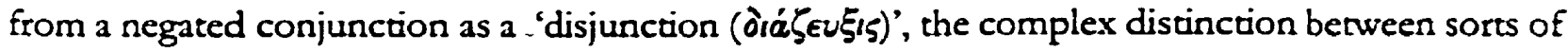
contradictories, and the proper distribution of these various sorts between the syllogism from a negated conjunction and the syllogisms from a disjunction. Additionally, Philoponus classified conditional sentences as relations of entailment and called disjunctions (but not negated conjunctions) by the name 'separative'.

Hence, it is now easy to see why, as I cited at the beginning of this chapter, Philoponus had written just a bit earlier in his commentary that not only Theophrastus and Eudemus, but also the Stoics, had composed lengthy treatises on the subject of hypothetical syllogistic. As his list indicates, he was mostly unaware of the original differences between Peripateric hypothetical syllogistic and the Stoic indemonstrables. In fact, he was so far removed from the logical theory of both of the schools that he could even claim that his fourth and fifth modes of hypotherical syllogism are in a sense reducible to the third mode:

Now, it should be seen that we can make both the fourth and fifth modes from a negated conjunction: in this way, I say that the diagonal is not both commensurable and incommensurable with the side, and that the one line is not both equal to and bigger and smaller than the other line. I say, then, that when we formulate it in this way we make the third mode - except that it is superfluous to formulate it in this way when it was possible to formulate it separatively. So, the hypothetical modes are certainly materially distinguished as we have divided them already [i.e., into those from a relation of entailment and those from a disjuncrion], and next by the figure of the inference itself and of the formulation. If this is the case, it is also no wonder that we say that the fourth and fifth modes, which are not materially distinguished, are the third mode, since we may formulate them with a negated conjunction. ${ }^{52}$

Neither a Peripatetic nor a Stoic would have made this claim: on the Peripatetic view, the logical syntax of a statement or a syllogism is not the criterion for distinguishing it from other statements or syllogisms; on the Stoic view, the five indemonstrables are not interreducible. Thus, Philoponus's list of types of hypothetical syllogism is an amalgam of Peripatetic and Stoic theory that neither school would have recognized as sound. It exemplifies, then, just how distant the hypothetical syllogistic of his time was from that of early Peripatos, as well as the culmination of the trend towards Stoic syntactic formalism that Peripatetic hypothetical syllogistic had begin to follow

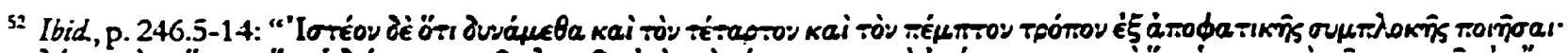

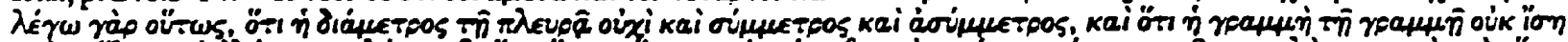

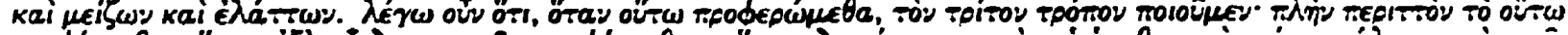

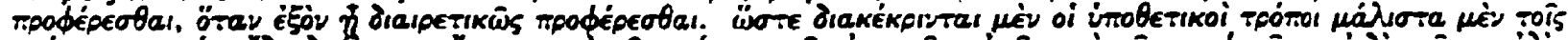

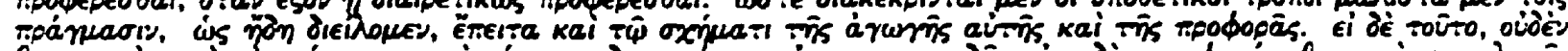

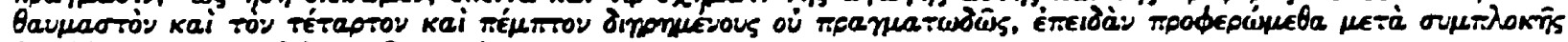

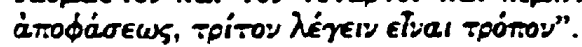


sometime between Theophrastus and Eudemus in the third century BC and Alexander of Aphrodisias and Galen in the second century $A D$.

9. Philoponus was a contemporary of Boethius's, who himself produced not just a list of types of hypothetical syllogisms, but rather a full monograph on hypothetical syllogistic. With the general disappearance in the West of the books of the ancient logicians and of their commentators soon after Boethius's death in $524 \mathrm{AD}$, his monograph on hypotherical syllogistic became the only full exposition of the topic to have survived from classical antiquity. What the character of Boethius's hypotherical syllogistic was, and whether it was of the sort that had transformed under Stoic influence such as I have described here, are thus some of the questions whose answers are crucial for determining the extent to which Peripatetic and Stoic logic had come to blend in later antiquity. I shall turn to them in the next chapter. 


\section{Boethius: On bypotbetical syllogisms}

1. The single most extensive account of hypothetical syllogistic that has survived from classical antiquity, in either Greek or Latin, is the sixth-century monograph On bypothetical syllogisms by Boethius, which is a full introduction to the subject in three books. In fact, not only is it the most extensive work of its kind to have survived from the period, it is also the only work of its kind. Other surviving accounts of hypothetical syllogistic are of two shorter sorts. One sort is a piecemeal discussion of hypothetical syllogistic in the context of a commentary on Aristotle's Prior Analytics or Topits, which takes its order from the order in which Aristotle made his spare comments on the subject. The discussions of hypothetical syllogistic in Alexander's and Philoponus's commentaries on the Prior Anabytics are of this sort, for example. The other sort is merely a list of types of hypothetical syllogism, with brief supporting discussion. Examples of such lists include the two atrributed to Ammonius, which I discussed in the previous chapter. As a sustained introduction and exposition, then, Boethius's monograph is presently unique.

Even Boethius himself asserted his work's uniqueness in its dedication:

Dedicated to your wisdom, then, our labor - although long, yet sufficient for the endeavor - has refined what is found cursorily and confusedly among extremely few Greek writings indeed, and in no Latin writings. Because you had entirely acquired knowledge of categorical syllogisms, you often sought knowledge of hypothetical syllogisms, concerning which nothing is written by Aristotle. Theophrastus, a man full of all learning, only goes through the elements of these things; Eudemus advances further along the way to instruction, but in such a way as if he seems to have sown some seeds and yet not produced a harvest. We undertake, then, to elucidate carefully and pursue in detail what has been either briefly discussed or entirely omitted by them, as far as we are able in virtue of our natural powers and fondiness for your friendship. ${ }^{1}$

In Boethius's own words, his monograph was the first of its kind in his language, as well as clearer,

1 Boethius, De byp. s.h, 1.1.3-4: "Quod igitur apud scriptores quidem Graecos perquam maissimos strictim atque confuse, apud Latinos varo nullos repperi, id tuae scientive dedicatum noster etsi diuturnus, cocpti tamen efficax labor excoluit. Nam cum categorconum syllogismorum plenissime notitiam percepisses, de hỵpotheticis syllogismis saepe quaerebas, in quibus nibil est ab Aristotele conscriprum. Theophnstus vero, vir omnis doctrinae capax, rerum tantum summas exsequitur, Eudemus latiorem docendi graditur viam, sed ita ut veluti quaedam seminaria sparisse, nullum tamen frugis videatur extulisse proventum. Nos igitur, quantum ingenii viribus et amicitise tuae studio sufficimus, quae $a b$ illis vel dicta breviter vel fundirus omissa sunt, elucidanda diligenter er suboiliter persequeada suscepimus". 
more careful, and more detailed than any of the rare Greek treatments of the subject, including the work of Aristodle's associates Theophrastus and Eudemus. As I indicated in the previous chapter, however, Boethius was at best wrong and at worst deliberately disingenuous in this assertion. Firstly, close analysis of the Boethian corpus has suggested to scholars that Boethius either had not been able to acquire, or simply had not used, any Greek texts on logic from the period before Porphyry, with the exception of Aristode's Organon.2 Porphyry died in 309 AD; thus, for example, Boethius either did not have or did not use the logical commentaries of Alexander or the introduction to logic by Galen, both of which I cited extensively in the previous chapter as sources for early Peripatetic hypothetical syllogistic. The original treatments of the subject by Theophrastus, Eudemus, and other early Peripatetics themselves, about which Boethius professed an opinion, as well as any original Stoic material, were also probably unknown to him. At the same time, close analysis of $O n$ bypothetical syllogismsin particular has led some scholars to think that Boethius followed a Greek source or sources in its composition to some degree, not least because the abrupt changes of topic and organizational problems in the first book suggest compilation of source material, perhaps in the form of scholia. ${ }^{3}$ If these scholars are correct, it is possible that Boethius was ignorant or even disingenuous in his claims about Greek texts on hypothetical syllogistic.

Secondly, there may also have existed Latin accounts of hypothetical syllogistic at the time Boethius wrote. His compatriot and contemporary Cassiodorus Senator recorded two:

Now, if someone wants to know more regarding the modes of hypotherical syllogisms, let him read the book by Marius Victorinus, who wrote On bypothetical syllogisms He should also know, since Tullius Marcellus of Carthage treated categorical and hypothetical syllogisms cautiously and carefully in seven books, that they are very extensively discussed by various philosophers, . . . and also that hypothetical syllogisms have been treated by the Stoics in countiess volumes (collected by this man in his fourth and fifth books). ${ }^{+}$

Although no copies of either of these works are presently available (Tullius Marcellus of Carthage is in fact otherwise unknown), the tide of the account by Marius Victorinus suggests that it was a

2 Bidez, "Boèce et Porphrre"; Shiel, "Boethius' Commentaries on Aristode"; Ebbesen, "Boethius as an Aristotelian Commentator". Shiel and Ebbesen disagree about how limited Boethius's source or sources were - and especially whether or not his only source was a set of scholiz in his copy of Aristotle's Organon. They agree, however, following Bidez, that his source or sources were Porphyrian or post-Porphyrian.

3 Striker, "Zur Frage nach den Quellen von Boethius' de bypotbeticis syllogismis"; Mlaróth, "Die Hypothetischen Syllogismen", pp. 421-36.

- Cassiodorus, 2.3.13: "modos autem hypotheticorum syllogismonum si quis plenius nosse desiderat, legat librum 1 [arii Victorini qui inscribitur de Syllogismis Hypotheticis. sciendum quoque quoniam Tullius Marcellus Carthaginensis de categoricis et hypotheticis syllogismis, quod a diversis philosophis latissime dictum est, septem libris caute suptiliterque tractavit .. quod autem de hypothericis syllogismis ab Stoicis innumeris voluminibus tractatum est, ab isto quarto et quinto libro colligeretur". 
full exposition of hypothetical syllogistic like Boethius's work, and not merely a brief discussion. Tullius Marcellus's book seems to have been more than just a list of hypothetical syllogisms as well. Nevertheless, Cassiodorus's records are often unreliable or even textually corrupt; perhaps neither of these works ever existed in the form that he described. It thus remains unclear how suspicious Boethius's claim to originality in Latin is, even if it is likely that it was wrong with regard to Greek.

All the same, Boethius's monograph has long been unique - but not because it necessarily was when he wrote it. Rather, it seems to have been the only treatise on hypothetical syllogistic in either Greek or Latin that survived, not only to the present, but even through the few centuries after Boethius's death in $524 \mathrm{AD}$, and thus through the transition in the Latin West from late antiquity to the early Middle Ages, during which Greek learning became truly scarce. In other words, it has been the only available full introduction to hypothetical syllogistic from classical antiquity since the end of classical antiquity itself. On bypothetical syllogismsis therefore a crucial source of information about the nature of hypothetical syllogistic during the later period of classical antiquity, as well as about the influence of ancient logic during the early Middle Ages. For my purposes, then, it is a crucial source of information about the conflation of Peripatetic and Stoic logic during this transitional ime.

2. In 1951, Karl Dürr published the first modern study devoted entirely to On bypotbetical syllogisms, in which he concluded that "it seems unmistakable that this Stoic logic was not the model of Boethius". 6 By 'this Stoic logic', Dürr meant the system that derives from the five basic indemonstrable arguments. He provided three reasons for his conclusion: (1) Boethius mentioned the Peripaterics by name in On bypothetical syllogisms but not the Stoics, (ii) Boethius did not include the third indemonstrable - that is, the argument schema from a negated conjunction - in his account of hypothetical syllogistic and it would be incorrect to assume that he thought of it as superfluous to Stoic logic, and (iii) any similarity between Stoic logic and Boethius's account of hypotherical syllogistic is due merely to the fact that both derive from early Peripatetic hypothetical syllogistic. Dürr then concluded, "All of these facts suggest acceptance of the view that the work

5 See also the brief account of hypothetical syllogisms from the probably fifth-century Capella, 4.41+-22, and the very brief and partial list of hypothetical syllogisms in Cicero, Top., 13.53-54, the latter of which Boethius knew. Boethius might have reasonably considered these two as not properly works on hypothetical syllogistic, however.

- Dürr, The Propositional Logic of Boethins, p. 11. 
of Boethius was not directy influenced by the propositional logic of Chrysippos". "

Now, Dür was surely correct in the strictest sense: Boethius was not directly influenced by Chrysippus or the Stoics. Indeed, as I indicated, Boethius probably never even read a single Stoic book on logic. Boethius also certainly did not take Stoic logic as a model in the way Dürr seems to have meant - that is, by merely reproducing and commenting upon the five indemonstrable argument schemata. Nonetheless, each of Dürr's reasons for concluding that Stoic logic was not Boethius's model, or a direct influence on Boethius, is misguided in precisely the way that at least opens the possibility that Boethius's hypothetical syllogistic may include elements that came indirectly from Stoic logic, as follows:

(1) Dürr was correct to note that Boethius did not mention the Stoics in On bypothetical syllogisms as I have pointed out, Boethius almost certainly never read any Stoic texts. However, he also almost certainly never read the texts of two of the three Peripatetics whom he mentioned in the work: Theophrastus and Eudemus. (The third is Aristotle.) Moreover, he nowhere mentioned the authors or the iitles of whatever Greek texts he did see, if any, which seem to have been no older than from the very end of the third century $A D$. Now, mention of Aristode, Theophrastus, and Eudemus, but not the Stoics, does indeed suggest that Boethius's sources were in the Peripatetic tradition and not the Stoic. However, as I have shown in the previous chapter, the hypothetical syllogistic that had originated in the Peripatetic tradition had already begun to take on a Stoic cast at least as early as the beginning of the third century $A D$, before Boethius's Greek sources would have been writing, and was thoroughly mixed with Stoic theory by the beginning of the sixth century $A D$, when Boethius himself was writing. All or some of Boethius's later, neo-Peripatetic sources may thus have conflated Peripatetic with Stoic theory, transmitting it in mixed form to Boethius.

(ii) Dürr was also correct to note that an inference schema corresponding to the Stoic third indemonstrable does not appear in On bypothetical syllogisms However, as I showed in the previous chapter, the fact that particular schemata appear or do not appear in a given list or account of hypothetical syllogisms proves very little about the origin of the list or account. Both the early Peripatetics and the Stoics concerned themselves with the same kind of reasoning, but in very different ways. In their hypothetical syllogistic, the early Peripatetics divided hypothetical statements on a semantic basis, according to which one sort of hypothetical statement expresses a 7 Ibid. 


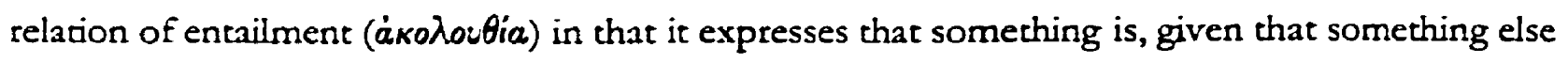
is, and another sort expresses an incomparibility $\left(\mu \dot{a}_{x} \eta\right)$ in that it expresses that something is, given that something else is not (or vice versa). Hypothetical syllogisms in tum belong to one of two corresponding sorts in virtue of having a major premiss that expresses either a relation of entailment or an incompatibility. In their theory of the five indemonstrables, however, the Stoics divided major premisses and syllogisms on a syntactic basis instead - that is, on the basis of certain sentential operators, such as 'if and 'or'. Confusion of Periparetic hypothetical syllogistic with the Stoic five indemonstrables on the part of later, neo-Peripatetic commentators consisted preciseiy in confusion of these two differing criteria for division, which in turn led to conflation of types of syllogism. Thus, whether Boethius's account of hypotherical syllogistic is Peripatetic in character, or Stoic in character, or both, depends more on the way in which he classified hypothetical statements and syllogisms, and less on whether or not his syllogisms appear on some list or another. Furthermore, as I shall discuss in the next chapter, Boethius did indeed consider an inference schema corresponding to the third indemonstrable in a commentary that he composed on Cicero's Topics.

(iii) For these reasons, Dürr's explanation for the similarity between Stoic formal logic and Boethius's account of hypothetical syllogistic is also misguided, for he claimed that both "were connected with" the hypothetical syllogistic of the early Peripatos. Regarding the Stoic connection to the early Peripatos, he wrote:

That there are important resemblances between the Stoic and the Peripatetic logic is shown by the fact that Ioannes Philoponus refers to the Peripatetics and Stoics and compares the terminology of the two schools when he is concerned with hypotherical syllogisms. It can also be noticed that Scholz, in his History of Logic, points out that Theophrastus and Eudemos anticipate the Stoic theory of hypothetical and disjunctive syllogisms. ${ }^{8}$

As I have demonstrated in the previous chapter, this view of the relationship between Stoic logic and early Peripatetic hypothetical sÿllogistic is mistaken. Philoponus's account of hypothetical syllogistic, especially, is so much a conflation of Stoic and early Peripateic theory that neither school would have recognized it as sound. Thus, the claim by Heinrich Scholz, originating with Carl Prant, that Theophrastus and Eudemus anticipated the Stoic "theory of hypothetical and disjunctive syllogisms" (by which he must have meant the indemonstrables), is simply unfounded."

Moreover, while Dürr's complementary claim that the hypothetical syllogistic of the early

I Ibid

? Scholz, Abriss der Geschichte der Logik, p. 32. Scholz, citing Prantl beavily, gave Theophrastus and Eudemus credit for the indernonstrables and for founding sentencial logic. 
Peripatos influenced Boethius is beyond doubt, his reasons for having made this claim are not. ${ }^{\text {io }}$ Dürr pointed out that Boethius's hypotherical syllogistic includes syllogisms whose first premiss is a conditional, syllogisms whose first premiss is a disjunction, and syllogisms that are similar to the totally hypotherical syllogism. Now, Dürr was correct to note that Alexander had connected Theophrastus to the theory of the totally hypothetical syllogism, and that Boethius's account of syllogisms arising from what he called "intermediate connective statements" bears some resemblance to the theory of the totally hypothetical syllogism. ${ }^{n}$ However, according to Dürr, Boethius's other syllogisms also have a Peripatetic origin because the list of types of hypothetical syllogism that Alexander reported includes them, and because this list enumerates the early Peripateric hypothetical syllogisms. Once again, as I have demonstrated in the previous chapter, this view (originating again with Prantl) is mistaken. Even Alexander conflated Peripatetic and Stoic theory to some degree, so that his list of types of hypothetical syllogism is not purely Peripatetic in character, even though it does not include any type that the early Peripaterics did nor discuss under some description. (The exception is the syllogism from a negated conjunction, which is properly Stoic, but on whose inclusion Alexander hedged. Dürr uncritically ascribed even this syllogism to the early Peripatetics on the grounds that it appears on Alexander's list.)

Hence, I conclude thas, while Dür's claim that the Stoics did not directly intluence Boethius is surely right, there is no reason to think that Stoic formal logic could not have indirectly influenced Boethius in ways of which Boethius himself was not aware. Indeed, the very reasons that Dürr marshaled to prove his claim suggest, upon examination, ways in which this influence might in fact have occurred. Boethius wrote his work long after early Peripatetic hypotherical syllogistic and the Stoic five indemonstrables had begun to blend; moreover, whatever sources upon which he relied almost surely did not predate the time when Peripatetic hypothetical syllogistic began to lose some of its peculiarly Peripatetic character to Stoic theory as a result.

3. In 1969, Luca Obertello published the second and only other modern study devoted entrely to On bypothetical syllogisms in which he also took up the question of the possible influence of Stoic logic on Boethius's hypothetical syllogistic. Controverting Dürr, Obertello concluded that “... in

10 Dürs, The Propositional Logic of Boethius, pp. 6-9.

$"$ Boethius, De byp. glh, 1.6.2-3 and 2.9.1-3.6.5 
Boethius's logical thought, as many elements of the Peripatetic tradition as of the Stoic are found. It could not have been othenvise". "2 It could not have been otherwise, according to him, because Boethius's circumstances necessitated that he draw on a logical theory that was already a blend of the Peripatetic and the Stoic. As Obertello wrote:

One thing is clear, at any rate: that, like what happens in the writings of the commentators contemporaneous to him, for example in John Philoponus, Boethius sets out in the De bypotheticis syllogismis a doctrine that cannot be classified either as purely Aristotelian (or Peripateric) or as purely Stoic. ${ }^{13}$

However, because Obertello lacked any account of the conflation of Peripatetic and Stoic theory that he thought contributed to the mixed hypothetical syllogistic in both On bypotbetical syllogismsand the work of other commentators such as Philoponus, he concluded that there were traces of Stoic logic in Boethius's monograph for two inadequate reasons.

Firstly, Obertello pointed out that, while Boethius had most often used letters as variables when formulating logical schemata, he had sometimes also used ordinal numbers. ${ }^{\text {t }}$ The use of numerical variables is traditionally Stoic, while the use of alphabetical variables is traditionally Peripatetic; more importandy, Stoic numerical variables stand for whole sentences while Peripateric alphabetical variables stand for terms. Now, Obertello concluded from these considerations merely that Stoic logic had made some appearance in On bypothetical syllogisms and not that it had necessarily exerted any great influence. To his mind, use of numerical variables shows that Boethius knew of Stoic logic, but it does not show that this knowledge was an important influence on Boethius's work. Obertello's caution was well-founded; Boethius's infrequent use of numerical variables does not in itself prove any great influence, especially since Boethius was writing at a time when the differences between Peripatetic and Stoic logic seem to have blurred to a large extent. In fact, as Obertello recognized, Boethius's regular use of alphabetical variables for predicate terms demonstrates that he did not think of his hypothetical syllogistic as a logic for sentences. ${ }^{15}$ This caution notwithstanding, however, Obertello was wrong to conclude that Boethius knew of Stoic logic because he

12 Obertello, A.M. Severino Boepro: De hypotheticis syllogismis, p. 57 : “. . nel pensiero logico di Boezio si trovano tanto elementi della radizione pecipatetica, qunnto di quella stoica. Non potevz essere altrimenti".

13 Ibid, pp. 153-54: "Una cosa comunque è certa: che, a somiglianza di quella che aviene negli scritri di commentatori 2 lui contemporanei, ad esempio un [sid Giovanni Filopono, nel De bypotheticis syllogismis Boezio espone una dottrina che non può essere classificata né come puramente aristotelica (o peripatetica), né come puramente stoica".

is Ibid, Pp. 147-48.

15 Given that Obertello recognized this point, I do not understand his eavlier claim that "La logica stoica è una logica proposizionale, $e$ in questo senso, genericamente, si può ben dire che essa ha un punto sostanziale di contatto con la dottrina boeziana dei sillogismi ipotetici" - see ibid., p. 146. 
sometimes used numerical variables, for this limited use does not confirm that had knowledge of Stoic logic in any significant sense - let alone any sense that is relevant to his treatment of hypotherical syllogistic. It is open to question whether or not Boechius even knew of the different histories and connotations of the two kinds of variables. Perhaps he merely copied the use of ordinal numbers as variables from certain scholia or texts, the authors of which may also themselves not have been aware of the connotations of such use. In fact, it is not even clear from the passage that Obertello cited, in which Boethius used numerical variables, that Boethius used them like the Stoics did - namely, to stand for a sentential item. In that passage, Boethius wrote 'est primum' and 'est secundum, which are ambiguous phrases; both 'the first is (the case)' and 'it is the second' are grammatically acceptable translations. ${ }^{16}$

Secondly, and more to the point, Obertello took issue with one of the arguments that Dürr had advanced to show that Boethius was not under Stoic influence:

We have said above that Boethius did not use the third indemonstrable in any way. According to Dürr, this would indicate that he did not use as his source Chrysippus's logic - that is, Stoic logic. In any case, the peremptoriness of this judgement notwithstanding, it must be recognized that numerous elements of Stoic doctrine regarding the indemonstrables passed into Boethian logic, in which inference schemata are in fact found that concern the first, the second, the fourth, and the fifth indemonstrables.

... The fact remains that Boethius demonstrates, even if implicitly, that he knows this part of Stoic logic. ${ }^{17}$

This argurnent, however, is as misguided as Dürr's own. Dürr, on the one hand, had wanted to reason from the absence of a particular inference schema appearing on the list of Stoic indemonstrables directly to the claim that Stoic logic had not influenced Boethius. Obertello, on the other hand, wanted to reason from the presence of several inference schemata appearing on the list of Stoic indemonstrables directly to the claim that Stoic logic had influenced Boethius. As I have mentioned above in my own treatment of Dürr's argument, whether or not particular syllogisms appear on one list or another proves very little about the tradition, either Peripatetic or Stoic, to which the syllogisms belong. Early Peripatetic hypothetical syllogistic differed from the Stoic five

"Boethius, De byp. 5 hl, 1.4.4.

17 Obertello, A.M. Severino Boezrio: De hypothericis syllogismis, Pp. 148-49: “Abbiamo detro sopra che Boezio non usa in alcun modo il terzo indimostrabile. Secondo il Dür, questo indicherebbe che egli non usa come sua fonte la logica di Crisippo, cioè la logica stoic2. E tuttavia, nonostante la perentorietì di questo giudizio, bisograa riconoscere che numerosi elementi della dottrina stoica circa gli indimostrabili sono passati nella logica boeziana, nella quale si ritrovano infatri schemi d'inferenza che riguardano il primo, il secondo, il quarto, e il quinto indimostrabile. ... Sta di fatto che Boezio dimosera, anche se implicitamente, di conoscere questa parte della logica stoica". 
indemonstrables more in the way in which it classified and accounted for certain patterns of reasoning, and less in the patterns of reasoning themselves.

All the same, I have no quarrel with Obertello's claim that Boethius was writing at a time when Peripatetic logic and Stoic logic had become conflated to some extent. In the previous chapter, I gave an account of this conflation with respect to Peripateric hypothetical statements and hypothetical syllogistic on the one hand, and Stoic complex propositions and the five indemonstrables on the other. Obertello's arguments fail, in fact, precisely because he did not have such an account. Furthermore, I have no quarrel with the claim that Boethius's hypothetical syllogistic in particular exhibits this conflation of Peripatetic and Stoic logic, for close examination of it reveals that Boethius, like other commentators before him, did not fully appreciate the distincrion between the early Peripatetic semantic account of hypothetical statements and the Stoic syntactic account of complex propositions.

4. Boethius sensibly began his discussion of hypothetical syllogistic by first discussing hypotherical statements. I use the word 'statement' to translate Boethius's word 'propositio', rather than the cognate word 'proposition', for four reasons. Firstly, I have so far reserved the word

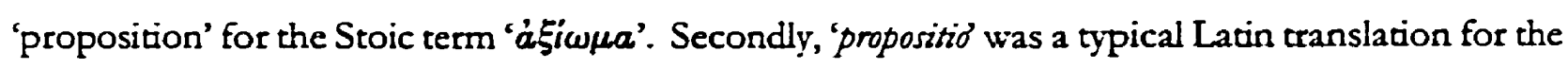

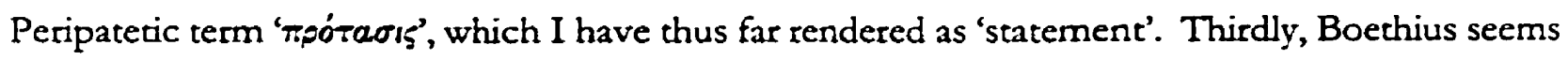

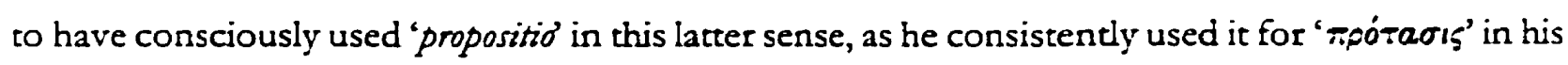
translations. ${ }^{18}$ Finally, he regularly called the major premiss of a syllogism a propositio, reflecting the

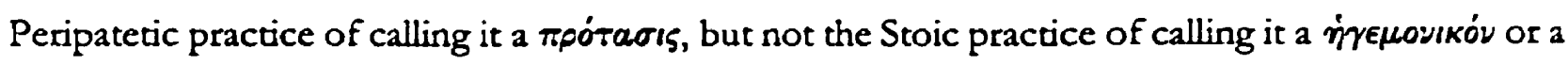
теотікóv. ${ }^{19}$

However, in various places throughout On bypothetical syllogisms as well as in other works such as his commentary on Cicero's Topics, Boethius used the word 'enuntiatio' apparenty synonymously with "propositio. The definition of "propositio' in his monograph $O n$ the topical differencesconfirms that he in fact thought of the terms as synonymous:

A propositio is a sentence that signifies something true or false, as when someone says that the heavens are spherical. It is also called an enuntiatio and a proloquium. ${ }^{20}$

18 Nuchelmans, Theories of the Proposition, p. 131.

19 Boethius used 'propositio' in this way throughout the second and third books of On bypothestical syllogisms, for example. For the Stoic terms see, Alexander, In An. Pr., Pp. 262.30-31; Galen, Inst. log., 7.1. Galen wrote that the Stoics used the latter term because the syllogism is built upon the major premiss like a ship upon a keel (Tpór15).

20 Boethius, De top. diff., 2.22-23: 'Propositio est oratio verum falsumve significans, ut si quis dicat 'coelum esse volubile' 
Regarding the term 'proloquium', the Latin doxographer Aulus Gellius had written over three centuries before Boethius:

In general, whatever is said by means of a full and complete thought in words, so that it necessarily is either true or false, is called an a $\xi_{i \omega \mu}$ a by the logicians, a proloquium by Varro (as I have said), and a pronuntiatum by Cicero - which term, however, he allowed himself to use just so long as "until," he said, "I find a better one".21

Cicero did indeed search for a better term; in his Onfate, he explicitly translated 'áfiwua' by the term 'enuntiatio'." The terms 'proloquizm' and 'enuntiatio', then, which Boethius construed as synonymous

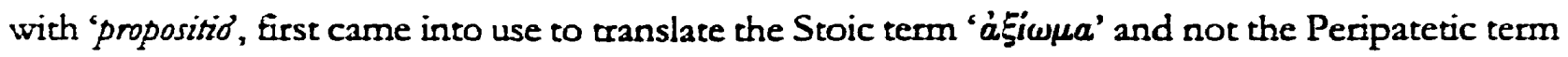
'трот табוs'. (The term 'propositio' does not itself seem to have been a candidate for translating

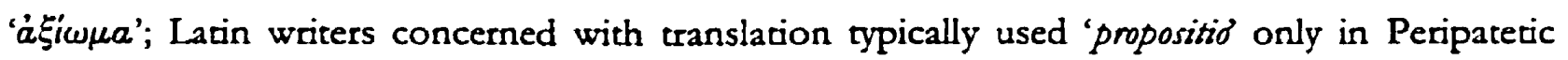
contexts. ${ }^{23}$ ) Indeed, Gellius's definition of ' $\dot{a} \xi i \omega \mu a$ ' is a paraphrase of the canonical Stoic definition. ${ }^{24}$ Now, as I showed in the previous chapter, there were originally important differences between Peripatetic hypotherical statements and Stoic complex propositions, so that a careful

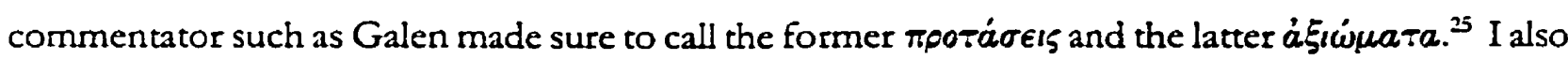
showed that later, less careful commentators blurred these differences, conflating Peripateric and Stoic theory. It is not enough that Boethius construed the terms 'propositio', 'proloquizm', and 'enuntiatio' as synonyms to show that he was also party to this conflation of theory, as he may only have either confused or followed in the confusion of Latin usage that was already about five centuries old. ${ }^{20}$ However, it is enough to lead me to translate 'propositio' as 'statement' (and also as 'major premiss' if the context demands) and 'enuntiatio' as 'proposition'. Such a scheme of translation will, at the very least, mirror Boethius's own use of two different words, and will be all the more proper if independent evidence does indeed show that he was party to a conflation of Peripateric and Stoic theory such as I detailed in the previous chapter. ${ }^{27}$

[sic]; haec et enunciatio et proloquium nuncupatur".

"Gellius, 16.8.8: “omnino, quicquid itn diciur plena atque perfectn verborum sententia, ut id necesse sit aut verum aut falsum esse, id a dinlecticis afiwna appelatum est, a . M. Varrone, sicuti divi, proloquiam, a M. autem Cicerone pronuntiatum, quo ille tamen vocabulo tantisper uti se adtestatus est, 'quoad melius' inquit 'invenero"'. Gellius's quote is from Cicero, Tusc. disp., 1.14.

$\because$ Cicero, De fat., 1.1 and 10.20. He also used 'enuntiatum' synonymously — see 9.19 and 12.28.

3 Nuchelmans, Theories of the Proposition, p. 119.

it Diocles, opud Diogenes, 7.65.

25 See, for example, Galen, Inst. log., 3.4.

26 Gabrël Nuchelmans has detected a conflation of Peripatetic and Stoic terminology during the course of late antiquiry, beginning even in Greek - see his Theories of the Proposition, Pp. 89-90 and 105-118.

2 In the two cases in $O n$ bypothetical syllogisms in which Boethius used the expression 'enuntiata propositio', the participle 'enuntiatd' is not technical; tather, it means 'expressed' - see his De byp. syL, 1.2.1 and 2.1.2. 
Now, according to Boethius, every statement is either categorical or hypothetical. ${ }^{28}$ Categorical statements are of the familiar form ' $A$ is $B$ ', in which something is predicated of another thing. For hypothetical statements, on the other hand, Boethius provided four characterizations, as follows:

(1) Hypothetical statements express that something is, if something else is:

A hypothetical statement is one that declares, together with some hypothesis, that something is, if another thing is — for instance, when we say, 'If it is day, it is light'. 29

(2) Hypothetical statements consist of categorical statements, while categorical statements are simple:

On the one hand, a categorical statement is simple, but a statement will not be able to be hypothetical unless it is composed from categorical statements. For example, when we say, 'If it is day, it is light', 'It is day' and 'It is light' are two categorical - that is, simple statements. ${ }^{30}$

(3) Hypothetical statements have their own proper force that differs from the force of categorical statements, in that it rests on a hypothesis rather than on a predication, even with regard to the same terms:

For, in the case of some statements, the categorical statement does not seem to differ from the hypothetical statement, except only in the mode of the sentence. For instance, if someone claims 'A human is an animal', and if he asserts again, If it is a human, it is an animal', these statements are different in the mode of the sentence, but do not seem to have signified different things. We must first say, then, that the categorical statement contains its own force, not in virtue of a hypothesis, but in virtue of a predication alone. But, in the case of the hypothetical statement, the grounds for the entailment are derived from a hypothesis. ${ }^{31}$

(4) Hypothetical statements express that something is or is not, if something else is or is not:

3 Ibid, 1.1.4-5. He also provided the alternative Latin tems 'predicative (praedicativa)' and 'suppositional (conditionakis)'. Because we use the Greek words in English just as Boethius usually did in Latin, I shall continue with 'categorical' and 'hypothetical' rather than 'predicative' and 'suppositional', even in translation. 'Condicional' is a particularly inappropriate translation for 'ionditionalis', given both the modern technical sense of the term and the fact that disjunctions are, for Boethius, propositiones conditionales (see below).

* Ibid, 1.1.5: "Hypothetica est quae cum quadam conditione denuntiat esse aliquid si fuerit aliud, veluti cum ita dicimus: 'si dies est, lux est"'.

30 Ibid, 1.1.6: "Rursus praedicativa simplex est propositio, conditionalis vero esse non poterit, nisi ex praedicativis propositionibus coniungatur, ur cum dicimus: 'si dies est, lux est', 'dies est', atque lux est', duae sunt praedicativae, id est simplices, propositiones".

31 Ibid, 1.1.6: "Videtur enim in aliquibus propositionibus nihil differre praedicativa propositio a conditionali, nisi tantum quidem orationis modo; velut si quis ita proponat: 'homo animal est', id si ita rursus enuntiet 'si homo est, animal est', hae propositiones orationis quidem modo diversae sunt, rem vero non videntur significasse diversam. Primum igitur dicendum est quod praedicativa propositio vim suam non in conditione, sed in sola praedicatione constituit, in conditionali vero consequentiae ratio ex conditione suscipitur". 
The statements that do indeed differ from simple statements [sc. hypothetical statements] are the ones when something is said to be or not to be, if something else either is or is not. ${ }^{32}$

Boethius's complete definition of the hypothetical statement emerges from these four characterizaions taken together. For him, a hypothetical statement is a complex or non-simple statement that signifies, in virtue of and together with a hypothesis, that something is or is not, if someching eise is or is not. I construe the first characterization as a compatible abbreviation of the fourth; Boethius certainly allowed for hypotherical statements with negative elements on either side.

At first glance, this definition appears Peripatetic in character. As I mentioned above, the early Peripaterics designated as hypothetical the kind of statement that signifies either a relation of entailment - that is, that something is, given that something else is - or an incompatibility - that is, that something is, given that something else is not (or vice versa). Boethius's definition seems to fit closely in this tradition, especially in respect of characterizations (1) and (4). However, a more detailed examination of each of the four characterizations above demonstrates that, while the definition does indeed fit into the Peripatetic tradition in a broad sense, there are yet major discrepancies between the original early Peripatetic account of hypothetical statements and Boethius's own.

5. In accordance with Boethius's second characterization, hypotherical statements consist of categorical statements; in the hypotherical statement 'If it is day, it is light', the two components are each categorical. Categorical statements are of the form ' $A$ is $B$ '; thus, the most general form of a hypothetical statement seems to be 'If $A$ is $B, C$ is $D$ '. It seems, in other words, that only in the particular example 'If it is day, it is light' and others like it are the two subject terms are the same (assuming the impersonal construction counts as having a subject), for nothing in Boethius's definition rules out that the two subject terms might differ. Indeed, Boethius himself at one point presented the statement 'When fire is hot, the heavens are spherical' as an example of a hypotherical statement. ${ }^{33}$ (Boethius explicitly took 'when (cum)' as equivalent to 'if $(s i)^{\text {'. }} .7$ ) But, if the subject terms of the component parts of a hypothetical statement may differ, then nothing in Boethius's

\footnotetext{
32 Ibid, 1.2.7: "quae vero a simplicibus differunt illae sunt, quando aliquid dicitur esse vel non esse, si quid vel fuerit vel non fuerie".

${ }^{33}$ Ibid., 1.3.6.

H Ibid., 1.3.1.
} 
definition rules out that hypotherical statements express relations between categorical statements themselves and not between predicate terms. Thus, one of two conclusions may follow: either early Peripatetic hypotherical syllogistic was a logic for sentences, or Boethius or one or more of his sources had misconstrued early Peripatetic hypotherical syllogistic as a logic for sentences. If the latter follows, perhaps Boethius or his sources did so under the influence of Stoic logic, which was

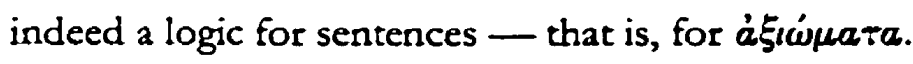

Now, I have argued in my first chapter that the original early Peripatetic hypothetical syllogistic was not, in fact, a logic for sentences, and could even accommodate, without invoking a logic for sentences, most hypotheses relating categorical statements whose subject terms differ. However, I shall not conclude merely on the basis of Boethius's example statement, When fire is hot, the heavens are spherical', that he or one or more of his sources had misconstrued early Peripatetic hypothetical syllogistic as a logic for sentences, or that they were under the influence of the Stoics in doing so. This example statement is just a single case; in all other cases he allowed only the predicate terms to vary, so that the most general form of a hypothetical statement is If $A$ is $B, A$ is C'. Nonetheless, the scattered appearances of these aberrant examples, both in Boethius's work and in the work of other commentators, as well as the use of impersonal constructions such as It is day' and 'It is light', whose grammatical subjects stand for nothing clearly identifiable, are noteworthy. ${ }^{35}$ For they may at least indicate that some neo-Peripatetic commentators, including Boethius himself, were losing or had already lost touch with a purely Peripatetic logic, in which the atomic units are terms and not sentences. If so, it is perhaps connected with the fact that they also were losing or had already lost touch with the differences between Stoic indemonstrable arguments and Peripatetic hypothetical syllogisms. ${ }^{36}$ Indeed, the sentence 'If it is day, it is light' is so common an example in Stoic accounts of complex propositions and of the indemonstrables that it often serves scholars as an indicator of possible Stoic fragments or testimonia.

Boethius's third characterization of the hypothetical statement, by contrast, shows a more clear discrepancy between his hypothetical syllogistic and that of the early Peripatos. According to this characterization, the locus of the force of a hypothetical statement is a hypothesis and not a

35 I have in mind here Barnes's report of a totally hypothetical syllogism the component parts of whose hypothetical statements have differing subject terms. See the discussion of the totally hypothetical syllogism in the first chapter.

${ }^{36}$ Christopher Martin has argued that Boethius had no notion of propositionality. If so, then whatever he or his sources might have had in mind by introducing statements such as When fire is hot, the heavens are spherical', he himself could not have thought of his hypotherical syllogistic as a logic for sentences. See Martin, "The Logic of Negation in Boethius". 
predication, which is instead the locus of the force of a categorical statement. As Boethius elaborated:

What is set as subject in a categorical statement seems to take as its name what is set as predicate in the same statement, as follows. When we say ' $A$ human is an animal', for example, the subject is 'human', the predicate is 'animal', and human takes its name from animal, because human itself is claimed to be animal. But, in the statements that are called hypotherical, the same mode of predication does not exist. For one thing is not predicated of another thing at all; rather, it is only that one thing is said to be, if another thing is, as when we say 'If she has given birth, then she has slept with a man'. For here it is not said that to have given birth is what it is to sleep with a man; rather it is only claimed that there could never have been birth unless there had been intercourse with a man.

... In the case of categorical statements, then, we will see that human itself is animal - that is, it derives for itself its name from animal. But, in the case of hypothetical statements, we understand that, if there is a certain thing that is called human, then it is necessary that there is a certain thing that is called animal. So, the categorical statement makes it clear that the thing that it sets as subject takes its name from a thing set as predicate, but the hypothetical statement has this meaning: something accordingly in fact is, if something else is - even if neither takes the name of the other. ${ }^{37}$

It is clear from this passage that, for Boethius, a hypothetical statement has its force in some relationship between the things named by the predicate terms of its parts, even if these things may not also stand to one another in the relation of predication. It is the causal but not predicative relationship between intercourse and birth, for instance, that lends force to the hypotherical statement 'If she has given birth, she has slept with a man'. Even in the case of the hypothetical statement 'If it is a human, it is an animal', the taxonomic relationship between human and animal alone lends force to the statement. There is no predicative force such as there is in the categorical statement 'Every human is an animal', for when someone utters 'If it is a human, it is an animal' there simply is no assertion that to be an animal is, or is part of, what it is to be a human.

Since a hypothetical statement has its force in virtue of a hypothesis, then, a hypothesis must be for Boethius whatever non-predicative relationship exists between the things that the predicate

37 Boethius, De bpp. s\%, 1.1.7-2.2: ". . . quod in praedicativa propositione subicitur, iilius suscipere nomen videtur quod in eadem proposicione praedicatur hoc modo, ut cum dicimus: 'homo animal est', 'homo' subiectum est, 'animal' praedicatum, et homo animalis suscipit nomen, cum ipse homo animal esse proponitur. At in his propositionibus quae conditionales dicuntur aon est idem praedicationis modus; neque enim omnino alterum de altero praedicatur, sed id tannum dicitur esse alterum fuerit, veluti cum dicimus: 'si peperit, cum viro concubuit'. Non enim tune dicirur ipsum peperisse id esse quod est cum viro concumbere, sed id tantum proponitur quod partus numquam esse potuisset nisi fuisset cum viro concubitus. ... In praedicativa igitur id spectabimus quod ipse homo animal sit, id est nomen in se suscipiat animalis, in conditionali vero illud intellegimus, quod si fuerit aliqua res quae homo esse dicatur, necesse sit aliquam rem esse quae animal nuncupetur. Itaque pracdicativa propositio rem quam subicit praedicatae rei suscipere nomen declarat; conditionalis vero propositionis haec sententia est, ut ita demum sit aliquid, si fuerit alterum, etiamsi neutrum alterius nomen excipiat". 
terms of the component parts of a hypothetical statement name. The definition of the hypothesis that Boethius provided confirms this point; according to him, a hypothesis is a relation of consequence (consequentia), expressed in a conjunction (coniunctio) or a disjunction (disiunctio). ${ }^{38}$ Now, Boethius was following at least partly in the Peripatetic tradition in the terms of this definition, which he attributed to Eudemus (in all likelihood, at second-hand at the least). As I mentioned above, the early Peripatetics had recognized some hypothetical statements, which they had called

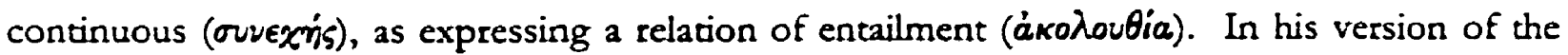
definition, Boethius used the Latin term 'consequentid, which, like the similar Greek term 'ákoh.ou6ia', derives from a verb that means 'to follow upon'. He also called what expresses this relation by the

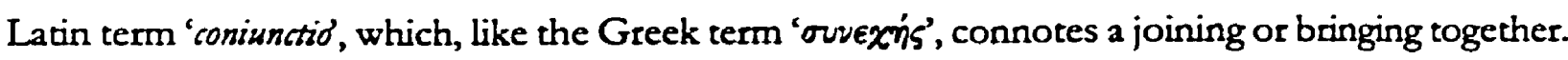
Yet Eudemus and the other early Peripatetics had also recognized a second sort of hypothetical

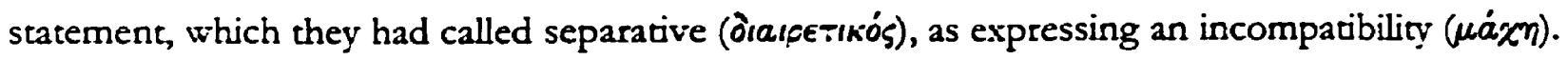
Boethius, however, made no explicit mention of the relation of incompatibility in his definition of hypothesis, even if he did mention that, in addition to the conjunction, the disjunction also expresses a relation of consequence. For this reason, his term 'consequentid cannot mean the same

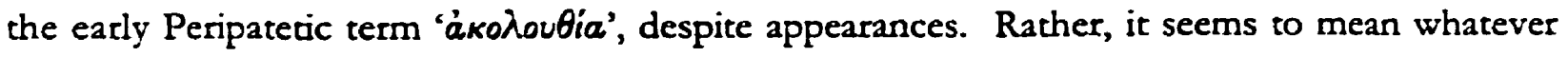
relation powers any given hypothetical syllogism, whether a relation of entailment or of incompatibility.

Consideration of Boethius's first and fourth characterizations of the hypothetical statement uncovers a further discrepancy between the theory that he reported and the original theory of the early Peripatos. In accordance with the first characterization, hypothetical statements express that something is, if something else is; in accordance with the fourth characterization, they express that something is or is not, if something else is or is not. Again, these two characterizarions appear to have originated in the early Peripatetic account of hypothetical statements. ${ }^{37}$ An examination of the way in which Boethius actually divided hypothetical statements, however, suggests that they nonetheless do not play the same role in his account of hypothetical statements as they do in the

38 Ibid., 1.2.5.

39 However, Boethius's use of the logical particle 'if in this context (which he repeated in every case - see ibid., 1.2.1, 1.2.2, 1.2.7, and 1.3.1) is probably less circumspect a formulation than would have satisfied the most careful early Peripaterics. As I discussed in the previous chapter, the eady Peripatetic account of hypothetical statements favors the genitive absolute construction: 'given that something else is (or is not)'. This formulation is suited to the semantic nature of their division of hypothetical statements. All the same, Boethius's 'if is not restrictive, for he certainly allows for a hypothetical statement whose main operator is 'or', as I shall presendy indicate. 
early Peripatetic, if they play any role at all. For, had Boethius been closely following the early Peripatetics, he would have used his first and fourth characterizations as the basis for a semantic division of hypothetical statements, distinguishing statements that express that something is, if something else is, and thus express a relation of entailment, from others that express that something is, if something else is not (or vice versa), and thus express an incompatibility.

In keeping with his omission of the relation of incompatibility from the definition of the hypothesis, however, Boethius did nothing of the sort. Instead, he classified some statements that express an incompatibility together with statements that express a relation of entailment:

For example, when we say 'If it is a human, it is an animal', 'If it is trinary, it is odd', and other statements of this sort, these statements are always set out with a conjunction, for these statements are set out so that if some given thing is, something else follows. And when we say 'If it is a human, it is not a horse', this statement is set out negatively, by contrast, in the same mode in which the above statement was set out affirmatively, for here 'If it is this, it is not that' is said, and so on in this way. ${ }^{+0}$

According to him, then, hypothetical statements "set out negatively", such as "If it is a human, it is not a horse', belong to the same class of hypothetical statement as the statement 'If it is a human, it is an animal' - namely, the conjunctive class. The early Peripatetics, by contrast, understood the former sort of statement as expressing an incompatibility and therefore separative, and the latter sort of statement as expressing a relation of entailment and therefore continuous. Boethius coninued:

Now, there are also hypothetical statements through disjunction, like so: 'Either it is this, or it is that'. This statement must not be seen as the same as the one above, which is expressed as 'If it is this, it is not that', for the latter statement is not through disjunction, but rather through negation. Now, every negation is indeterminate, and for this reason can come to be between contraries, between things mediate to contraries, and between disparates (I call disparates things that are merely different from each other, yet not incompatible on account of any contrariety - for instance, earth, fire, clothing, and so on).

... But, in the case of statements-that are through disjunction, it is necessary that one thing is always claimed to be, as follows: 'Either it is day, or it is night'. ${ }^{+1}$

to Ibid, 1.3.1: "Hae semper cum coniunctionibus proponuntur, ut cum dicimus: 'si bomo est, animal est', 'si ternarius est, impar est', vel caetera huiusmodi. Haec enim ita proponuntur, ut si quodibet illud fuerit, aliud consequatur. Vel cum dicimus: 'si homo est, equus non est', rursus baec eodem modo proponitur in negatione, quo superior in affirmatione proponebatur, hic enim dicitur. 'si hoc est, illud non est'; et ad hunc modem caeterae".

"I Ibid, 1.3.2-3: "Fiunt vero propositiones hypotheticne etiam per disiunctionem ita: 'aut hoc, aut illud est'. Nec eadem videri debet haec propositio quae superior, quae sic enuntiatur. 'si hoc est, illud non est'; haec enim non est per disiunctionem, sed per negationem. Negatio vero omnis infinita est, atque ideo et in contraniis, et in contraciorum medietatibus, et in disparatis fieri potest (disparata autem voco, quae tanturn a se diversa sunt, nulla contrarietate puganatia, veluti tern, ignis, vestis, et caetera). . . . at in ea quae disiunctione fit, alteram semper poni necesse est hoc modo: 'aut dies est, aut nox est"'. 
Boethius's second, disjunctive class of hypothetical statement, then, consists only of those statements that express what Galen had centuries earlier called complete incompatibility (redeia $\mu \dot{a}_{(\gamma)}$ ), which I discussed in the previous chapter. That is to say, Boethius's disjunctive class consists only of statements that concern what can neither simultaneously be the case nor simultaneously not be the case. Statements that express what Galen had in turn called incomplete incompatibility

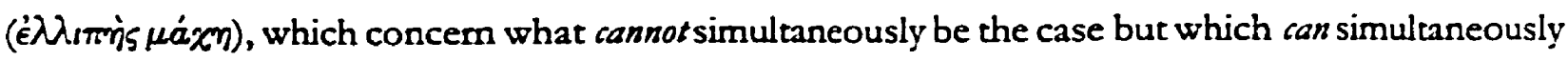
not be the case, instead belong for Boethius to the conjunctive class of statement. They are through negation (per negationem) rather than through disjunction, and are proper to contraries (e.g., white and black), things mediate to contraries (e.g., red and blue), and disparates (e.g., fire and clothing). For the early Peripatetics, by contrast, hypothetical statements expressing incompatibility of any sort, whether complete or incomplete, belong to the same class of separative statement. The type of incompatibility that a statement expresses is irrelevant to the fact that it expresses that one thing is given that another thing is not, or vice versa, and is therefore separative.

Now, the conjunctive and disjunctive classes exhaust between them all hypothetical statements, according to Boethius:

Every hypothetical statement, then, is either through connection (and I assert that the mode that is through negation is also through a connection) or through disjunction, for each of these modes is composed from simple statements. ${ }^{42}$

(His usage both here and elsewhere shows that the two terms 'conjunction (coniunctio)' and 'connection (conexio)' are synonymous in their technical sense.) On Boethius's account, then, just as on the early Peripatetic account, there are only two sorts of hypothetical statement. However, Boethius's two sorts cut across those of the early Peripatetics, as I have demonstrated; more importantly, they do so precisely because Boethius nowhere used his first and fourth characterizations of the hypothetical statement as a semantic basis for a division of hypothetical statements, as the early Peripatetics did. In fact, he did not use them in his division at all.

In his account of the hypothetical statement, then, Boethius deviated from the early Peripatetics both in omitting mention of the relation of incompatibility from his definition of hypothesis, as examination of his third characterization shows, and in omitting the peculiarly Peripateric semantic criteria for dividing hypothetical statements, as examination of his first and fourth characterizations

\$2 Ibid., 1.3.4: "Omnis igitur hypothetica propositio vel per conexionem fit (per conexionem vero illum quoque modurn qui per negationem fit esse pronuntio), vel per disiunctionem; uterque enim modus ex simplicibus propositionibus comparatur". 
show. I contend that these omissions are the direct result of the fact that Boethius had substituted, or followed some source in substituting, Stoic syntacric criteria in place of the Peripateric semantic criteria, according to which hypothetical statements are connective only because 'if' is their main operator, and disjunctive only because 'or' is. In combining a definition of hypothesis and of the hypotherical statement that derives from the early Peripatetics with a division of the hypothetical statement that derives from the Stoics, then, Boethius was indeed party to the conflation of Peripatetic and Stoic theory that I described in the previous chapter. He was following in a Peripatetic tradition that had, by his time, become so infused with elements of Stoic theory that Boethius failed to recognize the original basis for the early Peripatetic account of hypothetical statements.

6. Five aspects of Boethius's account of hypothetical statements and hypothetical syllogisms provide evidence for my contention. Firstly, I submit Boethius's terminology for types of hypothetical statement: 'through connection (per conexionem)' and 'through disjunction (per disiunctionem)' ${ }^{43}$ The terms 'conexum' and 'disiunctum' were standard Latin translations for the properly

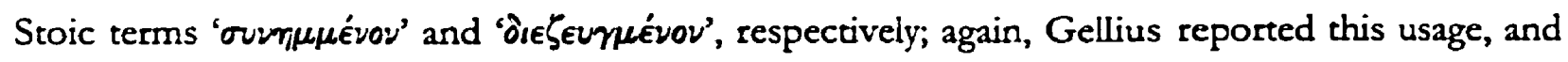
Cicero also employed these terms in this way when discussing the Stoics. ${ }^{4}$ Naturally, these Stoic terms refer to types of proposition that differ from one another on the basis of logical syntax; for the Stoics, a disjoined proposition is one whose main operator is 'or' and a connected proposition is one whose main operator is 'if. Nonetheless, just as Boethius's synonymous usage of 'propositio', 'proloquium', and 'enuntiatio' does not by itself prove that he was under even indirect Stoic influence, neither does his usage here by itself prove the same. As I have indicated, Boethius in all likelihood did not read Stoic or early Peripatetic logical texts, and he may only have been confusing terms already five centuries old. However, a case is building that he was ignorant of the differences between Stoic and early Peripatetic terminology at least in part because he was ignorant of the

13 Boethius's alternative term 'coniunctio' is somewhat strange in this context, for 'coniunctum' was a standard translation

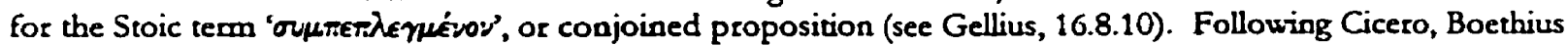
himself used the word to mean 'conjunction' in this sense in his commentary on Cicero's Topics, a point that I shall raise in the next chaprez. 'Coniunctio' could also mean 'connective' in the grammatical sense. I know of no other author who used 'coniunctio' as a technical term for a conditional sentence; however, both Cicero and Augustine used it for complex or molecular sentences in general - see Cicero, De orat., 2.38.158; A ugustine, De dial., p. 84.

+ Gellius, 16.8.9; Cicero, De fat., 6.11-8.16, passim. Cicero used 'conexum' and 'quod conectitur' in this way when discussing Chrysippus's response to Diodorus Cronus's Mlnster Argument; he also used 'disiunctio' in a list of seven modes of argument that derives from the Stoic indemonstrables - see his Top., 14.56. 
differences between Stoic and early Peripatetic logic.

Secondly, and more strongly, I submit Boethius's further division of connective hypothetical statements into four modes, according to the combinations of their component categorical statements. I have already indicated that the hypothetical statement through negation, such as 'If it is a human, it is not a horse', falls under the class of connective statements on Boethius's view. In fact, he construed every possible combination of affirmative and negative statements with the operator 'if' as a connective statement:

Because every simple statement is either affirmative or negative, hypothetical statements can be made in four modes through connection: either from two affirmatives, or from two negatives, or from an affirmative and a negarive, or from a negative and an affimative. ${ }^{45}$

For Boethius, then, the hypothetical statement through negation is merely one of four modes proper to the connecrive hypothetical statement. Now, on the early Peripatetic account, two of these other modes, those from two affirmatives and two negatives, express a relation of entailment; the final mode, from a negative and an aftirmative, expresses an incompatibility. However, the incompatibility that it expresses is different from the one proper to the hypothetical statement through negation. In the latter case, the incompatibility can be incomplete; 'If it is a human, it is not a horse' relates two predicate terms that can simultaneously fail to apply to one and the same subject. In the former case, on the other hand, the incompatibility must be complete; 'If it is not $A$, it is B' holds only if $A$ and $B$ can neither simultaneously apply to one and the same subject nor simultaneously fail to apply. The only pairs of predicates of which one must apply if the other does not apply are pairs of immediate contraries or contradictories, such as day and night, or human and not-human. Mediate contracies such as white and black, things mediate to contraries such as red and blue, disparates such as fire and clothing, and things that stand in a relation of entailment such as human and animal, are all unsuitable.

However, as I indicated just above in the course of discussing Boethius's division of hypothetical statements, Boethius differentiated between the statement through negation and the disjunctive statement exactly on the grounds that the disjunctive statement must express complete incompatibility. Indeed, this distinction between statements that express complete incompatibility and those that do not might have seemed at first glance to be the very criterion for his division of

$\$ 5$ Boethius, De byp. 5.L, 1.3.5: "quoniam omnis simplex propositio vel affirmativa est vel negativa, quatuor modis per conexionem fiet hypotheticae propositiones possunt, aut enim ex duabus affirmativis, aut ex duabus negativis, aut ex affirmativa et negativa, aut ex negativa et affimaniva". 
hypothetical statements into the disjunctive and the connective. Yet, because connective statements of the form 'If it is not $A$, it is B' express complete incomparibility, it follows that Boethius did not employ this criterion, despite appearances. Now, stricty-speaking, Boethius did not explicity claim that connective statements cannot express complete incompatibility; he merely claimed that disjunctive statements must. Hence, the fact that Boethius countenanced connective statements of the form 'If it is not $A$, it is B' technically does not constitute any violation of his own rule. Nonetheless, it does follow that his criteria for dividing hypothetical statements into the connective and the disjunctive must be syntactic, since the two sorts of statement differ from one another in no other relevant way. On Boethius's account, then, a hypothetical statement is connecrive just because its main operator is 'if, and disjuncrive just because its main operator is 'or'. Boethius had indeed conflated Peripateric and Stoic theory. ${ }^{26}$

A third piece of evidence for my contention is a syntactic restriction that Boethius placed on the formulation of hypothetical statements through negation:

In the case of statements that are through disjunction, it is necessary that one thing is always claimed to be, as follows: 'Either it is day, or it is night'. However, if we transfer to the disjunction everything that is properly said through negation, the rule does not turn out to be the case. For, what if someone were to say: 'Either it is white or black', 'Either it is white or red', 'Either it is a discipline or a human'? For it can turn out that it is none of these things. ${ }^{47}$

In effect, Boethius did not allow the hypothetical statement through negation to take 'or' as its main operator. His explanation for this restriction is precisely that a statement such as 'Either it is white or black' would thereby count as a disjunctive statement, but for the rule that disjunctive statements must concern things that are completely incompatible. Since the colors white and black stand instead in the relation of incomplete incompatibility, the only sense in which 'Either it is white or black' would count as a disjunctive statement is syntactic - that is, simply because its main operator is 'or'. Hence, in general, a hypothetical statement is disjunctive on Boethius's account if and only'

to Miklós Maróth took Boethius's fourfold division of the connective statement as evidence that early Peripatetics such as Theophrastus had done the same, on the erroneous grounds that it accords completely with Galen's definition of the hypothetical statement. As I showed in the previous chapter, according to this eady Peripateric definition, a continuous statement expresses only that something is given that something else is. A statement that expresses that something is not given that something is (or vice versa) belongs rather to the separative class of hypotherical statement. Thus, despite having Galen's early Peripateric definition to hand, Maróth followed Boethius in conflating Peripatetic and Stoic theory - see his Ibn Sina und die Peripatetiscbe .Aussagenlogik", pp. 39-40.

"Boethius, De byp. 5y, 1.3.3: "in ea quae disiunctione fit, alteram semper poni necesse est boc modo: 'aut dies est, aut nox est'; quod si cuncta ea quae per negationem dici convenit ad disiuncrionem transferamus, ratio non procedit. Quid enim si quis dicat 'aut album est, aut nigrum', 'aut album est, aut rubrum', 'aut disciplina est, aut homo'? fien enim potest ut nihil horum sit". 
if its main operator is 'or'. The rule that it concerns only things standing in the relation of complete incompatibility yet holds, but is secondary.

Now, this account of the disjunctive statement is the same as the canonical Stoic definition of the disjoined proposition. ${ }^{*}$ It is objectionable on the early Peripatetic account of hypothetical statements not only because the early Peripatetics considered any statement expressing incomparibility, whether complete or incomplete, to belong to one and the same separative class of hypothetical statement, but also because it picks out a class of statement according to logical syntax. For the early Peripatetics, however, a statement is separative because it expresses that something is not given that something else is (or vice versa), even if its main operator is not 'or'. Thus, Boethius, or someone before him, unwittingly substituted the canonical Stoic account of disjoined propositions for the canonical eariy Peripatetic account of separative statements, conflating the two. "7

The manner in which Boethius's conflation of early Peripateric and Stoic theory transfers from his account of hypotherical statements to his account of hypothetical syllogisms is a fourth piece of evidence for my contention. Boethius divided hypothetical syllogisms into the connective and the disjunctive in respect of the type of hypothetical statement that serves as major premiss. Since hypothetical statements divide on a syntactic basis, it follows that hypothetical syllogisms divide on a syntactic basis as well. The syllogisms that Boethius constructed from the connective statement 'If it is not $A$, it is $B$ ', which expresses complete incompatibility, provide an illustration. After noting that one valid syllogism from this statement is 'If it is not $A$, it is $B$; but, it is not $A$; therefore, it is B', Boethius explained:

However, if you turn it around and assume that B is - that is, the consequent - it will not be necessary that it either is or is not what is antecedent. But an example of this case cannot be found because of the fact that, if the statement is set out like so: When it is not $A$, it is $B^{\prime}$, nothing seems be mediate between $A$ and $B$. Rather, in these cases, if it will not have been the one, it is immediately necessary that it is the other; and if it will have been the other, it is immediately necessary that it is not the one. ${ }^{50}$

See, for example, Sextus, Pyr. inst., 2.191; Diocles, apud Diogenes, 7.72; Gellius, 16.8.12-14. See also Frede, Die stoische Logik, p. 95-96.

39 I have pointed out in the previous chapter that the logicians in the circle of Ammonius differentiated between the syllogism from the negated conjunction and the disjoined syllogisms on the ground that the disjoined syllogism is suitable only for immediate contraries and contradictories. Perhaps they, too, are following whomever subsrituted the Stoic account of the disjoined proposition for the Peripateric account of the separative statement.

so Boethius, De byp. gh, 2.2.3-4: "quod si convertas et sumas esse b, id est quod sequitur, non necesse erit vel esse vel non esse id quod praecedit. Sed huius exemplum non potest inveniri, eo quod si ita proponitur, ut 'cum non sit a sit b', nihil esse medium videatur inter a atque b; sed in his si alterum non fuerit, statim necesse est esse alterum, et si alterum fuerit, statim alterum non esse necesse est". 
Boethius, in other words, could not find a counter-example to invalidate the inference 'If it is not $A$, it is $B$; but, it is $B$; therefore, it is not $A$ '. He had the same difficulty with the inference 'If it is not $A$, it is $B$; but, it is $A$; therefore, it is not $B$ '. In consequence, Boethius admitted that there were four valid syllogisms from the connecrive statement 'If it is not $A$, it is B': rather than the expected two corresponding to modus ponens and modus tollens, there is also one from the affirmation of the consequent and one from the denial of the antecedent. ${ }^{51}$ Now, Boethius had earlier undertaken to prove that affirming the consequent and denying the antecedent are, in general, invalid inferential moves; nevertheless, he made a special exception for syllogisms from the statement 'If it is not $A$, it is $B^{3}{ }^{52}$ The reason for Boethius's difficulry, however, is precisely that this statement expresses complete incompatibility like a disjunctive statement, so that it may never be the case that something is neither A nor B. Its syllogisms are thus similar to those from a disjunctive statement, as even Boethius himself noted. ${ }^{53}$ Yet, Boethius's willingness to allow for a special case, instead of classifying 'If it is not $A$, it is B' and its four syllogisms as disjunctive despite the operator 'if, confirms that his criteria for dividing hypotherical syllogisms are purely syntactic.

As a fifth and final piece of evidene for my contention, I submit Boethius's treatment of the disjunctive hypotherical syllogism. ${ }^{54}$ As I mentioned just above, Boethius was aware of the similarity between the connective statement 'If it is not $A$, it is $B$ ' and the disjunctive statement. In fact, this similarity formed the very foundation of his treatment of disjunctive syllogisms. He wrote:

The syllogisms that are posed in disjunction take their modes and forms from, and seem to be connected to, the syllogisms that are posed in connection and that we said above are made from those statements that are composed of two simple statements. Thus, if I will have demonstrated the similarity of statements that are set out in disjunction to those that are set out in connection and are composed of simples, it is necessary that there are also as many modes and sorts of conclusions in those statements that are expressed through disjunction and that are shown to have the same force of connection, as there are in each of those statements that are made through connection. ${ }^{55}$

Boethius's plan is clear: a demonstration that disjunctive statements have the same force (vis) as

51 Ibid, 2.3.4 and 6 .

52 Ibid, 1.4.3-6.

53 Ibid, 2.2.5.

it Ibid, 3.10.3-11.5.

${ }^{35} \mathrm{Ibid}, 3.10 .3$ : "Hi vero qui in disiunctione sunt positi illis videntur adiuncti, eorumque modos formasque suscipiuntm quos superius in conexione positos ex his propositionibus ficri diximus quae duabus simplicibus iungerentur. Si igitur in disiunctione propositarum propositionum ad eas similitudinem demonstraverim quae in conexione positae ex simplicibus copulatae sunt, quot modi qualesque conclusiones sunt in unaquaque illarum quae per conexionem fiunt propositionum, tot etiam in his esse necesse est quac per disiunctionem pronuntiatae eamdem vim conexioni babere monstrantur". 
certain connective statements is a demonstration that disjunctive syllogisms reiterate certain connective syllogisms and are thus the same in number and kind. He implemented this plan by first noting that, just as in the case of the connective statement, there are also four types of disjuncrive statement corresponding to the various combinations of affirmative and negative categorical statements. He then paired every type of disjunctive statement with the type of connective statement that has the same force, as follows:

'Either it is $A$, or it is $B$ ' has the same force as 'If it is not $A$, it is $B$ '

'Either it is not $A$, or it is not $B$ ' has the same force as 'If it is $A$, it is not $B$ '

'Either it is $A$, or it is not B' has the same force as 'If it is not $A$, it is not B'

'Either it is not A, or it is B' has the same force as 'If it is A, it is B'.

Boethius then showed that the inferential moves from each statement in a given pair are the same, so that, for example, the same four syllogisms arise from each statement in the first pair, as follows:

Either it is A, or it is B / If it is not A, it is B; but, it is not A; therefore, it is B'

'Either it is $A$, or it is B / If it is not A, it is B; but, it is not $B$; therefore, it is $A$ '

'Either it is $A$, or it is B / If it is not A, it is B; bue, it is $A$; therefore, it is not B'

'Either it is $A$, or it is $B$ / If it is not $A$, it is $B$; but, it is $B$; therefore, it is not $A$ '.

By parity of reasoning, the same holds for the other pairs.

Two features of this treatment are important to my contention. Firstly, the equivalence of force between the four types of disjunctive statement and the four types of connective statement constitutes a violarion of Boethius's own rule that disjunctive statements must express complete incompatibility, for connective statements need not. Boethius, however, appears not to have noticed. He explicitly wrote of the disjunctive statement 'Either it is not $A$, or it is not B' that it concerns things that cannot simultaneously be the case even if it is not necessary that one of them is in fact the case - that is, that it expresses incomplete incompatibility. He also wrote of the statements 'Either it is A, or it is not B' and 'Either it is not A, or it is B' that they concern things that "hang on (adbaerere)" each other - that is, that they express a relation of entailment. ${ }^{56}$ In keeping with these readings, Boethius proposed the statements 'Either it is not white or it is not black', 'Either it is an animal or it is not a human', and 'Either it is not a human or it is an animal' as examples of disjunctive statements, none of which expresses complete incompatibility. ${ }^{57}$ Thus, if the fact that some connective statements can express complete incompatibility scuttes any distinction between connection and disjunction on a purely semantic basis, then the fact that some

so Ibid., 3.10.7, 3.11.2, and 3.11.4.

57 Ibid, 3.11.2, 4, and 5 . 
disjunctive statements can fail to express complete incompatibility makes very clear that the criterial distinction between them is syntactic. Moreover, as I have mentioned, the requirement that a disjunction express orly complete incomparibility - that is to say, that 'or' means just this very relation of complete incompatibility - is canonically Stoic. Boethius's example disjunctive statements, then, are not acceptable Stoic disjoined propositions. At the same time, however, they are acceptable Peripatetic hypothetical statements. The latter two express relations of entailment and are thus continuous, for something is an animal given that it is a human, while the first expresses an incomplete incompatibility and is thus separative, for something is not black (or white) given that it is white (or black). In so violating the Stoic account of disjunction that he himself had adopted, Boethius not only appears to have been unaware of the tension between Peripatetic and Stoic logical theory, he also demonstrated his ignorance of and distance from both. ${ }^{58}$

The second important feature of Boethius's treatment of disjunctive hypothetical syllogisms is that he even treated them as an independent sort of syllogism. No early Peripateric would have done so, for in the context of the early Peripateric semantic division of hypothetical syllogisms, the fact that Boethius's disjunctive syllogisms in a sense reiterate his connective syllogisms makes them needless. On the early Peripatetic account, the significant distinction is not between Boethius's connective and disjunctive syllogisms, but rather between those connective and disjunctive syllogisms that turn on a relation of entailment, and those that turn on an incompatibility. To have a set of connective syllogisms that take their inferential force from both a relation of entailment and incompatibility and a set of disjunctive syllogisms that do exactly the same is simply redundant. On Boethius's account, however, there is no such redundancy to the disjunctive syllogisms, for his division between connective and disjunctive syllogisms is wholly syntactic: a syllogism is connective if and only if the main operator in its major premiss is 'if; a syllogism is disjunctive if and only if the main operator in its major premiss is 'or'. Thus, despite the fact that it is not possible to deduce, by means of a disjunctive syllogism, any conclusion that is also not deducible by means of a connective syllogism, the disjunctive syllogism and the connective syllogism are nevertheless distinct. In this way, then, Boethius's hypothetical syllogistic is far from its early Peripatetic origins, for Boethius's syntactic division of hypothetical statements led him to a division of hypothetical

58 Immediately after presenting this account of disjunctive syllogisms, which explicitly requires some disjunctive statements to fail to express any incompatibility at all, Boethius reasserted part of his restriction on such statements, writing that they concern things that cannot simultaneously be the case (see ibid., 3.11.6-7). I have no charitable interpretation of this passage. 
syllogisms that had no place in the logic of the early Peripatos.

7. On the basis of these five pieces of evidence, I conclude that the discrepancies between the hypothetical syllogistic of the early Peripatos and that of Boethius's On bypotbetical syllogisms are indeed due to a conflation of Peripatetic and Stoic theory. In adopting a Stoic-like division of hypothetical statements, according to which the difference between the disjunctive statement and the connective statement is a matter of logical syntax, Boethius developed an account of hypothetical statements that deviated sharply from that of the early Peripatetics, for whose own division logical syntax was not crucial. Thus, he was able to classify statements such as 'If it is $A$, it is not B', which the early Peripatetics had understood as expressing incompatibility and thus separative, together with statements such as 'If it is A, it is B', which the early Peripatetics had understood as expressing a relation of entailment and thus continuous - and vice versa Moreover, this exclusive reliance on syntactic criteria for dividing hypotherical statements led Boethius to misunderstand the early Peripateric account of the hypothesis, which he claimed to report faith fully. He omitted the relation of incompatibility from his own account of the hypothesis, and he asserted that a hypothesis is a relation of consequence (consequentia) that is expressible in both a connection and a disjunction because, for him, connective statements duplicate disjunctive statements in respect of what they express. The early Peripatetic distinction between a relation of entailment and an incompatibility thus lost any significance in Boethius's hypothetical syllogistic, leaving him - or perhaps one of his sources - with no reason to make a point of it in a definition of the hypothesis.

The proofs that Boethius provided to demonstrate that affirming the consequent and denying the antecedent are invalid inferential moves support and extend this point. These proofs, which caused Boethius some difficulty in relation to syllogisms from the connective statement 'If it is not $A$, it is B', show that Boethius not only imported Stoic criteria for dividing hypotherical statements and syllogisms into a Peripatetic context, but also that he was unaware of even broader differences between the two logics. For Boethius seems to have thought of his proofs as perfectly general:

From these things, then, I judge that it has been demonstrated that, in the case of the conjoined hypothetical statement, if it is the first it follows that it is the second; if it is not the second, it follows that it is not the first. But, if it is not the first, it does not follow that it is or is not the second. It is also clear that, if it is the second, it does not follow that it is or is not the first. ${ }^{59}$

59 Ibid, 1.4.5-6: "Ex his igitur demonstratum esse arbitror, in coniuncta hypothetica propositione, si sit paimum 
Now, Boethius was in one sense correct. So long as the numerical variables 'first' and 'second' stand, in Stoic fashion, for whole sentences, affirming the consequent and denying the antecedent are invalid inferential moves. That is to say, no matter what the content of the sentences ' $p$ ' and ' $q$ ', the inferences 'If $p$, then $q$; but, $q$; therefore, $p$ ' and 'If $p$, then $q$; but, not-p; therefore, not- $q$ ' are simply invalid.

For the purposes to which Boethius put his proofs, however, they are not perfectly general, as he discovered in respect of syllogisms from 'If it is not $A$, it is $B$ '. In the passage above, I have translated 'est primum' and 'est secundum' as 'it is the first' and 'it is the second' rather than 'the first is' and 'the second is' because, as I have discussed, the manner of Boethius's regular use of Peripatetic alphabetical variables for predicate terms shows that his hypothetical syllogistic is not a logic for sentences. Indeed, he could not have sensibly accepted the validity of the syllogisms 'If it is not $A$, it is $B$; but, it is $B$; therefore, it is not $A^{\prime}$ and 'If it is not $A$, it is B; but, it is $A$; therefore, it is not B' if he had used ' $A$ ' and ' $B$ ' as sentential variables. So long as Boethius allowed for three further forms of the connecrive statement besides 'If it is $A$, it is $B$ ', then, he was obliged to provide three more sets of proofs to demonstrate the general invalidity of affirming the consequent and denying the antecedent - that is, invalidity in respect of all types of connective statement encompassing all combinations of affirmative and negative categorical statements. In other words, so long as the numerical variables 'first' and 'second' in Boethius's proofs stand, in Peripateric fashion, for predicate terms, three more sets of proofs are necessary. Hence, Boethius's failure to provide the necessary three additional proofs (which is impossible in any case, given the complete incompatibility of 'If it is not $A$, it is $B$ ') resulted from his failure to see the difference between a Peripatetic logic for terms and a Stoic logic for propositions. His uncharacteristic use of Stoic numerical variables in the proofs that he did provide supports this conclusion, for it suggests that either Boethius or one of his sources took proofs of Stoic origin regarding the invalidity of affirming the consequent and denying the antecedent and applied them in a Peripateric context in which they do not belong.

All the same, Boethius was aware of some of the tension in his account, for he tried to justify the deviant syllogisms from 'If it is not A, it is B' by claiming that they are yet invalid in some sense. ${ }^{6 n}$ The manner of his justification, however, is in keeping with his unconscious confusion of

consequi ut sit secundum; si non sit secundum, consequi ut non sit primum; si vero sit primum, non consequi ut sit vel non sit secundum. Nam et illud apparet, si sit secundum non consequi ut sit vel non sit primum".

${ }^{\infty}$ Ibid, 2.2.4 and 2.3.6. 
Peripateric and Stoic logic. Boethius qualified his admission of the syllogism from the affirmation of the consequent by claiming that it was valid as far as concerns the nature of things (natura rerum), but not as far as concerns the hypothesis of the statement (conditio propositionis). In reiterating this qualification a few sentences later, he recast his distinction, claiming that the syllogism was not valid as far as concerns the combination of the statements (complexio propositionum). Later still, when admitting the syllogism from the denial of the antecedent, he recast the distinction a third time, claiming that the syllogism was valid as far as concerns the terms (termini), but not as far as concerns the nature or form of the combination (natura or figura complexionis). In each case, he supported his claims by pointing out that, in the case of the statements ' $I f$ it is $A$, it is B' and 'If it is $A$, it is not B', neither affirming the consequent nor denying the antecedent are valid inferential moves. In the remainder of his discussion of these hypothetical syllogisms, as well as others like them (such as from 'If it is not $A$, then, when it is $B$, it is $C$ ), he preferred to point to a distinction between terms and combination.

The distinction that Boethius wanted to make in these special cases clearly concerns, in some way, the distinction between the structure of the statement 'If it is not $A$, it is $B$ ', which is similar to the structures of other connective statements, and its terms, which are different. That is to say, the distinction turns on the fact that, insofar as the statement 'If it is not $A$, it is $B$ ' has the sentential structure 'If $\mathrm{p}$, then $\mathrm{q}$ ', it is similar to other connective statements, and insofar as the only terms that make it true stand in relationships of complete incompatibility, it is different. Taken merely as a conditional sentence without regard for the terms, then, it does not support inferences from the affirmation of its consequent and the denial of its antecedent, as Boethius had expected from the proofs that he had given earlier, taken merely as a statement that expresses complete incompatibility between its terms, it does. Thus, even Boethius's attempt to justify the deviant syllogisms from 'If it is not $A$, it is $B^{\prime}$ rests on confusing a logic for sentences with a logic for terms, for the relationships in which terms may stand support entailments that are invalid in a logic for sentences. Had Boethius simply classified the statement 'If it is not $A$, it is $B$ ' as disjunctive on semantic grounds like an early Peripatetic, or like a Stoic coupled his syntacric criteria with a sentential logic on which the deviant syllogisms are simply invalid, he would have needed no justification.

Indeed, the fact that he first formulated his justification as a distinction between the hypothesis of the statement (conditio propositionis) and the nature of things (natura renom) is especially telling. For the early Peripatetics, a statement is hypothetical because of what it expresses, either a relation of 
entailment or an incompatibility. In his justification, by contrast, Boethius related the idea of the hypothesis to a statement's structure or logical syntax, and thus to the statement's main operator, irrespective of a relation of entailment or an incompatibility. Thus, not only did Boethius conflate early Peripatetic hypothetical syllogistic with Stoic logic, he also gave little indication that he was aware that there had ever been any difference between them.

8. The single most extensive account of hypothetical syllogistic to have survived from ciassical antiquity, then, is an unwitting and problematic confusion of Peripatetic and Stoic logic. In this respect, it is similar to that of Boethius's Greek contemporaries in the circle of Ammonius, whose lists of hypothetical syllogism I discussed in the previous chapter, and who also seem to have had little idea of the differences between Peripateric hypothetical syllogistic and the Stoic indemonstrables. Yet, Boethius also went on to discuss hypothetical syllogistic again, in his commentary on Cicero's Topics. There, he wrotc:

We have analyzed all the hypothetical syllogisms . . fully and copiously in the books that we have composed chiefly about their basics, from which the reader who has leisure-time to open them will receive full and complete instruction. However, since we have now undertaken to explain Cicero's Topics, and since Cicero mentions some of their modes in this work, I think that I must discuss these seven hypothetical syllogisms briefly, and what their nature and the arrangement of their statements is. ${ }^{61}$

Boethius, then, seems to have thought of the shorter exposition of hypothetical syllogisms in his commentary as merely an extract from, or abridgement of, his On bypothetical syllogisms Whether this shorter exposition also shows evidence of the conflation of Peripatetic and Stoic theory that appears in the monograph is a question to which I shall turn in the next chapter.

o1 Boethius, In Cic. Top., 1129C-D: "De omnibus quidem hypotheticis syllogisimis ... plene abundanterque digessimus in his libris, quos de eorum principaliter insicutione conscripsimus, a quibus integram perfectamque doctrinam, cui resolvendi illa vacuum tempus est, lector accipiet. Sed quia nunc Ciceronis Topica sumpsimus exponenda, atque in his aliquorum M. Tullius modorum meminit, dicendum mihi breviter existimo de bis seprem conditionalibus syllogismis, qux eorum natura sit, propositionumque contextio". 


\section{Boethius: On Cicero's Topics}

1. On 28 july of the year 44 BC, Cicero sent to his friend Gaius Trebatius Testa a copy of a work that he called "the Aristotelian topics", which he had begun only about a week beforehand. 'As his name for it implies, he devoted the work to techniques for dialectical argumentation such as Aristotle had discussed in his Topics. ${ }^{2}$ In the dedication, Cicero reminded Testa that he had composed it at his friend's repeated requests, for Testa had once happened upon a copy of Aristotle's Topics on the shelves of Cicero's personal library and, after finding Aristotle's writing obscure, desired an introduction to help him understand it. ${ }^{3}$ It was not yet five months since the assassination of Julius Caesar, and about one and one-half years before Cicero's own execution. It was also over three centuries since Aristotle had written the treatise that had interested Testa.

Cicero also explained in the dedication that he had composed the introduction while on a journey by sea from Italy to Greece, and thus had not had the benefit of consulting either Aristodle's treatise or any other books." As a result, he had had to work from memory. Perhaps these conditions explain why Cicero's self-described Aristotelian work includes, under the topic from consequents, antecedents, and incompatibles (locus ex consequentibus et antecedentibus et repugnantibu), a list of seven argument schemata that not only do not appear as such in Aristotle's Topics, but also very plainly derive from the five Stoic indemonstrables. ${ }^{5}$ However, as is clear from Cicero's full exposition, his "Aristotelian topics" is really neither an introduction to, nor a commentary on, Aristotle's treatise. Cicero's topics do not always correspond to Aristotle's, and his account, which is more a list of topics with examples than a theoretical treatment of the subject, generally lacks the philosophical character of Aristotle's. Cicero's work is instead a practical introduction to the subject, in the form of a compilation of techniques for generating arguments useful in a public setting, such as the courts in which he and Testa practiced law. Moreover, in On the orator, Cicero

'Cicero, Adfam., 7.19.

2 Ibid., 7.20 .

3 Cicero, Top., 1-5.

4 Ibid, 5.

5 Ibid, 53-57. 
had briefly presented virtually the same list of topics as he would recount from memory for Testa eleven years later, in the same order and under the same divisions. ${ }^{6}$ Now, Cicero had written $O_{n}$ the orator during a period that he spent party at his Tusculan villa, where Testa found Aristode's treatise on the shelves. ${ }^{7}$ Cicero's memory in fact did not serve him badly; rather, he treated the topics differently than Aristotle had.

It seems that the circumstances of the three centuries since Aristotle had written his Topics had obscured knowledge of his doctrine to some extent. When Testa asked Cicero to compose an introduction for him, Cicero had replied:

I urged either that you read them yourself, or that you learn the whole theory from a certain very learned orator. As I heard from you, you had tried both. However, the books' obscurity put you off them, and that great orator replied that he did not know these works, which are, as I think, Aristotelian. I am indeed not in the least surprised that this philosopher is unknown to the orator; he is unknown to the philosophers themselves, except to a very few. ${ }^{8}$

Cicero lived, in fact, during the only period in Western intellectual history since Aristotle's death when Aristotle was not pre-eminent among philosophers. The revival of Peripatetic philosophy that would soon begin would not reach its apex until Alexander composed his commentaries around the turn of the third century AD, over five centuries after Aristotle's lifetime and two after Cicero's. Moreover, the Stoics had come to dominate philosophy - and especially logic - during much of those intervening five centuries. The appearance of a list of Stoic argument schemata in Cicero's self-described Aristotelian work, then, may be an early predecessor to the more pervasive conflation of Peripatetic and Stoic theory in the logical commentaries of the neo-Peripatetics, which I discussed in regard to hypotherical syllogistic in my second chapter. Aristotle's and Theophrastus's logic had been somewhat forgotten since their deaths, and the obscure style of the Aristotelian texts that had survived made regaining these doctrines difficult. Stoic logic could easily have confused the issues further, or at least demanded explanation in relation to Peripateric logic. As I have indicated before, in his own commentary on Aristotle's Topics, Alexander explained some topics as "fitting" the Stoic indemonstrables.

- Cicero, De orat., 162-173.

7 Cicero, Ad Atric., 4.13; Ad fam., 1.9.23.

8 Cicero, Top., 2-3: "vel ut cos per te ipse legeres vel ut totam rationem a doctissimo quodam thetore acciperes, hortatus essem, utrumque, ut ex te audiebam, es expertus. Sed a libris te obscuritas reiecit; thetor autem ille magnus haec, ut opinor, Aristotelia se ignorare respondit. Quod quidern minime sum admiratus eum philosophum rhetori non esse cognitum, qui ab ipsis philosophis praeter admodum paucos ignoretur". 
Even later, over eight centuries after the time when Aristode wrote on the topics and over five after Cicero did, Boethius took up Cicero's text as a subject for commentary itself. In the course of his commentary, Boethius took Cicero's brief mention of the seven argument schemata as an opportunity to discuss hypothetical syllogistic:

Since we have now undertaken to explain Cicero's Topics, and Cicero mentions some of their modes in it, I think that I must discuss these seven hypothetical syllogisms briefly, and what the nature and arrangement of their statements is.'

Construing Cicero's seven schemata as modes of hypothetical syllogism is novel; Cicero himself had not called them by this name. Boethius's easy transition from a commentary on a work about the topics to a discussion of hypothetical syllogistic, on the basis of schemata that resemble the Stoic indemonstrables, is a mark of how much he conflated Peripatetic and Stoic logical theory. I have given a more detailed account of some of this contlation in the previous chapter, in which I focused on Boethius's full exposition of hypothetical syllogistic, On bypothetical syllogisms In this chapter, I shall turn to the shorter treatment of hypothetical syllogistic in his commentary on Cicero's Topics. In this work as well, Boethius demonstrated that the conflacion of Peripatetic and Stoic theory that may have begun as early as Cicero's time, and was certainly noticeable by Alexander's, had transformed early Peripateric hypotherical syllogistic into something quite different from its original form.

2. Cicero's account of the topic from consequents, antecedents, and incompatibles has a threefold treatment, as its name suggests. For, as Cicero wrote, it is possible to draw the same conclusion in a particular case in three ways; for instance, it is possible to conclude in three ways that a woman to whom someone has bequeathed all the silver therefore has as a bequest the coin, as follows:

'If the coin is silver, it has been bequeathed to the woman; but, the coin is silver; therefore, it has been bequeathed', or in this way: 'Tf the coin has not been bequeathed, the coin is not silver; but, the coin is silver; therefore, it has been bequeathed', or, in this way: Not both has the silver been bequeathed and the coin not been bequeathed; but, the silver has been bequeathed; therefore, the coin has been bequeathed'. ${ }^{10}$

? Boethius, In Cic. Top., 1129C-D: "quiz nunc Ciceronis Topica sumpsimus exponenda, atque in his aliquorum ML Tullius modorum meminit, dicendum mihi breviter existimo de his septem conditionalibus syllogismis, qux eorum natura sit, propositionumque contextio".

${ }^{10}$ Cicero, Top., 53-54: "Si pecunia signata argentum est, legata est mulieri. Est autem pecunia signata argentum. Legata igiur est; an illo modo: Si numerata pecunia non est legata, non est numerata pecunia argentum. Est autem numerata pecunia argentum; legata igitur est; an illo modo: Non et legatum argentum est et non est legata numerata pecunia. 
However, had Cicero been closely following Aristotle's Topics, he would not have classified all of these forms of argument together under one topical heading. Setring aside the fact that Cicero's examples turn on contingent relationships between sentences, whereas Aristodle's theory of the topics turns on necessary relationships between predicates, Aristotle considered only the first two forms of argument as belonging to a single topic, by which one exploits the necessary connecion of things." The third form of argument, by contrast, belongs to a different topic, from the contrariety of things. ${ }^{12}$ Now, Cicero was aware of the distinction between the third mode and the first and second, for he noted that what is consequent upon something is necessarily connected with it, and what is incompatible with something can never be connected with it. ${ }^{13}$ Presumably, as Cicero's treatment implies, the third mode is from incompatibility while the first two are not. Yet, Cicero's purpose in enumerating the topics in this way was a more practical one; as he implied, it makes no difference to his classification (as it also would not to a court of law, he might have added) how many logical permutations there are by which one can reach the same conclusion using the same assumptions said in different ways.

Cicero also revealed a further reason why someone might classify these three forms of argument together:

Now, the logicians call this way of concluding an argument - in which, when you have additionally assumed the first part, what is connected follow's - the first mode of inference. When you deny what is connected, so that what will have been connected with it must also be denied, it is called the second mode of inferring. And when you deny that certain things are conjoined and assume one or more of them, so that what remains must be rejected, it is called the third mode of inference. ${ }^{14}$

According to the logicians, then, these three forms all belong to the same list of "modes of inference (modi conclusionis)" or "modes of inferring (modi concludendi)". These logicians, whoever they are

Legatum autem argentum est; legata igitur numerata pecunia est".

"For the non-sentential character of the topics, see Aristode, Top., $101 \mathrm{bl} 1 \mathrm{ff}$; for the topic from necessary connection of things, see ibid, 111b17-23. Nore, however, that . Aristode did not require the use of any sentential operators in formulating topical arguments - see my discussion in the first chapter.

12 Ibid, 113a20-32. Cicero's example in fact belongs to the topic exploiving the connecrion of things, since it really trades on the connection between the bequest of the silver and the bequest of the coin. His aplanation of this mode, however, which I cite below, shows that it can also belong to the topic exploiting the contranietry of things, such as in the case of 'Not both is Cicero a human and a stone; but, Cicero is a buman; therefore, Cicero is not a stone'. This dual character of Cicero's third mode caused Boethius some difficulty, as I shall discuss below.

${ }^{13}$ Cicero, Top., 53.

is Cicero, Top., 53-54: "Appellant autem dialectici eam conclusionem argumenti, in qua, cum primum assurnpseris, consequitur id quod annexum est primum conclusionis modum; cum id quod annexum est negaris, ut id quoque cui fuerit annexum negandum sit, secundus is appellatur concludendi modus; cum autem aliqua coniuncta negaris et ex eis unum aut plura sumpseris, ut quod relinquitur tollendum sit, is tertius appellatur conclusionis modus". 
exactly, are following the Stoics in this regard; these three modes of inference correspond to the first three Stoic indemonstrables, in the proper order and formulated with the proper logical operators. Indeed, in own example of the third mode, Cicero even obeyed the Stoic injunction that the negative particle of a negated conjunction should precede the encire conjunction, so as to clearly indicate that the whole proposition carries the denial, and not merely one of its parts. ${ }^{15}$ Another reason why someone might classify these three modes of inference together, then, is that the Stoics had done so.

Further evidence that Cicero came under the influence of Stoic logic in his treatment of this topic are the other forms of argument that he classified together with the above three:

There are many other remaining modes that belong to the logicians, which consist in disjunctions: 'Either this or that; but, this; therefore, not that'; likewise: 'Either this or that; but, not this; therefore, that'. These inferences are valid for the reason that, in a disjunction, more than one part cannot be true. And of the inferences that I have written above, the former is called the fourth mode by the logicians, and the latter the fifth.

Next, they add the negation of conjunctions, as follows: Not both this and that; but, this; therefore, not that'. This mode is the sixth, and the seventh is Not both this and that; but, not this; therefore, that'.

From these modes, countless inferences arise, in which is nearly all òraheкtı $\dot{\eta}^{16}$

Cicero here provided the remaining two Stoic indemonstrables, as well as two other inference schemata. Again he formulated the indemonstrables with the proper logical operator and in the proper order. He also added the peculiarly Stoic claim that all logic or logical argumentation

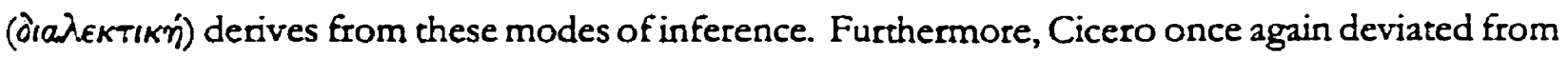
Aristodle's account of the topics by classifying these additional modes under the same topical heading as his first three. For Aristotle, they belong to yet a third topic, by which one exploits the necessary disconnection of things. ${ }^{17}$ However, the same considerations of practicality apply to this classification, as does the fact that the unnamed logicians, following the Stoics, list them all together. Indeed, Cicero himself wrote that the topic from consequents, antecedents, and incompatibles

15 For this rule, see Sextus, $A d$ math., 8.88-90.

${ }^{16}$ Cicero, Top., 56-57: "Reliqui dialecticorum modi plures sunt, qui ex disiunctionibus constant: Aut hoc aut illud; hoc autem; non igitur illud. Itemque: Aut hoc aut illud; non autem hoc; illud igitur. Quae conclusiones idcirco mtae sunt quod in disiunctione plus uno verum esse non potest. Atque ex eis conclusionibus quas supra scripsi prior quartus posterior quintus a dialecticis modus appellatus. Deinde addunt coniuncrionum negantiam sic: Nion et hoc et illud; hoc autem; non igitur illud. Hic modus est sextus. Septimus autem: Non et hoc et illud; non autem hoc; illud igitur. Ex eis modis conclusiones innumerabiles nascuntur, in quo est tota fere diarekrık" ".

17 Aristote, Top., 112224-32. At least the fourth and fifth do. To which topic the sixth and seventh belong is unclear, as how these two schema function is a matter of debate (for which see below). 
contains those types of argument that are peculiar to the logicians. ${ }^{18}$

Thus, Cicero's treatment of the topic from consequents, antecedents, and incompatibles is far from Aristotelian, and certainly Stoic, in inspiration. It is perhaps unsurprising that he treated a properly Aristotelian or Peripatetic subject in this way, given the intellectual circumstances of the period in which he lived. Yet, even after the later revival of Aristotle's philosophy, the Stoic influence on Peripatetic logical theory remained, as I have thus far argued. Indeed, I shall presently show that the appearance of this Stoic material in an ostensibly Peripatetic text did not give any pause at all to Boethius, as he prepared his own commentary on it.

3. In 1962, William and Martha Kneale offered an analysis of Cicero's seven modes of inference that eventually led some scholars to ponder the relarionship between Boethius's commentary on Cicero's Topics and Stoic logic. ${ }^{19}$ After noting that the first five of Cicero's modes are the five Stoic indemonstrables in the proper order, the Kneales pointed out that the extra sixth mode, Not both this and that; but, this; therefore, not that', is merely a repetition or reformulation of the third, and that the seventh mode, Not both this and that; but, not this; therefore, that', is invalid as it stands. The Kneales also pointed out that a similar list of seven modes of inference, which agrees with Cicero's list even in the apparent invalidity of the seventh mode, also appears in the work of the Latin author Martianus Capella. ${ }^{20}$ From these observations, the Kneales concluded that both Cicero and Capella had been reporting a later, seven-member Stoic variant on the canonical five indemonstrables, as follows:

(1) If $p$, then $q$; but, $p$; therefore, $q$

(2) If $p$, then $q$; but, not $q$; therefore, not $p$

(3) Not both $p$ and not q; but, p; therefore, $q$

(4) Either $p$ or q; but, p; therefore, not $q$

(5) Either $p$ or $q$; but, not $p$; therefore, $q$

(6) Not both $p$ and q; but, p; therefore, not q

(7) Not both not $p$ and not q; but, not $p$; therefore, $q$.

In this variation, the canonical third indemonstrable takes sixth place, just as Cicero and Capella

18 Ibid.

19 Kreale and Kneale, The Development of Logic, pp. 179-81.

:0 Capella, 4.414-22. The Kneales in fact read Capella's third, Not both $p$ and not q; but, p; therefore, q', as different from Cicero's by the negative particle in the second conjunct of the major premiss - despite the fact that Cicero's example of the third mode, regarding the bequest of the silver, has Capella's form. Only Cicero's explanation of the mode differs in failing to make special mention of any aegative particle; the Kneales, then, were following the explanation rather than the example in reconstructing Cicero's schema. Yet, there are textual variants that render Cicero's explanation in 2 way that agrees with Capella's formulation - see Frede, Die stoische Logik, p. 160. 
reported it, and Cicero's and Capella's own third stands in its stead. In the seventh place is a valid mode of inference that differs from Cicero's and Capella's by the addition of two negative particles in the first premiss, which, according to the Kneales, a copyist could easily have omitted by mistake.

The Kneales justified their interpretation by appealing both to the Stoic emphasis on logical syntax as the criterion for dividing propositions, according to which the main operator determines the class of proposition, and to the fact that, for the Stoics, the operators 'if and 'or' had restrictive senses stronger than simple material implication and inclusive disjunction. In order to capture these weaker senses, then, the Stoics would have been obliged to find or invent other operators. The first premiss of schema (3), for example, is the logical equivalent of material implication in terms of 'and' and 'not'; the first premiss of schema $(7)$ is the logical equivalent of inclusive disjuncrion expressed in the same terms. The Kneales thus envisioned this list of seven schemata as a later development of the canonical list of Eve indemonstrables, which some Stoic logician before Cicero had proposed in order to deal with novel and weaker sentential operations. Cicero and Capella had repeated this list, but unknown copyists introduced an error into their texts.

One problem with the Kneales' interpretation, however, is that modes (3), ( $G$ ), and ( 7 ) on their reconstructed list are not significantly different, since 'and' signifies the same sentential operation in each, and since each has as its additional assumption the affirmation of one of the conjuncts. That is to say, the modes all begin from the negated conjunction and the affirmation of a conjunct; they differ only in the patterns of negation of the conjuncts. Yet, had the Stoics - or even only some Stoics - intended to differentiate one indemonstrable from another on the sole ground that the leading premiss of one contains a negated element that the other does not, even though the main operator is the same, they would also have had to countenance several more indemonstrables than merely the additional two - for instance, of the forms 'If $p$, then not $q$; but, $p$; therefore, not q', 'If not $p$, then q; but, not $p$; therefore, q', and so on. There is no evidence at all that they did. In any case, there would have been no real compulsion to do so, since the Stoics understood double negation in the classical sense and do not seem to have required explicit documentation of its use in an inference. Thus, the original third indemonstrable from the negated conjunction would have sufficed to capture both material implication and inclusive disjunction without the addition of extra indemonstrables. What is more, both Cicero and Capella presented an example of mode (2) in the form If not $p$, then not $q$; but, $q$; therefore, $\mathrm{p}^{\prime}$, and Capella explicitly recorded this very schema as well. If the Kneales' interpretation is correct, then the list that they reconstruct on the basis of the 
testimony of these two authors should reflect Capella's negative particles in the second mode, giving rise to a further, unexplained discrepancy between their reconstructed, late Stoic list of seven indemonstrables and the canonical five.

In 1974, Michael Frede took issue with the Kneales' interpretation on somewhat different grounds." According to him, the Kneales were mistaken even to begin their analysis from the claim that Cicero's sixth mode is redundant and his seventh is invalid. In other words, Frede thought the Kneales mistaken to have interpreted the sixth and seventh modes as proceeding from the negated conjunction, despite the syntax of their major premisses. On Frede's view, the Stoics had rather intended them for a weak type of disjunction that, in contrast to their stronger one, does not require for its truth that its disjuncts be completely incompatible - that is, that its disjuncts be neither simultaneously true nor simultaneously false. Rather, it requires only that its disjuncts not be simultaneously true, and that at least one of them be true. In these requirements, it also differs from the negated conjunction, whose elements may all be simultaneously false, even if they may not all be simultaneously true. Thus, the sixth mode does not repeat the third, for it does not function from a negated conjunction despite appearances, and the seventh is perfectly valid, for if one of the disjuncts is false, the other must be true. Additionally, Frede's interpretation provides sense to the order in which Cicero reported the seven modes: the first and second are for the conditional, the third is for the negated conjunction, the fourth and fifth are for a strong disjunction, and the sixth and seventh are for a weak disjunction.

Nevertheless, Frede's interpretation is also problematic. He himself realized that one problem is that no surviving source, including Cicero, provides any direct evidence for it. A further problem that he did not address, however, is that the earliest source for the weak type of disjunction, the jurist Proculus of the first century $\mathrm{AD}$ (as recorded in the later Digesta of the Emperor Justinian), claimed that it has two variants. In one variant, the disjuncts cannot all be true but can yet all be false, such as in 'Either he sits or he walks'. In the other variant, the disjuncts cannot all be false, but can yet all be true, such as in 'Every quadrilateral either has four sides or is a square'. "2 Later sources, such as Apollonius Dyscolus and Aulus Gellius for instance, tended to give accounts or examples that focus more, or even solely, on the latter variant, and the careful Galen treated of both,

21 Ibid., Pp. 158-166.

$\approx$ Justinian, Digesta, 50.16.124. Proculus's own example of the latter variant, Every animal is either doing something or lying passive', is not particularly clear. 
but under different names. ${ }^{33}$ Now, the former variant fits the two modes in question, for it is presumably true only if at least one of its disjuncts is true. The latter variant, however, invalidates the sixth mode, according to which if one of the disjuncts is true, the other is false. Thus, Frede's interpretation settles the question of the invalidity of the seventh mode possibly at the price of calling into question the validity of the sixth. No surviving source reports an eighth indemonstrable reserved for the latter variant as opposed to the former.

4. More important for my purposes here, however, is that Frede contested the Kneales' claim against the validity of Cicero's seventh mode by specifically citing the fact that the mode appears identically in the work of the later authors Capella, Cassiodons, Isidore, and Boethius (in his commentary on Cicero's Topics). Frede suggested that it is uncharitable to assume that all of these authors had unthinkingly transmitted a mode as obviously invalid as the Kneales thought it. In doing so, he also implied that Boethius's commentary on Cicero's Topics has at least some small merit as a source for the study of Stoic logic. In 1987, when Eleonore Stump challenged Frede's interpretation of the sixth and seventh modes, she did not also challenge this implication. ${ }^{2+}$ Instead, she expanded it, going so far as to claim that Boethius's own interpretation of the sixth and seventh modes is not only incompatible with Frede's interpretation, but also at least as persuasive. In other words, Stump went so far as to claim that Boethius's commentary is not only somewhat useful for the study of Stoic logic, but is in fact a trustworthy guide to it.

Stump's account of Boethius's interpretation of the sixth and seventh modes depends on a passage from his commentary in which he associated them closely with the fourth and fifth modes:

The sixth and seventh modes are derived from the disjunctive statement of the fourth and fifth modes, namely by attaching a negation and removing the disjunctive particle from the statement, and by adding a conjunctive particle to the statements that have been previously posed in disjunction, as follows: Not both is it day and is it night'. Formerly, then, it was a disjunctive statement of the following sort: 'Either it is day or it is night'. Given, then, that the connective 'or' (which was disjunctive) has been taken from this statement, we have added 'and' (which is copulative) and posed a negation in front. So, by adding a negation, we have made a statement of the sixth and seventh modes from the conjoined parts of a disjunctive statement, which is: 'Not both is it day and is it night'. ${ }^{25}$

23 Apollonius, De con., 219.12-24; Gellius, 16.8.14; Galen, Inst. log., 5.1-2. See also Frede, Die stoisithe Logik, Pp. 98-100.

24 Stump, "Boethius's In Ciceronis Topica and Stoic Logic", especially Pp. 19-22.

is Boethius, In Cic. Top., 1135B-C: 'Sextus vero modus ac septimus ex quarti et quinti modi disjunctiva propositione deducuntur, una negatione videlicet adjuncta, et disjunctiva propositione detracta, additaque conjuncriva his propositionibus qux superius in disjunctione sunt positx, boc modo: non et dies est, et nox est. Dudum igitur in 
According to Boethius, then, the sixth and seventh modes are for statements that derive from the disjunctive statements of the fourth and fifth modes by mere substitution of syntax. However, as Stump noted, Boethius also wrote that the disjunctive statements of the fourth and fifth modes must express complete incompatibility - that is, their disjuncts can neither be simultaneously true nor simultaneously false. Hence, Boethius's example disjunctive statement is 'Either it is day or it is night', and his example derived conjunctive statement is 'Not both is it day and is it night'. Moreover, as Stump also noted, Boethius went on to note explicitly and repeatedly that the sixth and seventh modes are only for those contrary things that lack intermediates - that is, for things that are completely incompatible. ${ }^{26}$ Thus, if Boethius's interpretation is correct, the sixth mode does not repeat the third and the seventh is valid, as Frede had suggested. However, Frede's own interpretation must be incorrect, for the sixth and seventh modes are not for any weak type of disjunction whose elements may be simultaneously false, but rather for the same strong disjunction of the fourth and fifth modes under different syntax.

Stump, for her own part, thought that Boethius's interpretation was a more plausible and more likely historically accurate guide to Stoic logic than Frede's. In her view, then, Stoic logic informs the discussion of hypothetical syllogistic in Boethius's commentary on Cicero's Topics to a great extent. In 1991, however, Christopher Martin rejected Stump's view; on his account, Boethius lacked any notion of propositionality, and thus any notions of propositional content or propositional operation." Without these notions, Martin argued, Boethius could not have understood Stoic logic, which is propositional, and thus could not be a trustworthy guide to it. Because Stump gave no specific reason to think that Boethius was trustworthy other than claiming that his interpretation of the sixth and seventh modes is at least as plausible, if not more so, than Frede's, her claim is vulnerable to Martin's general considerations. All the same, even if Martin is correct to think that Boethius lacked the notion of propositionality (an evaluation that I shall not undertake here), the precise extent of the relationship between Boethius's commentary and Stoic logic still remains unclear. Perhaps Boethius's commentary lacks merit as a source for the study of Stoic logic as such, as Martin would have it; nevertheless, it may have great merit as a source for understanding part of

disjunctiva ita fuit, ut aut dies est, aut nox est. Ex hac igitur propositione sublata, aut conjunctione, qux erat disjunctiva adjecimus, et qux copulativa est, praposuimusque negationem. Itaque fecimus ex partibus disjunctiva propositionis copulatis, addita negatione, propositionem sexti atque septimi modi, qux est, non et dies est et nox est".

I6 Ibid, $1135 \mathrm{D}, 1136 \mathrm{D}-37 \mathrm{~A}$, and $1145 \mathrm{~A}$.

7 Martin, "The Logic of Negation in Boethius", especially Pp. $29+95$. 
the legacy that Stoic logic had in late antiquity, especially in relation to Peripateric logic.

However, Stump's appraisal of Boethius is untenable in any case. It is misguided for precisely the reasons that suggest that Boethius was conflating, or following in conflating, Peripateric hypothetical syllogistic with the Stoic indemonstrables, just as he had in his monograph on the subject. For Stump failed to recognize that Boethius's interpretation of the sixth and seventh modes so directy ignores the Stoics' strict emphasis on logical syntax as the criterion for identifying propositions that it cannot belong to them. On Boethius's interpretation, the sixth and seventh modes are merely the fourth and fifth modes under the syntax of negated conjunction rather than disjunction. Yet, no Stoic took the negated conjunction as having the same meaning as the disjoined proposition. As I have indicated often before, a proposition is disjoined on the Stoic account precisely because its main operator is 'or'. The operator 'and' had for them another meaning, from which the negated conjunction derived its own meaning. For these reasons, merely transforming a disjoined proposition into a negated conjunction by shuffling syrtax, as Boethius suggested, would in fact change the very meaning of the proposition on the Stoic account. It would neither continue to be a disjoined proposition nor - as Boethius also suggested — continue to suit only what is completely incompatible. Boethius's interpretation of the sixth and seventh schemata, then, can be no guide to their Stoic purpose.

At the same time, the early Peripatetics did not divide hypothetical statements according to logical syntax. Rather, they attended to the semantics of a statement - namely, to whether it

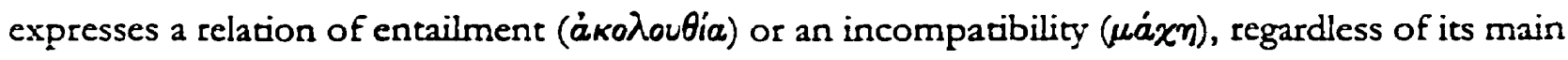
operator. Now, the major premisses of the sixth and seventh modes clearly express an incomparibility, just as the major premisses of the fourth and fifth modes do; indeed, following Boethius's interpretation, they express the same kind of incompatibility. Thus, they are completely superfluous as independent syllogisms on the early Peripatetic account. It is irrelevant that they have different main operators. I have explained before that Alexander argued precisely in this way against the independence of the syllogism from negated conjunction, for its major premiss, 'It is not both $A$ and $B$ ' is reformulable without any loss of meaning as 'If it is $A$, it is not $B$ ' - that is, it is a separative statement expressing incomplete incompatibility regardless of having if as its main operator.

Now, this confusion between Peripatetic and Stoic criteria for dividing hypothetical statements permeates Boethius's monograph on hypothetical syllogistic, On bypothetical syllogisms. Indeed, it is 
characteristic of a conflation of Peripatetic and Stoic logic that had become so widespread and wellentrenched by the time Boethius wrote his monograph that he himself seems to have been ignorant of the original differences between the two. As I shall show below, he demonstrated the same ignorance in his commentary on Cicero's Topics. Thus, although Boethius cannot guide us to a better understanding of Stoic logic as such, his commentary is yet a valuable source for determining the legacy of Stoic logic in late antiquity.

5. At the end of the previous chapter, I cited a passage from Boethius's commentary in which he introduced his brief exposition of hypothetical syllogistic as something of an extract from, or abridgement of, the longer treatment of his monograph. He repeated the same claim in summarizing his comments:

Now, in the books that we have written on hypothetical syllogisms, we have very carefully explained in what way all hypothetical syllogisms are true. However, we have not attached here what can be considered a more complete treatment of them, but rather what could be suited to explaining Cicero's meaning. ${ }^{28}$

In fact, the account of the commentary does repeat that of the monograph in many respects. Among the seven hypothetical argument schemata on Cicero's list, for instance, the first, second, fourth, and fifth have direct counterparts in the hypothetical syllogistic of Boethius's monograph. The order of the exposition in the commentary also repeats that of the monograph in an abbreviated way, beginning with a distinction between categorical and hypotherical statements, proceeding through a discussion and division of the types of hypothetical statement, and ending in an enumeration of the types of hypothetical syllogism.

The commentary also repeats Boethius's conflation of early Peripatetic and Stoic logic. It does so implicitly insofar as it is subordinate in Boethius's own mind to the monograph; thus, what Boethius did not repeat explicitly in the commentary for the sake of brevity, as well as what he did not contradict, remain part of his overall account. For instance, both Boethius's violation of his own rule that disjunctive hypothetical statements must express complete incompatibility, and his claim that it is valid to affirm the consequent and deny the antecedent in the case of a syllogism from the connective statement 'If it is not A, it is B', appear in the monograph but not in the

${ }^{33}$ Boethius, In Cik. Top., 1135D: "Quo autem modo omnium syllogismorum conditionalium veritas sese habeat, his diligentissime explicuimus libris quos de hypotheticis conscripsimus syllogismis. Nune vero, non quod de his perfectior consideratio inveniri potest apposuimus sed id quod ad explanandum M. Tullii seatenciam poterat accommodan". 
commentary. As I showed in the previous chapter, the former had led Boethius to countenance disjunctive statements that express not only incomplete incompatibility, but also no incompatibility whatsoever, and thus removed any doubt that the criteria for his division of hypothetical statements are syntacic, in Stoic fashion. The latter proved in turn how far removed Boethius's hypotherical syllogistic was from the logic of both the early Peripatos and the Stoa, for it turned upon a confused attempt to account for the grounds for entailment both in respect of sentences and of terms. Implicity, then, Boethius continued in these claims and their consequences.

Moreover, some of what Boethius did in fact repeat exhibits the same conflation of early Peripatetic and Stoic logic. For instance, he wrote in his commentary that hypothetical statements are composites of categorical, or simple, statements. ${ }^{29}$ He continued:

Every hypothetical statement comes to be either through connection or through disjunction - through connection in this way: 'If it is day, it is light', through disjunction like so: 'Either it is day or it is night. ${ }^{30}$

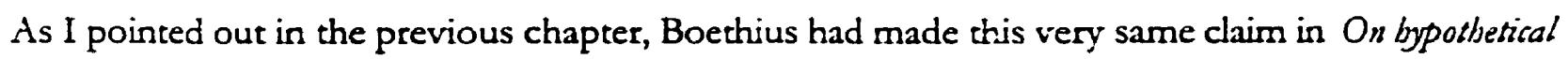
syllogisms. He had also maintained there that there are four types of connective statement, corresponding to four possible combinations of affirmative and negative simple statements. Two of these combinations, from two affirmatives and two negarives, express a relation of entailment on the early Peripatetic account; the other two express an incompatibility. For this reason, the early Peripatetics would have classified these sorts of statements separately. For Boethius, by contrast, they are all connective statements, a point that he reiterated in his commentary:

Of the statements that come to be through a connection, some are composed from two affirmatives, such as 'If it is day, it is light', for 'It is day' and 'It is light' each affirm something. Others are from two negatives, such as 'If it is not light, it is not day', for that it is not light and that it is not day are each negations. Others are combined from and affirmative and a negative, such as 'If it is day, it is not night', and others are composed from a negative and an affirmative, such as 'If it is not day, it is night'. Nonetheless, all are posed in connection. ${ }^{31}$

Now, in the previous chapter, I used this four-fold division as evidence for my claim that, for

7 Ibid, $1131 \mathrm{~B}$.

30 Ibid: "Omnis autem hypothetica propositio, vel per connexionem fit, vel per disjunctionem. Per connexionem hoc modo, si dies est, lux est. Per disjunctionem ita, aut dies est, aut nox est".

3t Ibid, 1131B-C: "Eanum vero qux per connexionem fiunt, alix ex duabus affirmativis copulate sunt, ut si dies est, lux est, namque dies est, et lux est, utraque aliquid affimant; alix, ex duabus negativis, ut si lux non est, dies non est, nam lucem non esse, et diem non esse, utraque negatio est; alix vero ex affirmativa negativaque conjunctxe sunt, ut si dies est, nox non est; alix vero ex negativa affirmativaque copulantur, ut si dies non st, nox est: omnes tamen in connexione positz sunt". 
Boethius just as for the Stoics, a statement is connecrive simply because its main operator is 'if. Thus, in his commentary, Boethius again deviated from early Peripatetic hypothetical syllogistic by emphasizing, in Stoic fashion, logical syntax as the criterion for division of hypothetical statements.

Additionally, in his commentary, Boethius repeated his rule that disjunctive statements must express complete incompatibility, as I mentioned above in my discussion of Stump's objections to Frede. In explaining why Cicero's fourth and fifth modes are valid, he wrote:

He says that the necessity of these conclusions is a result of the fact that what is asserted in a disjunction does not seem to admit of an intermediate, so that something besides the one or the other could be the case. For this reason, given that one part has been taken away, the other is concluded to be the case, and, given that one part has been asserted, the other is concluded not to be the case. But, if there is an intermediate that can be the case besides the one or the other, the statement is not true and the conclusion is not valid. ${ }^{32}$

Yet, as I have already cited before, Cicero in fact had written only:

These conclusions are valid for the reason that, in a disjunction, more than one part cannot be true. ${ }^{33}$

Cicero's explanation, then, does not rule out that a disjuncrion may have all false disjuncts (although presumably at least one disjunct is true if the disjunction is true). Boethius's explanation, by contrast, does. Now, Cicero may only have lapsed slightly, for he was fairly familiar with Stoic logic, according to which the disjoined proposition is true if and only if exactly one of its disjuncts is true. In any case, it is important to note that Boethius himself was so sure of the condirions of truth for a disjunction that he altered Cicero's words. The early Peripatetics, however, did not differentiate between statements expressing complete incompatibility and statements expressing incomplete incompatibility as much as they differentiated between statements expressing some sort of incompatibility and statements expressing none. Rather, they classified them both as separative statements, since they both express that something is not if something else is (or zice versa). The requirement that the disjoined proposition express only complete incomparibility is instead canonically Stoic, and Boethius adopted it both in his commentary and in his monograph. Indeed, Boethius's confident reformulation of Cicero's text makes especially clear how pervasive the conflation of early Peripatetic and Stoic logic had become by his time.

32 Ibid, 1144C-D: "Quanum conclusionum necessitatem ex eo dicit evenire, quia qux in disjunctione posita, medium non videntur admittere, ut esse aliud prxter corum alterum possit, atque ideo uno sublato alterum esse, unoque posito alterum non esse concluditur. Quod si sit medium, quod prater alterutrum esse possit, nec vera propositio, nec rata est conclusio".

33 Cicero, Top., 16.56-57: “Quae conciusiones idcirco ratae sunt quod in disiunctione plus uno verum esse non potest". 
6. Despite the similarities between the monograph and the commentary that $I$ have oudlined, and despite even Boethius's own claim that the latter is but an extract from the former, the commentary in fact covers some new material. The most significant addition is a discussion of Cicero's three modes of inference from the negated conjunction. These modes do not appear in the monograph, nor does the conjunction itself, negated or otherwise. Nevertheless, the manner in which Boethius presented this new material is in strict keeping with his earlier conflation of early Peripatetic hypothetical syllogistic and Stoic logic.

I pointed out just above that Boethius claimed, both in his commentary and monograph, that every hypothetical statement is a connective or disjunctive composite statement. In his commentary, he also recognized a third type of composite, but not hypothetical, statement:

Now, from these categorical statements composite statements come to be, of which some are joined by a copulative connective, such as 'Both it is day and it is light'. Others, which are also called hypothetical propositions, come to be through a hypothesis. ${ }^{34}$

Now, Boethius had discussed in his monograph what he called "intermediate connective statements", which have the forms 'If it is $A$ it is $B$, and if it is $B$ it is $C$ ', 'If it is $A$ it is $B$, and if it is not $A$ it is $C^{\prime}$, and so on. According to his treatment of them, however, they are hypothetical and not copulative. ${ }^{35}$ It follows, then, that the presence or absence of the copulative operator 'and' is irrelevant to a statement's hypothetical status. The relevant criterion is rather the hypothetical or categorical status of the component parts of a statement. Hence, Boethius had had no reason to discuss the copulative operator or copulative statements in his monograph, even though he had concerned himself with intermediate connective statements. In his commentary, too, he mentioned copulative statements only in passing.

In fact, Boethius was following the early Peripatetics in treating conjunctions as composite but not hypothetical, and thus omitting them from his hypothetical syllogistic. On the early Peripatetic account, a statement is hypothetical if and only if it expresses either a relacion of entailment or an incompatibility. A true conjunction, such as 'Dion is walking and Theon is talking', however, expresses neither a relation of entailment nor an incompatibility, as Galen reported and as I discussed in my second chapter. They are not hypotherical for this reason. Indeed, according to

36 Ibid, 1131A: "Ex his autem prxdicativis propositionibus existunt compositx propositiones, quarum alia quidem copulativa conjunctione nectuntur, ut et dies est, et lux est; alia vero per conditionem fiunt, quxe etiam conditionales enuntiationes vocantur'. See the previous chapter for a discussion of the terms 'propositio' and 'enuntiatio' and their translations.

${ }^{35}$ Boethius, De byp. syl, 1.6.2-3 and 2.9.1-3.6.5. 
Galen, true conjunctions and their negations are useless for argumentation, since they express no useful relationship between their parts. ${ }^{36}$ Boethius, too, denied conjunctions hypothecical status because they do not come to be through a hypothesis. In his monograph, Boethius had defined a hypothesis as the relation of consequence (consequentia) between the parts of a hypothetical statement, as I discussed in the previous chapter. Thus, conjunctions are not hypothetical for Boethius because their parts lack this relation.

However, Boethius's specific example of a copulative statement bends this rule, and illustrates the limits of the Peripatetic character of his treatment. Being day and being light do indeed stand in a relation of consequence or entailment; thus, the statement 'Both it is day and it is light' does not qualify as a true conjuncrion on the early Peripateric account. The oniy reasons that 'Both it is day and it is light' qualifies as copulative for Boethius, then, are that its main operator is 'and', and that its component parts are each categorical and not hypothetical. Hence, although Boethius followed the Peripatetics in rejecting the copulative statement as hypothetical, he nonetheless identified them syntactically, in Stoic fashion. Indeed, there would have been no compulsion for him to adopt semantic criteria for identifying copulative statements, either in practice or in rule, when he had not adopted them for connective and disjunctive hypothetical statements. In general, then, Boethius's scheme for dividing composite statements is an uneasy combination of a Stoic syntacric division, under which a statement is either copulative, connective, or disjunctive according to main operator, and a Peripatetic semantic division, under which a statement is hypothetical or merely composite according to what relation its parts have to one another.

Although Boethius did not consider the copulative statement hypotherical, he nevertheless endorsed hypothetical syllogisms from statements with the form of the negated conjunction, reproducing in his commentary Cicero's sixth and seventh modes of inference exactly: Not both is it $A$ and is it B; but, it is $A$; therefore, it is not $B$ ' and 'Not both is it $A$ and is it $B$; but, it is not $A$; therefore, it is B'. Now, as I discussed earlier when I considered Stump's interpretation of this part of the commentary, Boethius did not treat the major premisses of these syllogisms as true negated conjunctions, but rather as disjunctive statements expressing complete incompatibility under a different syntax. Boethius wrote:

These statements cannot have a valid conclusion unless in respect of disjoined things that lack an intermediate. For, let us say like so: 'It is not the case that both it is white and it is

${ }^{36}$ Galen, Inst. log., 14.7-8. 
black', and let us assert that it is not white. It does not follow that it is black, for there can be an intermediate. A statement of this sort - as Cicero says, through the negation of a conjunction - is suited to disjoined things that lack an intermediate, if it is to make valid its conclusions. Otherwise, the conclusion will not be valid. ${ }^{37}$

In fact, Boethius placed strong emphasis on this point, making the same claim on three other occasions. ${ }^{38}$ According to him, then, Cicero's sixth and seventh modes funcrion identically to his fourth and Eifth, for Boethius tcok the negated conjunctions of the sixth and seventh modes as derivable from the disjunctions of the fourth and fifth by a mere shuffling of syntax.

The early Peripatetics, however, had been no more willing to classify negated conjunctions as hypothetical statements than they had been conjuncrions. As I noted in my second chapter, Galen pointed out that, if a true conjunction expresses no relation of entailment or incompatibility, then a negated conjunction is simply a denial of a statement that conjoins two unrelated assertions. For instance, Not both is Dion walking and Theon talking' need not imply that the one entails the other or that they are incompatible; for example, it may simply happen to be the case coincidentally that Dion is not walking while Theon is talking. Boethius, however, saw no tension in denying the hypothetical status of conjunctions for these reasons, while simultaneously permitting negated conjunctions as major premisses of hypothetical syllogisms. Indeed, he circumvented any tension by eliminating all functional difference between Cicero's sixth and seventh modes and the disjunctive hypothetical syllogism. As a result, the only difference remaining between the two types of syllogism is syntactic: one type begins from a statement of the form Not both $A$ and $B$, and the other begins from a statement of the form 'Either A or B'. That is to say, Boethius's Stoic emphasis on syntactic criteria for differentiating between types of hypothetical statement and hypothetical syllogism led him to countenance Cicero's sixth and seventh modes as independent forms, while his semantic identification of the negated conjunctions in these syllogisms with the disjunctive statement permitted him to simultaneously maintain his Peripatetic claim that every hypothetical statement is really either connective or disjunctive.

The result, however, was a conflation of Peripatetic and Stoic logic that neither school could

37 Boethius, In Cic. Top., 1145. "Qux propositiones nisi in disjunctis medioque carentibus rebus ratam conclusionem habere non poterunt. Age enim ita dicamus, non et album, et nigrum, ponamusque non esse album, non consequitur ut sit nigrum, potest enim esse quod medium est. Hujusmodi iginut per negationem coniunctionum (ut Tullius ait) propositio si ratas factura est conclusiones in disjunctis rebus, medioque carentibus accommodetur, alias non etit rata conclusio". I have translated the word 'conixnctio' as 'conjunction' rather than 'connection' despite the fact that Boethius used it for the latter, since he is reporting Cicero's usage, which is for the former.

38 Ibid., 1135D, and 1136D-37A. 
have accepted. For the Stoics, Not both $\mathrm{p}$ and $q^{\prime}$ is a completely different type of proposition from 'Either $p$ or $q$ ' and thus funcrions differently in an argument; for the Peripatetics, 'It is not both $A$ and $B$ ' expresses incompatibility in the same way 'If it is $A$, it is not B' does, and thus is not an independent type of statement. Thus, whatever the original purpose of Cicero's sixth and seventh modes - either according to the Kneales or to Frede, or in line with some other interpretation Boethius incorporated them into his hypothetical syllogistic in such a way that shows precisely how much early Peripatetic hypothetical syllogistic and the Stoic indemonstrables had ceased to retain their distinct natures by his time. Moreover, Boethius did so even despite having some small reason to pause. As the citation above demonstrates, Boethius was aware that Cicero had called the major premisses of the fourth and fifth modes disjunctions, and those of the sixth and seventh modes negated conjunctions. Cicero had thus implied some difference between them even though he had not specified in what that difference consists. Boethius himself took that difference to consist in sỹntax but not in semancics.

The treatment that Boethius gave Cicero's third mode, which is from the negated conjunction as well, illustrates these points further. Cicero's example of the third mode is: Not both has the silver been bequeathed and the coin not been bequeathed; but, the silver has been bequeathed; therefore, the coin has been bequeathed'. Boethius, however, took liberies with the example:

'It is not the case that, if the silver has been bequeathed, the coin has not bcen bequeathed; but, the silver has been bequeathed; therefore, the coin has been bequeathed'. Now, Cicero formulated the statement like so: Not both the has silver been bequeathed and the coin not been bequeathed'. However, we have attached the causal connective, which is 'if, in order to show in what genus such a statement belongs. For an incompatible comes to be from a connection given that a negation is added to the consequent. ${ }^{39}$

Boethius, then, thought that Cicero would have done better to have formulated the major premiss of the third mode as 'It is not the case that, if the silver has been bequeathed, the coin has not been bequeathed'. As Boethius saw it, the third mode, like the sixth and seventh, depends for its validity on the incompatibility between two things - for example, between the silver's having been

30 Ibid, 1140C: "Non si legatum argentum est, non est legata numerata pecunia, atqui legatum argentum est, legata est igitur numerata pecunia. ML vero Tullius propositionem ita formavit: Non et legatum argenrum est, et non est legata numerata pecunia. Sed nos idcirco causalem conjunctionem apposuimus eam qux est si, ut ex quo esset genere talis propositio monstraremus. Namque id ex consequenti connexo aegatione addita fit repugnans". Despite appeasances, the scope of the first negative particle in the passage does not include the entire conditional sentence that follows, but sather only the conditional's consequent, as I discuss below. In Cicero's negated conjunction, however, the scope of the first negative particle does indeed indeed include the entire conjunction, for Cicero was following the Stoic practice of prefixing a negative particle to indicate sentential negarion. 
bequeathed and the coin's not having been bequeathed, given that the coin is silver. However, the negated conjunction of the third mode expresses incomplete, and not complete, incompatibility; it can certainly be the case, for instance, that the coin has been bequeathed even if all the other silver items have not. Thus, although Boethius had re-interpreted the negated conjunction in Cicero's sixth and seventh modes as a disjunctive statement, which expresses complete incompatibility, he could not have done so with respect to the negated conjunction of the third mode without loss of meaning. ${ }^{* 0}$ Certain connective statements, however, can express a kind of incomplete incompatibility. For example, 'If the silver has been bequeathed, the coin has not been bequeathed' does, since it cannot both be true that the silver has been bequeathed and the coin has not been bequeathed. The last part of the citation above shows that Boethius had in mind this kind of incompatibility as expressed in a connection.

Yet, whereas the negated conjunction Not both the silver has been bequeathed and the coin has not been bequeathed' is true given that the coin is silver, the connective statement 'If the silver has been bequeathed, the coin has not been bequeathed' is false. The two statements are thus not equivalent in meaning. Boethius attempted to compensate:

The third mode from incompatibles is very clear, as follows: Not both has all the silver been bequeathed to the woman and coin not been bequeathed'. For here, it followed that, if all the silver was bequeathed, the coin had also been bequeathed. So that it becomes an incompatible, then, a negation is put in the consequent here, and it is said that, if all the silver was bequeathed, the coin has not been bequeathed.

But, since the statement is incompatible and false, another negation brings it back to the tuth, like so: 'It is not the case that, if the silver has been bequeathed, the coin has not been bequeathed' - namely, so that it accords with that affirmation that states that, if the silver has been bequeathed, the coin has been bequeathed. "l

Boethius thus created a special statement of the form 'It is not the case that, if it is A, it is not B' as his version of Cicero's negated conjuñction. In this type of statement, the scope of the first negarive particle does not include the entire conditional sentence that follows, but rather only the conditional's consequent. There is thus a double negation in the consequent. As Boethius wrote:

* In his monograph, Boethius had violated his own rule that disjunctive statements must express complete incompatibility. He did not do so, bowever, in his commentary.

"Ibid, 1140B-C: "Tertius modus a repugnanobus longe perspicuus boc modo est Non et legatum omne argentum est, et non est legata mulieri pecunia enumerata. Llic namque consequens erat: Si argentum esset omne legatum, pecuniam quoque numeratum fuisse legatam; ut igitur fieret repugnans, huic consequentix interposita negatio est, dictumque est, si argentum omne legatum esset, numeratam pecuniam non esse legatam; quod quia pugnat et falsum est, ad veritatem alia negatione sic reducitur. Non si legatum argentum est, non est legata numerata pecunia, ut scilicet ei affirmationi conveniat, qux dicit, si leganum argentum est, legatam esse pecuniam numeratam". 
The third mode is when a negation is put in between the parts of a connective statement composed from two affirmations, and that very negation is denied. This statement is called iтєратофатікं in Greek. For example, in the same statement that we asserted above, 'If it is day, it is light', if a negation comes between the parts of this statement, it will become, as follows, 'If it is day, it is not light'. If we deny this statement further, it will be like so: 'It is not the case that, if it is day, it is not light'.

The very meaning of this statement is that, if it is day, it cannot be that it is not light. This statement is called super-negative, and all statements in which a negation is asserted before a negation, such as ' $\mathrm{t}$ is not the case that it is not day', and also 'It is not the case that the Ausonians are not the Trojan people sent as colonists', are such. ${ }^{42}$

In this way, Boethius transformed the false statement 'If the silver has been bequeathed, the coin has not been bequeathed" into the "super-negarive" statement 'It is not the case that, if the silver has been bequeathed, the coin has not been bequeathed', which is true given his account of the scope of the first negative particle. The statement thus is equivalent in meaning to the true statement 'If the silver has been bequeathed, it is not the case that the coin has not been bequeathed', and ulimately to the true statement 'If the silver has been bequeathed, the coin has been bequeathed'. With this super-negative statement, then, Boethius was able to propose the syllogism, Tt is not the case that, if the silver has been bequeathed, the coin has not been bequeathed; but, the silver has been bequeathed; therefore, the coin has been bequeathed' as his version of Cicero's example of the third mode from the negated conjunction.

The fatal problem with Boethius's syllogism, however, is that it no longer depends on any kind of incompatibility, despite Boethius's repeated claims to the contrary. ${ }^{43}$ It does not because the statement 'If the silver has been bequeathed, the coin has been bequeathed', to which the statement 'It is not the case that, if the silver has been bequeathed, the coin has not been bequeathed' is equivalent in meaning, does not express any kind of incompatibility at all. Rather, as any early Peripatetic would have realized, it expresses a relation of entailment, which is in fact what drives the syllogism Boethius proposed. Boethius's own words illustrate his confusion on this point:

However, the assertion is valid for the reason that the incompatibility of the consequent produced by the middle negation is canceled out by the other negation, and the statement

12 Ibid, 1133D - 34.1: "Tertius modus est, cum inter partes connexx atque ex duabus affirmationibus copulatre

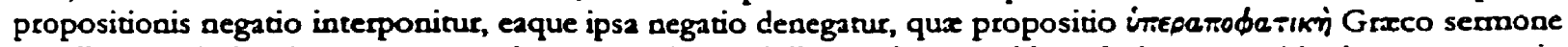
appellatur, ut in bac ipsa quam superius proposuimus, si dies est, lux est; si inter hujus propositionis partes negatio interveniat, fiet hoc modo, si dies es, lux non est; hanc si ulterius denegemus, erit ita, non si dies est, lux non est: cujus propositionis istz sententia est, quin si dies est, fieri non potest ut lux non sit. Qux propositio supernbnegarina appellatur, talesque sunt omnes in quibus negario praeponitur negationi, ut non <non> est dies, et rursus, Necron Ausonii Troja gens missa colont'. The correcrion is mine.

${ }^{43}$ Ibid, 1134C, 1135A, 1136C, 1137D, and 1140B. 
entirely regains the force of an affirmation. For, since it is understood to follow and be true that, if it is day, it is light, it is incompatible and false that, if it is day, it is not light. Given that this is denied in turn, like so: 'It is not the case that, if it is day, it is not light', it is true, and similar to the affirmation 'If it is day, it is light', since a double negation makes an affirmation."

Thus, even Boethius himself admitted that the statement ' $\mathrm{t}$ is not the case that, if it is day, it is not light' does not express the incompatibility that the statement 'If it is day, it is not light' does. The incompatibility is, as he wrote, "canceled out (destritur)" by the first negation.

Boethius's difficulty in accommodating Cicero's third mode stems, in fact, from his conflation of Peripatetic and Stoic logic. As I discussed above, Cicero had grouped all seven of his modes under the topic from antecedents, consequents, and incompatibles. He had also implied very clearly that the first mode is from antecedents, the second from consequents, and the third from incompatibles. Indeed, the minor premiss of the first mode, which corresponds to modus ponens, is the antecedent of its major premiss; the minor premiss of the second mode, which corresponds to modus tollens, is the consequent of its major premiss. In the case of the third mode, the negatively conjunctive form itself indicates that the inference proceeds from incompatibles, since the meaning of negated conjunction as such indicates an incompatibility. That is to say, Cicero's third mode is from incompatibles insofar as its major premiss has the form of a negated conjunction. Boethius, for his part, tried to mirror Cicero's classification in the context of his own hypothetical syllogistic by insisting that the third mode, even as he reformulated it, is from incompatibility.

He was unable to do so for two reasons. Firsty, his hypothetical syllogistic is too Peripateric in character to accommodate this originally Stoic syllogism in the form in which Cicero had reported it. In echo of the Peripatetic division of hypotherical statements into the continuous and separative, Boethius had claimed that every hypothetical statement is either connective or disjunctive. He also explicitly denied the hypothetical status of the copulative statement like a Peripatetic, for it expresses no relationship between its parts. Thus, Boethius was not able to retain the form of Cicero's third mode unless he construed its negated conjuncrion as semantically identical to a either a connective

4 Ibid, 1134B-C: "Sed idcirco rata positio est, quia consequentium repugnantia facta per mediam negationem alia negatione destruitur, et ad vim affirmationis omnino revocatur. Nam quia consequens esse intelligitur, ac verum, si dies est esse lucem, repugnat, ac falsum est, si dies est, non esse lucem, qux denegata nursus vera est ita, non si dies est, lux non est, et si consimilis affirmationi, si dies est, lux est, quia facit affirmationem geminata negatio". Stump herself seems to have succumbed to exactly the same confusion in her interpretation of Boethius's super-negative statement. According to her, since Boethius understands the statement as negating an incompatibility, on bis reading the statement must affirm that something cannot simulaneously be $A$ and not be $B$ - that is, it must 2 ffirm an incompatibility. See Stump, "Boethius's In Ciceronis Topica and Stoic Logic", p. 16. 
or a disjunctive statement, as he did in the cases of Cicero's sixth and seventh modes. Secondly, Boethius's hypothetical syllogistic is too Stoic in character to afford him this solution. The Peripatetics, who divided hypothetical statements semantically, easily disposed of syllogisms from the negated conjunction by subsuming those that express a relation of entailment under the continuous syllogism and those that express incompatibility under the separative syllogism. Boethius, however, had adopted a Stoic syntactic division of hypotherical statements that led him to attend principally to the form of the negated conjunction. Thus, he failed to recognize both that the incompatibility that he and Cicero saw in the negated conjunction Not both has the silver been bequeathed and the coin not been bequeathed' is a feature principally of the form of the statement, and that the statement in another sense expresses the relation of entailment between the bequest of the silver and the bequest of the coin. Ultimately, then, in regard to Cicero's third mode, Boethius unwittingly found himself in the confused position of attempring to assimilate a Stoic indemonstrable to a mixed Peripateric and Stoic hypothetical syliogistic, whose partially Peripateric character prevented him from admitting the indemonstrable it stands, and whose partially Stoic character prevented him from adopting the Peripatetic solution of denying the indemonstrable any independent syllogistic status on semantic grounds. His hypothetical syllogistic was such an uncomfortable mix of Peripatetic and Stoic theory that it was, in fact, internally problematic.

Indeed, in insisting that Cicero's third mode turns on incompatibility, Boethius seems to have been unaware of the original early Periparetic account of incomparibility and its role in their division of hypothetical statements. I noted in the last chapter that Boethius, unlike the early Peripatetics, made no mention of the relation of incompatibility in his definition of the hypothesis, and that he in fact had no use for the notion in his own, purely syntactic division of hypothetical statements. In his commentary, he demonstrated that this omission was also due in part to ignorance of the early Peripatetic origins of his subject. Although he was willing to recognize, like a Peripatetic, that a statement whose main operator is if can express incompatibility, the notion of incompatibility that he explained in his commentary was itself incompatible with theirs.

As I have mentioned before, Boethius repeated in his commentary the fourfold division of connective statements that he established in his monograph, encompassing the four possible combinations of affirmative and negative categorical statements. However, he also added to this division a claim that all four types of connecrive statement can express incompatibility:

But, it is clear that incompatibles are produced from connected statements, for, when an 
affirmation follows an affirmation, an incompatibility is made if a negation is put between them, in the following way. Here an affirmation follows an affirmation: 'If it is day, it is light'; but, when I say, 'If it is day, it is not light', the parts of the connected statement are incompatible between themselves, since a negation has been put in between.

Likewise, incompatibles are made whenever a negation follows a negation if a negative adverb is taken out of the latter part of a statement, in the following way. This connection, 'If it is not an animal, it is not a human', is set out from two negatives; but, if the negative adverb is removed from the latter part - that is, 'It is not a human' - it becomes 'If it is not an animal, it is a human', which is incompatible.

Now, if an affirmation follows a negation, incompatibles are made whether a negation is attached to the latter part or taken away from the former, in the following way. Here, then, an affimation follows a negation: 'If it is not day, it is night'. Therefore, whether a negation is attached to the latter part - that is, 'It is night' - so that it is like so: 'If it is not day, it is not night', or taken away from the former so that it is like so: 'If it is day, it is night', the statement must come to be incompatible.

Now, the parts of a connective statement turn out to be incompatible if a negation follows an affirmation and a negative adverb is taken away from the latter part, in the following way. Here, a negation follows an affirmation: 'If he is awake, he is not snoring'. But, if the negation is taken out of the latter part - that is, 'He is not snoring' - it becomes 'If he is awake, he is snoring', and it will be incompatible. ${ }^{45}$

According to the early Peripaterics, statements of the form 'If it is $A$, it is not B' and 'If it is not $A$, it is B' - Boethius's first two cases - are indeed canonical examples of statements expressing incompatibility, since they express that something is not given that something else is, and vice versa. Statements of the form 'If it is $A$, it is B' and 'If it is not $A$, it is not B', however, are instead canonical examples of statements expressing a relation of entailment, since they express that something is given that something else is.

Boethius's notion of incompatibility, then, was at complete variance with the early Peripatetic. As the above passage shows, he took incompatibility to be the very impossibility that two predicates

15 Boethius, In Cic. Top., 1131C-321: "sed ex connexis repugnantes manifestum est nasci, namque ubi affirmatio sequitur afämationem, his si media negatio interposita sit, repugnantiam facit hoc modo: si dies est, lux est. Hic affirmatio sequitur affimationem; at cum dico, si dies est, lux aon est, repugnant inter se partes propositionis connexx, interposita negacione. Item quoties negatio sequitur negationem, si posteriori propositionis parti negativum dematur adverbium, repugnantes funt hoc modo, si animal non est, homo non est; hre connexio est ex duabus proposita negativis. At si posterion parti, id est homo non est, negativum detrabatur adverbium, fiet, si animal non est, homo est, quod repugnat; at si affirmatio negationem sequatur, sive posteriori parti negatio jungatur, sive prioni auferatur, repugnantes fiunt, hoc modo, si dies non est, nox est. Hic igitur affimatio sequinar negationem. Sive igitur posteriori parti, id est, nox est, negatio copuletur, ut sit ita, si dies non est, nox non est, sive prioni auferatur, ut sit ita, si dies est, nox est, repugnantem fieri propositionem necesse est. Quod si negatio affirmationem sequatur, et posteriod parti negativum adverbium subtrahatur, propositionis connexx partes in repugnantiam cadunt, hoc modo, si vigilat, non stertit. Hic affirmationem sequitur negatio sed si posteriori parti, id est, non sterti, negatio dematur, fiet, si vigilat stertit, et erit repugnans". 
are simultaneously the case with respect to the same subject, such as being day and being night, or being a human and not being an animal. As a result, his examples of statements expressing incompatibility are all false: 'If it is day, it is not light', 'If he is awake, he is snoring', and so on. Naturally, there is a fairly clear sense in which these statements express a sort of incompatibility; however, it is not the sense relevant to the early Peripatetic account of hypothetical statements. Thus, whereas the statement 'If it is a human, it is not a horse' expresses an incompatibility on the early Peripatetic account, since it expresses truly that something is not given that something else is, it does not on Boethius's account, since the same subject must be both human and not a horse simultaneously. Conversely, and for the same reasons, the statement 'If he is awake, he is snoring' expresses incompatibility for Boethius, while for the early Peripatetics it does not. (It does not despite its falsity, for it asserts, even if falsely, that one thing is given that another thing is.) Hence, Boethius seems to have been so far removed from the hypothetical syllogistic of the early Peripatos that he was ignorant of the early Peripatetic account of incompatibility and its use in dividing hypothetical statements. Indeed, his willingness to allow one and the same type of hypothetical statement to express incompatibility given certain terms, and to fail to do so given other terms, is yet further evidence that his own division of hypothetical statements was exclusively syntactic, in the tradition of the Stoics.

7. In his commentary as well as in his monograph, then, Boethius consistendy conflated Peripatetic and Stoic logical theory. Yet, since his commentary deals with material missing from his monograph, he was strictly-speaking incorrect to have claimed that the exposition of the commentary is merely a briefer version of the more complete treatment of the monograph. More generally, however, the differences that I have discussed above do not entirely undermine this claim even if they weaken it, for the hypothetical syllogistic of the commentary is at least compatible with that of the monograph. Firstly, nothing in the monograph rules out the new accounts both of the incompatibility expressible in connective statements, and of the nature of copulative statements. Secondly, although the forms of the syllogisms corresponding to Cicero's sixth and seventh modes are novel, the inferences they represent are not, since Boethius treated the negated conjunctions in them as semantically identical with the disjunctive statement, whose syllogisms he had discussed in his monograph. Only Boethius's version of Cicero's third mode is entirely new, both in form and function. (In one sense, however, its major premiss is semantically identical to a connective 
statement expressing a relacion of entailment, Boethius's claims about its incompatibility notwithstanding.) Even this syllogism, however, is at least compatible with the syllogistic of the monograph.

All the same, the discrepancies between the commentary and the monograph are curious. The hypotherical syllogistic of Boethius's monograph lacks syllogisms from the negated conjunction because Boethius, like a Peripatetic, regarded conjunctions as non-hypothetical statements. Cicero's seven modes of inference include three from the negated conjunction, because Cicero's seven modes are essentially Stoic. Nevertheless, Boethius proceeded with an exposition of all three of these modes in his commentary as if they were nothing new to the hypotherical syllogistic of his monograph. In other words, Boethius does not seem to have even begun to doubt, as an early Peripatetic would have, the separate status of Cicero's third, sixth, and seventh modes. What is more, he does not seem to have doubted their separate status despite not even having considered them in his own, self-described complete treatment of the subject. Clearly, then, Boethius seems to have given little or no thought to how his own hypothetical syllogistic and Cicero's seven modes of inference differ. I conclude that the reason for his failure to recognize these differences is his ignorance of the differences between early Peripatetic hypothetical syllogistic and Stoic logic. Perhaps an earlier neo-Peripatetic commentator such as Alexander may have understood some of the differences; Alexander, at least, hedged on admitring the syllogism from the negated conjunction as separate. His more independently-minded contemporary Galen was unusually careful in drawing attention to the differences between the two schools' theories, but also rejected the syllogism from the negated conjunction as unnecessary. Boethius, by contrast, does not seem to have been able to recognize the differences between Peripatetic hypothetical syllogistic and the Stoic indemonstrables at all, even when presented with the characteristically Stoic syllogism from the negated conjunction as a separate argument form. Conflation with Stoic logic during the two and a half centuries between Alexander and Boethius had in fact transformed Peripatetic hypothetical syllogistic beyond recognition.

8. Boethius was not alone in his apparent inability to recognize the differences between the two original theories. As I discussed in my second chapter, the contemporary Greek school of Ammonius was party to similar conflation, and to a similar extent. Philoponus, for example, one of the members of this circle, also did not question the separate status of the syllogism from the 
negated conjunction, and even explicated syllogisms from disjunction in terms of it. Furthermore, Boethius had the company of fellow Latin writers: his predecessor Capella, his contemporary Cassiodorus, and the later Isidore. While none of them undertook any general discussion of hypothetical syllogistic as Boethius did, they each recorded Cicero's Stoic list of modes of inference as a list of hypothetical syllogisms, including the forms from the negated conjunction.

In my discussion of the Kneales's interpretation of Cicero's seven modes, I have already mentioned the list that Capella presented. It agrees with Cicero's; it is thus Stoic in origin. Unlike Cicero, however, Capella explicitly called the modes by the Peripatetic name 'hypothetical syllogisms', while at the same time using Stoic numerical variables to schematize them. ${ }^{*}$ Later, Boethius's contemporary Cassiodorus also presented the same seven-member list as Cicero and Capella. He, too, called the modes hypothetical syllogisms, and while he did not schematize them with numerical variables, his examples are Stoic commonplaces: 'If it is day, it is light; but, it is day; therefore, it is light', 'Either it is day or night; but, it is day; therefore, it is not night', and so on. Moreover, like Philoponus, he attributed a large body of work on hypothetical syllogistic to the Stoics. ${ }^{47}$ Cassiodorus also suggested that anyone who wants to know more about hypothetical syllogisms should consult a now-lost book on the subject by Marius Victorinus, who flourished around $300 \mathrm{AD}$, between Cicero and Capella. This suggestion directly follows presentation of his list; perhaps, then, Victorinus's lost hypothetical syllogistic revolved around these Stoic modes as well. ${ }^{+8}$ Finally, Isidore, who wrote approximately one century after Boethius and Cassiodorus, copied Cassiodorus's list nearly verbatim - including even the reference to Victorinus - and called the modes hypothetical syllogisms. ${ }^{40}$

Nevertheless, neither Capella, nor Cassiodorus, nor Isidore recorded any explanation for identifying these Stoic modes of inference with hypotherical syllogisms. Like Boethius's similarly unexplained decision to discuss hypotherical syllogistic on the basis Cicero's mention of the modes, this identification is a mark of how pervasive the conflation of Peripateric hypothetical syllogistic and the Stoic indemonstrables had become by the end of antiquity. The indemonstrables had, in fact, transformed into the subject of hypotherical syllogistic. No explanation for this transformation

to Capella, $4.41+22$.

* Cassiodorus, 2.3.13. Cassiodorus's second schemata is slightly different than Cicero's and Capella's; where the latter two have Tf not-p, then nnt-q; but, q; therefore, p', Cassiodorus has 'If $p$, then q; but, not-q; therefore, not-p'.

48 Pierre Hador assumed without question that Cassiodorus had been reporting Victorinus's wiork with kis list. See his Marius Victorinus, p. 148.

4) Isidore, 2.28 . 
was necessary, because no-one seems to have known that it had been otherwise. Indeed, Capella, Cassiodorus, and Isidore all presented their lists of Stoic "hypotherical syllogisms" without making any remark about the crucial Peripatetic issue of the reducibility of hypothetical syllogisms to categorical syllogisms. Peripatetic logic demands that all valid syllogisms be reducible to the categorical syllogisms of the first figure; even Aristotle himself had been concerned about the reducibility of hypothetical syllogisms, as I pointed out in my first chapter. Boethius, for his part, affirmed their reducibility in his monograph, but gave no indication of how such a reduction might proceed..$^{50}$ Now, Capella, Cassiodorus, and Isidore were not writing logical treatises; Capella's list appears in his general introduction to the liberal arts, and Cassiodorus's and Isidore's in their encyclopedic guidebooks for study. Thus, they may merely have left out such detail in the interest of brevity. Boethius, by contrast, whose On bypothetical syllogisms is a sustained treatment of the subject, was remiss. These omissions, then, suggest that this question had lost much of its relevance by the end of antiquity. However, to fail to recognize the relevance of this question, and thus to imply that categorical and hypotherical syllogisms together comprise a single theory side-by-side, is to abrogate the Peripatetic logical program. To fail to recognize its relevance while simultaneously identifying hypothetical syllogisms with the Stoic indemonstrables - for which the Stoics made the same kind of reducibility claim - is to so thoroughly conflate the Peripateric and Stoic logical programs as to abrogate both.

9. Now, the list of hypotherical syllogisms repeated in the work of Capella, Cassiodorus, and Isidore, together with Boethius's On bypothetical syllogismsand the discussion of hypothetical syllogistic in his commentary on Cicero's Topics, fully constitute the hypothetical syllogistic that survived the advent of the Middle Ages in the West. It is the subject of another work to discuss how this material influenced the development of hypothetical syllogistic in the medieval Latin West,

io Boethius, De byp. syl, 1.2.4. Alexander, however, explained the reduction procedure for a continuous statement he wrote that 'If virtue is knowledge, virtue is teachable' is provable through a categorical syllogism whose premisses are 'Every knowledge is teachable' and 'Virtue is knowledge' (see bis In An. pr., p. 263.22-25). While the conclusion of this syllogism is not that virtue is teachable if virtue is knowledge, the proof does show that there is a syllogistically valid inference between the two statements, so that the substinutional hypotherical syllogism from the hypothesis 'If virtue is knowledge, virtue is teachable' is also syllogistically valid. However, Alexander also provided the following categorical proof for 'If pleasure is the end, virtue is not chosen for its own sake': 'Everyching that is chosen as productive of something else is not chosen for its own sake; but, virtue (if pleasure is the end) is chosen as productive of pleasure; therefore, virtue (if pleasure is the end) is not chosen for its own sake' (see ibid, p. 264.2831). Alexander thus seems to have defeated the purpose of the proof by taking the minor premiss under the hypothesis in question. 
especially with regard to the conflation of Peripateric and Stoic theory that characterizes it. Nevertheless, it is clear from these sources, as well as from the Greek sources in the circle of Ammonius, that the hypothetical syllogistic that Aristotle, Theophrastus, and their associates had invented over eight centuries beforehand had already perished in its original form by the end of antiquity. It had, in effect, dissolved in solution with Stoic logic. 


\section{References}

\section{Ancient Sources}

ALEXtNDER OF APHRODISLAS, In Aristotelis Analyticorum priorum librum unum, ed. M. Wallies (Commentaria in Aristotelem Graeca 2.1), Berlin, 1883.

....-., In Aristotelis Topicoram libros octo, ed. M. Wallies (Commentaria in Aristotelem Graeca 2.2), Berlin, 1891.

AinIONIUS HERMLAiou, In Aristotelis Analyticorum priorum Librum unum, ed. M. Wallies (Commentaric in Aristotelem Graesa 4.6), Berlin, 1899.

ANovxhous, In Ammonii Commentarium in Analyticorum priorum librum unum, ed. M. Wallies (Commentaria in Aristotelem Graeca 4.0), Berlin, 1899.

APOLLONIUS DYSCOLUS, De coniunctionibus, ed. R. Schneider (Grammatici Graeci 2.1), Leipzig, 1878.

ARISTOTLE, Analytica priora, ed. W.D. Ross, Oxford, 1964.

------, De intepretatione, ed. L. Minio-Paluello, Oxford, 1949.

-----, Topica, ed. W.D. Ross, Oxford, 1958.

Augustine of Hippo, S.INT, De dialectica, ed. J. Pinborg, in B.D. Jackson, Augustine: De dialectica, Dordrecht, 1975.

BOETHIUS, ANICIUS MtNiliUs SEVERINUS, De bypotbeticis syllogismis, ed. L. Obertello, in OBERTELLO.

-...-.-, De topicis differentiis, ed. D.Z. Nikitas, in D.Z. Nikitas, Boethius, De topicis differentiis kai oi

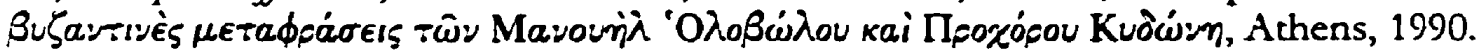

-.-.-, In Ciceronis Topica, ed. Glareanus (Patrologia Latina 64), Paris, 1891.

CAPELlat, MLtRTItNus, De nuptiis Pbilologiae et Murcurii, ed. J. Willis, Leipzig, 1983.

CASSIOdORUS SENATOR, Institutiones, ed. R.A.B. Mynors, Oxford, 1937.

Cicero, Mlarcus Tullius, Ad Atticum, ed. E.O. Winstedt, New York, 1912.

-----, Ad familiares, ed. W.G. Williams, New York, 1927.

-----, De fato, ed. H. Rackham, Cambridge (Mass.), 1942.

--.--, De oratore, eds. E.W. Sutton and H. Rackham, Cambridge (Mass.), 1942.

-----, Topica, ed. H.M. Hubbell, Cambridge (Mass.), 1949.

------, Tusculanes disputationes, ed. J.E. King, Cambridge (Mass.), 1927, revised 1945.

Dedxippus, In Aristotelis Categorias, ed. A. Busse (Commentaria in Aristotelem Graeca 4.2), Berlin, 1888.

DIOCLES OF MAGNESL, Breviarium philosophoram, in DIOGENES, 7.49-82.

DIOGENES LAËRTIUS, Vitae pbilosophorum, ed. H.S. Long, Oxford, 1964. 
G.LLEX; Cltudius, Institutio logica, ed. C. Kalbfleisch, Leipzig, 1886.

Gellils, Alius, Noctes Atticae, ed. P.K. Marshall, Oxford, 1968.

ISIDORE OF SP.uIN, Etymologiae, ed. W.M. Lindsay, Oxford, 1911.

J'stivltix Augustus, Digesta, ed. P. Bonfante et al., Milan, 1931.

Philopont's, JoHn, In Aristotelis Analytica priora, ed. M. Wallies (Commentaria in Aristotelem Graeca 13.2), Berlin, 1905.

-....-., In Aristotelis Categorias, ed. A. Busse (Commentaria in Aristotelem Graeca 13.1), Berlin, 1898.

SExTUS EMrPIRICUS, Adversus mathematicos (7 and 8), ed. R.G. Bury, Cambridge (Mass.), 1935.

-.., Pyrmboniae institutiones, ed. R.G. Bury, New York, 1933.

Sinplicil:s OF Ciliclt, In Aristotelis De caelo, ed. I.L. Heiberg (Commentaria in Aristotelem Graeca 7), Berlin, 1894.

\section{Modem Sources}

B.ARVES, JONithliN, “Aristotle and Stoic Logic”, in K. Ierodiakonou, ed., Topics in Stoic Pbiloscpby, Oxford, 1999.

----, "Roman Aristotle", in J. Barnes and M. Griffin, eds., Pbilosophia Togata II, Oxford, 1997.

--, "Terms and Sentences: Theophrastus on Hypothetical Syllogisms", Proceedings of the British Academy 69, 1983.

--.---, "Theophrastus and Hypotherical Syllogistic", in W.W. Fortenbaugh et al., eds., Theopbrastus of Eresus, New Brunswick (N.J.), 1985.

BIDEZ, JOSEPH, "Boèce et Porphyre", Revue Belge de philologie et d'bistoire 2, 1923.

BOCHENSN, IVAN M., La Logique de Théophraste, Fribourg, 1947.

CORCORtri, JOHN, "Aristotle's natural deduction system", in J. Corcoran, ed., Ancient Logic and Its Modem Interpretations, Dordrecht, 1974.

DÜRR, K+tRL, The Propositional Logic of Boetbius, Amsterdam, 1951.

EBBESEN, STEN, "Boethius as an Aristotelian commentator", in R. Sorabji, ed., Aristotle Transformed, Ithaca (N.Y.), 1990.

FREDE, MIICHAEL, Die stoische Logik, Göttingen, 1974.

------, "Stoic vs. Aristotelian Syllogistic", Archiv für Geschichte der Philosopbie 56, 1974.

GRtESER, AvDrE.tS, Die Logischen Fragmente des Theophrast, Berlin, 1973.

HiDOT, Pierre, Marius Victorinus: Recherches sur sa vie et ses auvres, Paris, 1971.

HÜLSER, KtRLHEINZ, Die Fragmente zur Dialektik der Stoiker, Stuttgart-Bad Cannstatt, 1987.

KNEALE, WILLLAM and MLARTHA, The Development of Logic, Oxford, 1962, revised 1964.

LEAR, JON_ATHAN, Aristotle and Logical Theory, Cambridge, 1980.

EUKtSIEWTCZ, JAN, Aristotle's Syllogistic from the Standpoint of Moder Formal Logic, Oxford, 1951, 
revised 1957.

Lrich, JOHN PATRICK, Aristotle's School: A Study of a Greek Educational Institution, Berkeley, 1972.

MLtRÓTH, MIKIOS, "Die Hypotherischen Syllogismen", Acta Antiqua 27, 1979.

........, Ibn Sina und die Peripatetische "Aussagenlogite", Leiden, 1989.

MORtUX, PAUL, Der Aristotelismus bei den Griechen von, Andronikos bis Alexander von Aphrodisias, Berlin, 1973.

MLARTIN, ChRISTOPHER J., "The Logic of Negation in Boethius", Phromesis 36, 1991.

MUELler, LAN, "Stoic and Peripatetic Logic", Archiv für Gescbichte der Pbilosophie 51, 1969.

NuCHELLLLNS, GABRIEL, Theories of the Proposition: Ancient and Medieval Conceptions of the Bearers of Truth and Falsity, Amsterdam, 1973.

OBERTELLO, LuCA, A.M. Severino Boezio: De hypotheticis syllogismis, Brescia, 1969.

POHLENZ, ALtX, Die Stoa, Göttingen, 1949.

PRANTL, C+RL, Geschichte der Logik im Abenlande, Leipzig, 1855.

REPICI, LLCLANA, La logica di Teofrasto, Bologna, 1977.

SCHOLZ, HEINRICH, Abriss der Geschichte der Logik, Berlin, 1931.

SHIEL, J-AIES, “Boethius' commentaries on Aristotle”, in R. Sorabji, ed., Aristotle Transformed, Ithaca (N.Y.), 1990.

SLOMKOWIKJ, PAUL, Aristotle's Topics, Leiden, 1997.

S.MILEY, TMOTHY, "What is a syllogism?”, Joumal of Philosophical Logic 2, 1973.

STRIKER, GIESLA, “Aristoteles über Syllogismen »dufgrund einer Hypothese«”, Hermes 107, 1979.

-.-.--, "Zur Frage nach den Quellen von Boethius' de bypotheticis syllogismis", Archiv für Geschichte der Pbilosopbie 55, 1973.

STUMr, EleONORE, "Boethius's In Ciceronis Topica and Stoic Logic", in J.F. Wippel, ed., Studies in Medieval Philosophy, Washington, 1987.

TARAN, LEONARDO, "P. Moraux, Der Aristotelismus bei den Griecben”, Gnomon 53, 1981. 